\title{
Salomon Mirsky
}

\section{Der Orient im Werk Velimir Chlebnikovs}

Verlag Otto Sagner München · Berlin - Washington D.C.

Digitalisiert im Rahmen der Kooperation mit dem DFG-Projekt „Digi20“

der Bayerischen Staatsbibliothek, München. OCR-Bearbeitung und Erstellung des eBooks durch den Verlag Otto Sagner:

http://verlag.kubon-sagner.de

() bei Verlag Otto Sagner. Eine Verwertung oder Weitergabe der Texte und Abbildungen, insbesondere durch Vervielfältigung, ist ohne vorherige schriftliche Genehmigung des Verlages unzulässig. 


\section{SLAVISTISCHE BEITRÄGE}

BEGRÜNDET VON ALOIS SCHMAUS

HERAUSGEGEBEN VON JOHANNES HOLTHUSEN UND JOSEF SCHRENK

REDAKTION: PETER REHDER

Band 85 
SALOMON MIRSKY

\section{DER ORIENT IM WERK VELIMIR CHLEBNIKOVS}

VERLAG OTTO SAGNER · MÜNCHEN

1975 


\section{Bayariscine Siazisbibllcther Munisinen}

\section{ISBN 3876900972}

Copyright by Verlag Otto Sagner, München 1975 Abteilung der Firma Kubon und Sagner, Minchen Druck: Alexander Großmann

8 München 19 , Ysenburgstrabe $7^{\mathrm{I}}$ 
VORBEMERKUNG

Die hier vorliegende Arbeit fubt auf einem doppelten Konzept. Das Vorhaben ist erstens, die wichtigsten Ideen und Inhalte, die das Thema "Der Orient im Werk Velimir Chlebnikovs" umfaßt, zu erörtern und darzulegen. Zum zweiten werden methodische Ansätze ausgearbeitet und exemplarisch angewendet, die einen möglichst produktiven Zugang zu den Texten Chlebnikovs bieten sollen.

Der vermutlich unumgängliche Nachteil dieses doppelten Konzepts besteht darin, daß auf eine umfassende Interpretation einzelner Werke verzichtet werden muB. Ein Umstand, der diesen bewubten Verzicht auszugleichen vermag, ist die Tatsache, da $B$ in Chlebnikovs Schaffen die Untersuchung der syntagmatischen Ebene (z.B. eine starke kontextuelle Bindung der einzelnen Dichtungselemente) oft relativ unergiebig, die der paradigmatischen dagegen (z.B. die Wiederkehr gleicher oder ähnlicher Bilder und Motive in Werken, die zeitlich und thematisch weit auseinanderliegen) äußerst fruchtbar ist.

Zum ersten Punkt des angeführten doppelten Konzepts wäre zu sagen, dab die meisten der hier behandelten Bereiche sehr wohl als selbständige Themen umfangreicher Arbeiten dienen können. Das gilt z.B. für Themen wie die Mythologie, die Geschichte RuBlands, die sprachliche und politische Utopie im Werk Chlebnikovs, der Komplex Razin. Da aber in einer Arbeit uber den Orient im Schaffen Chlebnikovs diese und viele andere Themenbereiche unbedingt ihren Platz finden müssen, litt daran nicht selten die Ausführlichkeit, mit der die einzelnen Themen behandelt werden.

Der zweite, also der methodische Pfeiler dieser Arbeit, will als ein Versuch betrachtet werden, einige verschiedene Techniken und Wege zu entwerfen, mit denen die Texte Chlebnikovs sich möglichst fruchtbar erschließen lassen, und diese an konkreten Beispielen zu demonstrieren. 
Das Problem in diesem Bereich liegt wohl darin, dab bis jetzt, soweit bekannt, nur ganz wenige Versuche unternommen worden sind, den spezifischen und oft komplizierten Problemen, die die Texte Chlebnikovs dem Forscher entgegensetzen, mit methodisch adäquatem Rüstzeug $z u$ begegnen.

Die vorliegende Untersuchung wurde im Wintersemester 1974/75 von der Philosophischen Fakultät II der Universität Minchen als Magisterarbeit angenommen. Ich möchte Herrn Prof.Dr.Johannes Holthusen herzlich für die Anregung $z u$ dieser Arbeit danken.

lüunchen, im Februar 1975

S. Mirsky 
1. Elnle1tung 1

2. Mythologische Aspekte des Orient-Themas 6

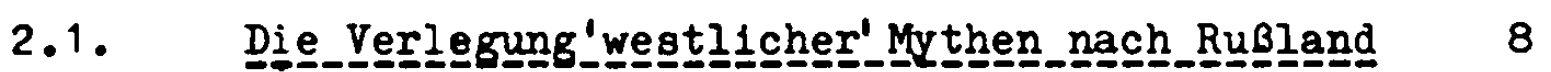

2.1.1. Die Orientalisierung des Aphrodite-Mythos und die Entstehung des Mythos von Azija 8

2.1.2. Die Verlegung der Genesis-Legende in die Randgebiete RuBlands

2.2. Die_Verlegung_orientalischer_Mythen_nach Ruㅡ그므므.

2.2.1. Der altägyptische Gott Ra (Rê) Im Wolgagebiet 26

2.2.2. Die kosmogonischen Mythen der Orotschen in Deti Vydry

3. RuBland und der Orient im geschichtlichen Denken Chlebnikors

3.1. Die_Umorientierung_der_geschichtlichen

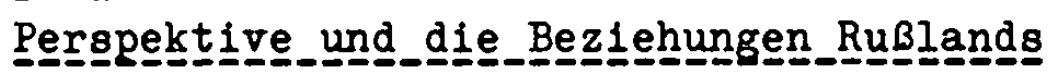
zum_orisient

3.2. Das 'Gesetz_der_Vergeltung '_und seine díchtererische_Realisiererung

4. Uberle1tung: Chlebnikors Konzeption der Zeit und der Orient 
5. Chlebnikovs Fntwurf einer Utopie und der Orient

5.1. Persien:_Prophezeiung_und_díchterische

Utongie

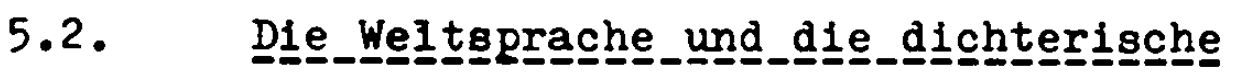

Utógie

5.2.1. Die Suche nach der gemeinsamen Schriftsprache 60

5.2.2. Der Buchstabe und der Klang als Vermittler von Inhalten

5.2.3. Die Zahl.als Grundeinheit der Weltsprache

5.2.4. Die Aufhebung der Sprache

5.3.

Das_'Eine_Buch!

5.4. Der_Orient_und_der_Staat__der_Zukunfft

5.4.1. 'Ijudostan' und 'Iadomir' - die harmonische Welt

5.4.2. Der Sieg iber den Tod und die Reinkarnation

5.5. Der_ortent_und_der_vel_lkommene_Mensch

6. Das Razin-Motiv in der Dichtung Chlebnikovs

7.

SchluBwort

8.

Iiteraturverzeichnis 
Der Futarist Velimir Chlebnikov, der in seiner Dichtung vielfach bahnbrechend neue Wege beschritt, kann in seinem Versuch, die eigenartige Stellung RuBlands zwischen Ost und West zu definieren, durchaus als innerhalb der russischen Tradition des XIX. Jahrhunderts stehend angesehen werden.

Der großen Auseinandersetzung Chlebnikovs mit der Zwischenstellung RuBlands ging ein langer als ein halbes Jahrhundert dauernder Streit zwischen den Westlern und den Slavophilen voraus, ein stre1t, der noch bis in die dreibiger Jahre unseres Jahrhunderts durch die Bewegung der sogenannten "Eurasier" aktuell blieb. So spricht V.Markov von der Petersburger Perlode Chlebnikovs als von einer Zeit der "...obsession with Asia, anticipating the ldeas of the Eurasianist movement and the 'Scythians'."1 In diese Zelt fält auch der Große EinfluB, den der bekannte Sozlalrevolutionär und Itteraturkritiker R.Ivanov-Razumik, der Herausgeber der Zeitschrift SkIfy, auf seine Zeitgenossen ausgeubt hat. Iranov -Razumnik und sein 'Skythentum' haben viel dazu belgetragen, die asiatische Thematik in der Iiteratur der ersten Revolutionsjahre auszuprägen.

Chlebnikov blieb von den Widersprichen, die die Auseinandersetzung um die Stellung RuBlands zwischen Ost und West gekennzeichnet haben, nicht unberihrt. So kommt z.B. in dem 1908 entstandenen Aufruf an die Slaven (Vozzvanie) seine Neigung zum Gedankengut der Slavophilen zum Ausdruck:

Werden wir denn nicht die Ereignisse als den entflammenden Kampf zwischen dem ganzen Deutschtum und dem ganzen Slaventum verstehen? Werden wir denn nicht auf die Herausforderung antworten, die die deutsche Welt der slavischen entgegenstellt? 2

1 V.Markov, The Longer Poems of Velimir Khlebnikov (Berkeley/ Los Angeles, 1962), S.16.

2 Alle Chlebnikov-Zitate, wenn nicht anders angegeben, sind der vierbändigen Munchner Ausgabe entnommen: $\nabla$ Chlebnikov, Sobranie sodinenif (Minchen, $9668-72$ ), III, S.405. Band I und II dieser Ausgabe enthalten die Bände 1-2 bzw. 3-4 der fünfbänigen Leningrader Ausgabe: V.Chlebnikov, Sobranie proizvedenif. Hrsg.N.Stepanov (Leningrad, 1928-33). Band III der Hilnchner Ausgabe enthält den 5. Band der Stepanov-Ausgabe und mehrere von $V$. Markov zusammengetragene Schriften Chlebnikovs. Band IV 1st ein Nachdruck der Moskauer Ausgabe: V.Chlebnikov, Neizdannye prolzvedenija,

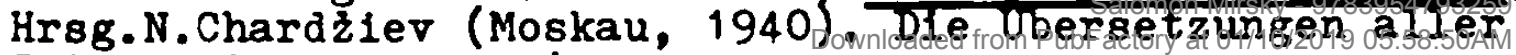
Zitate stammen von mir. 
Oder in einem frühen, nicht genau datierten dichterischen Fragment:

\section{Самовиты дух сдавян/0 проснися в нас воспрянь!}

Später aber kam Chlebnikov von dieser Haltung ab zugunsten eines umfassenderen "Orientalismus". Parallel dazu lieb die agoressiv anti-westliche Haltung erheblich nach.

Es gehört nun nicht zur eigentlichen Aufgabe dieser Arbeit, die Wandlungen der politischen und geschichtlichen Anschauungen Chlebnikovs zu erörtern. Vielmehr geht es um die dichteriscine Widerspiegelung des orientalischen Themas und die dichterische Argumentation, die, wie im Laufe dieser Arbeit gezeigt wird, sehr oft viel kompliziertere und vielschichtigere, ja sogar sich widersprechende Aussagen beinhaltet als das, was in verschiedenen "Aufrufen" und "lanifesten" verkündet wird.

Der Reichtum und die dialektische Spannweite der Gedichte Chlebnikovs, deren Themen sich im großen Umkreis der Orient-Problematik bewegen, treten besonders stark gegen den Hinter:srund der von seinen Zeitrenossen geschaffenen Werke mit ähnlicher Thematili hervor.

Aus Ursachen, deren Frğ rische, kultur- und kunstgeschicitliche Analyse erfordern wïde, nahm cas Interesse am Orient in suropa un die Jahrhundertwende beinahe explosionsartig zu. In iußland ivar die Intensitit der Beschäftigung mit dem Orient besonders JroB, sicherlich war es aber keinesfalls ein ausschließlich russiches Phänomen. llehr noch, es geht um ein Phänomen, das sich nicht allein auf die literatur beschränlete, sondern auch in der europäischen lalerei und in der bildenden Kunst wiederzufinden ist. Der EinfluB der japanischen Malerei auf die Küstler des Jugendstils oder, wie Vją.Vs.Ivanov ${ }^{1}$ ausfuhrt, der EinfluB der afrikanischen Skulptur auf das

1 Vjač.Vs.Ivanov, "Struktura stichotvorenija Chlebnikova 'Menja pronosjat nia slonovych...' " in: Teksty sovetshojo literaturovedceskoro struktur? i iz:za, Irsp.k.Eimermacner (!tinchen, 1971), S. $373-393 ;$ s.321. 
Schaffen von Picasso und Modigliani mögen als vereinzelte Beispiele für die allgemeine Tendenz dienen. Die Feststellung D.Tschižewskijs, daB um die Jahrhundertwende "...der Orient in Verbindung mit der russischen Revolution in den Augen der Intellektuellen eine gewisse Bedeutung zu gewinnen" beginnt, ist viel zu eng gefabt. Indem Tschižewskij das Phänomen nur im Zusammenhang der russischen Revolution sieht, verkennt er sowohl, daB die intensive Beschäftigung mit dem Orient in ganz Europa stattfand, als auch die Tatsache, dab der Orientalismus eines Dichters wie Chlebnikov einen (wie noch gezeigt werden wird) viel zu breiten und mannigfaltigen Themenkreis umfaBt, um nur auf die russische Revolution zurückgeführt werden zu können.

Die Feststellung Tschižewskijs trifft nur in jenen Fällen zu, wo die Künstler das Orient-Thema aufgreifen, um daran das in revolutionären Aufruhr geratene RuBland in seinem bedrohlich-uferlosen (also inrem Verständnis nach "asiatischen") Aspekt darzustellen. In derartigen Werken ist Asien bzw. der Orient meistens nur eine Allegorie. Die von Tschižewskij als Beweistücke für seine These angeführten Gedichte Grjadušcie gunny von V.Brjusov und Skify von A.Blok, zwei der berümtesten Gedichte des russischen Symbolismus, zeigen aber keine echten Hunnen und keine echten Skythen. Brjusov und Blok ging es vor allem um Schreckgespenster und nicht um konkrete historische Völker.Zu diesen beiden Gedichten bemerkt Ettore Lo Gatto:

....Die Begriffe 'Mongole', 'Skythe' und 'Hunne' werden in der ideologischen russischen Dichtung ... nahezu gleichwertig metaphorisch gebraucht, wenn es darum geht, Ruliland mit seinem autochtonen Charakter, nennen wir inn eurasiatisch, der westlichen Welt,
dem verdammten, feindlichen Europa gegenüberzustellen.

Brjusor - so schreibt Lo Gatto - ersetzt in seinem Gedicht

1 D. Tschižewskij, Zwischen Ost und West, Russische Geistesgeschichte II (Reinbek bel Hamburg, 1961), S. 131.

2 E.Lo Gatto, "Panmongol ismo di V.Solov'ev, I Venienti Unni di V.Brjusov e Gli Sciti di A.Blok" in: For Roman Jakobson. Essays on the occasion of his sixtieth birthday, Hrsg.M.Halle (Den Haag, 1956), S.295-300; S. 300. 
die konkrete Erwähnung des Proletariats durch die napokalyptische Vision der metaphorischen Hunnen"( "metaforial unnin")." Was die Skify von Blok anbelangt, so heibt es in einer Tagebucheintragung, in der der Dichter zu den für RuBland erniedrigenden Verhandlungen mit Deutschland, die im Dezember 1917 begannen, Stellung nimnt:"Wir werden uns als Asiaten verstellen, und der Osten wird euch überschwemenn2, eine Aussage, die er kurz darauf in dem Gedicht Skify verarbeitet hat.

Be1 Blok müssen also die Aslaten vorgetäuscht werden: seine Russen, die sich als Skythen geben, sind letzten Endes enttäuschte Europäer, die, von Europa erniedrigt und verraten, eine drohende Position dem Westen gegenliber einnehmen wollen und deshalb auf ihre asiatische Vergangenhelt zuruickgreifen. Bel Brjusov, wie oben von Lo Gatto gezeigt, sind die Hunnen eigentlich getarnte Proletarier.

Dieser eindimensionalen, abstrakt-allegorischen Verwendung eines historischen Stoffes, die den tiefen und sehr bedeutenden Verbindungen zwischen RuBland und Asien nicht gerecht werden kann, steht das stets sehr konkret behandelte orientalische Thema in den Werken Chlebnikovs gegenüber, das allein durch die große Komplexität und vielseitigkeit seiner dichterischen Verarbeltung eine Auseinandersetzung sowohl auf der historischen wie auf der sprachlichen und mythologischen Ebene verlangt.

Die Zahl der Gedichte Chlebnikovs, die sich mit den asiatischen und quasiasiatischen Gebieten RuBlands befassen (d.h. mit Gebieten, die zwar geographisch zu Europa gehören, aber von einer Bevölkerung asiatischen Ursprungs besiedelt sind, wie z.B. weite Teile des unteren Wolgagebietes), ist sehr groß. Chlebnikov begnügt sich aber nicht mit der Schllderung dieser ihm aus seiner $k$ indheit vertrauten Gebiete, sondern greift sehr viel weiter aus und bezieht

1 Lo Gatto, a.a.0., S. 296. Melnes Brachtens wäre hier die Bezeichnung "allegorisch" angebrachter als das von Lo Gatto gebrauchte "metaphorisch".

2 A.Blok, Sobranle sočinenli $\nabla$ ros'ml tomach (Moskau/Leningrad, 1963), Bd.7, S.317. 
historisches Material in seine Dichtung mit ein, das sogar uber die Verbindungen RuBlands zu seinen asiatischen Randgebieten hinausreicht: es fuhrt nach Persien, nach Indien, nach Japan und nach Afrika.

Auf den Zusammenhang zwischen der lebenslangen Beschäftigung Chlebnikovs mit dem Orient und seiner Biographie ist mehrmals hingewiesen worden. Sicherlich hatte Ju. Tynjanov recht, indem er in seinem Artikel uber Chlebnikov schrieb: "Man soll den Menschen nicht mit seiner Biographie abtunn1, dennoch läBt sich wohl feststellen, daB die Tatsache, daB Chlebnikov seine Kindheit unter den Wolga-Tataren zubrachte, sehr viel zur Beständigkeit des Orient-Themas in seinen Werken beigetragen hat. Loščic und Turbin schreiben:

Chlebnikov gehörte wahrscheinlich zu jenem nicht selten vorkommenden Ty pus von Dichtern, deren schöpferische Themen in vieler Hinsicht durch die Umstände ihrer Blographie vom Tag ihrer Geburt an sozusagen 'vorprogrammiert' sind.2

D.Mirskij (einer der Mitbegrunder der Bewegung der "Eurasier") erkannte bereits sehr frïh die Bedeutung, die die Stadt Astrachan', in deren Năhe Chlebnikor im Jahre 1885 auf die Welt kam, für die weitere Entwicklung des Dichters hatte:

Es scheint natürlich, daB Astrachan' Chlebnikovs Stadt war - der Knotenpunit von RuBland, Turan und Iran, die kahlste und ontologischste der russischen Städte ("самин годин и онтодогическин из русских городов"), eine Karawansere1, von den Elementen umrungen, wiste und Wasser. Astrachan' ist elner der Schlussel zu Chlebnikov. 3

1 Ju.Tynjanov, "0 Chlebnikove", in: Archaisty 1 novatory,

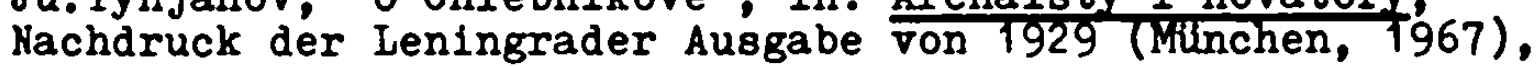
S.581-595;S.594.

2 Ju.Lośćlc und $\nabla$. Turbin, "Tema Vostoka $\nabla$ trorčestve V.Chlebnikova", in: Narody Az11 1 Afrik1, IV(1966), S.147$160 ;$ S. 151 .

3 D.Svjatopolk-Mirskij, "Godovščiny.Chlebnikov", in: Vërsty, III(1928), S.144-146; S.146. 
K. Erymovskij, der auf die entscheidenden Einflüsse der Kindheitsjahre in Astrachan' hinwies, schreibt:

Astrachan' war jene Stadt, in der Chlebnikov vom Osten angezogen wurde, vom Geflecht der Völker, dem lebendigen Widerhall der Zeiten - von Razin und Pugačèv bis zu seiner Gegenwart. 1

\section{Mythologische Aspekte des Orient-Themas}

Um von Anfang an die Besonderheit der Auseinandersetzung Chlebnikovs mit dem orientalischen Thema klarzustellen, scheint es sinnvoll, seine Behandlung der Mythologie und inrer Beziehung zum Orient darzulegen.

In der Arbeit von Claude Lévi-Strauss "Die Struktur der Mythen" heißt es:

Ein Mythos bezieht sich immer auf vergangene Ereignisse: 'Vor der Erschaffung der Welt' oder 'in ganz frühen Zeiten' oder jedenfalls 'vor langer Zeit'. Aber der dem Mythos beigelegte innere Wert stammt daher, da $B$ diese Ereignisse, die sich ja zu einem bestimnten Zeitpunkt abgespielt haben, gleichzeitig eine Dauerstruktur bilden. Diese bezieht sich gleichzeitig auf Vergangenheit, Gegenwart und Zukunft.2

Daraus ergibt sich die für unser Vorhaben wichtige Eigenschaft des Mythos, daB er, als eine Dauerstruktur betrachtet, nicht nur freie Bewegung auf der Zeitachse einschliebt bzw. wie es bei C.Lévi-Strauss heiBt - Vergangenheit, Gegenwart und Zukunft überspannt, sondern auch von einer analogen Ungebundenheit an den Raum gekennzeichnet ist.

Chlebnikov hat von dieser Ungebundenheit des Mythos intensiven Gebrauch gemacht, um auf seine Weise die eigentümliche Stellung RuBlands zwischen Ost und West zu charakterisieren.

$1 \mathrm{~K}$. Erymorskij, "Pevec Lebediin in: Legenda o lotose, (Elista, 1969), S.151-188; S. 169 .

2 C.Lévi-Strauss, "Die Struktur der Mythen" in: Strukturalismus in der Literaturwissenschaft, Hrsg.H.Blumensath (Köln, 1972), S.25-46; S. 27 . 
Er sah in Rußland den Mittelpunkt zweier großer Kulturbereiche, in dem die Mythologien von Ost und West zu einer Einheit verschmelzen.

Um das in seinem dichterischen Werk zu gestalten, bedient sich Chlebnikov zweier Verfahrensweisen:

1. Er verlagert 'westliche', also europäische Mythen in Richtung Osten, vor allem in die Randgebiete RuBlands. 2. Orientalische Mythen, also Mythen deren Ursprung z.B. im alten Ägypten oder bei den mongolischen Völkern des Fernen Ostens zu suchen ist, werden ebenfalls nach RuBland verlagert.

So schreibt Chlebnikov von "einem neuen Argonautenzug nach Astrachan', mit dem Ziel, den Lotos zu finden" (IV,S.378), und in einer in Moskau entstandenen Erzählung, Ka ${ }^{2}$ (lies: Ka-Quadrat), heiBt es:

In jenen Tagen suchte ich vergeblich die Ariadne auf Minos, mich darauf vorbereitend, im XX. Jahrhundert eine Erzählung der Griechen neu zu uberspielen. (III,S.128)

Man kann sagen, daß Chlebnikov seine dichterischkulturelle Aufgabe in der Verschiebung des geistigen Schwerpunktes von Westeuropa nach RuBland sah, wobei KuBland inm vorwiegend in seinem orientalischen Aspekt erschien.

Diese Einstellung erinnert an die Worte Novalis', der von Goethe behauptete:

Die Geognosten glauben, daß der physische Schwerpunkt unter Fez und Marokko liege - Goethe, als Anthropognost, meint, im 'Meister', der intellektuelle Schwerpunkt liege unter der deutschen Nation.'

Was Chlebnikov betrifft, so lag für ihn der "intellektuelle Schwerpunkt" unter der russischen Nation in ihrer asiatischen Prägung.

1 Aus: "Vermischte Bemerkungen ('Blutenstaub') 1797-1798" in: Novalis, Werke, Hrsg.G.Schulz (München, 1969), S. 351. 
2.1. Die Ierlegung 'westlicher'Mththen nach_Rüland

2.1.1. Die Orientalisierung des Aphrodite-Mythos und die Entstehung des Mythos von Azija

Bevor wir uns der Analyse konkreter Beispiele zuwenden, soll das Vorgehen noch einmal kurz begruindet werden.

Da Chlebnirovs Poetologie u.a. durch übereinandergeschichtete, stark verschlüsselte Bilder gekennzeichnet ist, ist es sehr oft unmöglich, die Bedeutung der poetischen Bilder in einem einzelnen Gedicht zu entschluisseln. Viele seiner Bilder, Metaphern, Wortspiele usw. lassen sich erst im weiteren Iontext seines Schaffens ergrinden, indem z.B. eine bestinte, breit ausgefuihrte Metapher in einem Gedicht auf eine dunkle, "verkuirzte" Stelle in einem andern Gedicht ein neues licht wirft. Daher sind die im folgenden häufig vorkommenden Springe und Querverbindungen zwischen verschiedenen Werken mit verwandten oder gleichen Motiven, also eine paradigmatische Lesart seiner Gedichte, für eine umfassende Behandlung eines Motivs unerläBlich.

Chlebnikovs Verfahren der "Orientalisierung" altgriechischer Hythen soll hier am Beispiel des AphroditeMythos gezeigt werden.

Im 5. Kapitel der friihen (1911-12) Dichtung Deti Vyary ist die zentrale Gestalt, die übrigens in der ganzen Dichtung nicht genannt wird, die des aus der griechischen Mythologie bekannten Peuerräubers Prometheus, wie es z.B. aus den Hinweisen der folgenden Stelle hervorgeht:

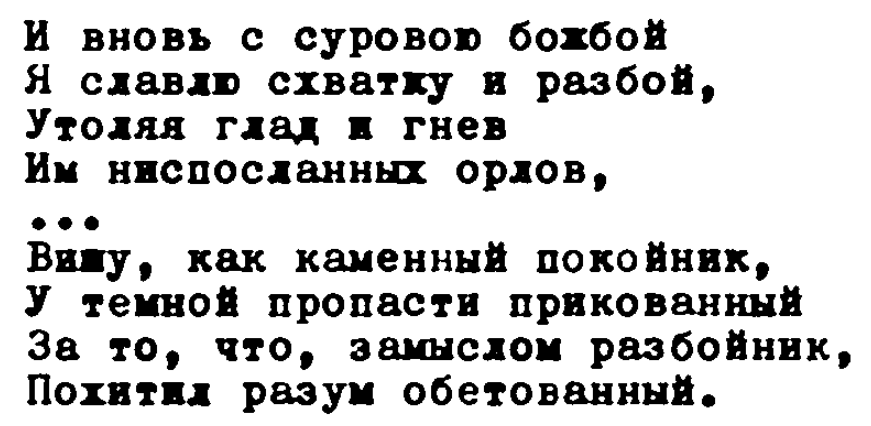

$$
(\mathrm{I}, \mathrm{Bd} .2, \mathrm{S.168f})
$$


Im Monolog des Prometheus, der seine Qual schildert, tauchen zunächst überraschend -Iandschaftsbilder auf, eine Schilderung der Frische des georgischen Morgens:

Смотри ух Грузия несет корзины И луч бдеснул ух на низины.

(ebenda,S.169)

Die Erwähnung Georgiens durch Prometheus hat aber eine ganz bestimmte Funktion. Der Leser wird auf die tberlieferung verwiesen, der zufolge Prometheus als Strafe für den Peuerraub auf Befehl des Zeus an einen Felsen im Kaukasus geschmiedet wurde. 1

Der gefesselte Prometheus wird aber nicht durch den PfeilschuB des Herakles befreit, wie es in der Mythologie heiBt, sondern uberraschenderweise durch die 'Tochter der Otter' (Дочь Выдр), die hier als Befreierin auftritt.

Diese 'Tochter der Otter' hat nun noch eine weitere Identität, die aber verschleiert ist. Durch eine Reihe von Merkmalen suggeriert der Dichter, daB diese Frau eine geheime Verwandschaft mit Aphrodite, der griechischen Göttin der Schönheit und der Liebe, besitzt (wobei der Name Aphrodite freilich nirgends fällt) :

Походить бы я хотела
Очертаниями тела,
что с великим и убогим
Бьть чаруощеи не ленится
И с искусством хромоногим -
Вечно оная изменница. (ebenda, S.1\%)

Die Anspielung auf Aphrodite ist auf eine für Chlebnikov typische Weise verschlüsselt. Jeder einzelne Hinweis für sich genommen würde nicht ausreichen, um

1 Siehe 'Prometheus' in: H.Hunger, Lexikon der griechischen Mythologie (Reinbek bei Hamburg, 1974),S.352. 
Aphrodite kenntlich werden zu lassen. In ihrer Gesamtheit Jedoch lassen die Andeutungen m.E. keinen Zweifel zu: "И с искусством хромоногим" ist ein Hinweis auf den lahmen, für seine Kunst berühmten Gott der Schmiede und der Handwerker Hephaistos, den Gatten der Aphrodite. Da an einer früheren Stelle in der Dichtung ausdriicklich auf die nOdyssee" Bezug genommen wird ("Andra moi enepe Musa", ebenda,S.146), liegt es nahe, "вечно оная изменница" als eine Anspielung auf die Ehebruchszene mit dem Kriegsgott Ares aus dem 8. Gesang der "Odyssee" aufzufassen, wo Hephaistos sich an die Olympier wendend sagt:

Komnt und schaut den abscheulichen unausstehlichen Frevel, Wie mich lahmen Mann die Tochter Zeus', Aphrodite, Jetzo auf immer beschimpft und Ares, den Bösewicht,herzet; Darum, weil jener schön ist und grade von Beinen, ich aber Solche Krüppelgestalt! Doch keiner ist schuld an der Lähmung.

"Вечно рная изменница" ist daher ein klarer Hinweis auf die Göttin, die den "Lahmen" mit dem "Mächtigen" betrügt.

Zwar sagt die 'Tochter der Otter' "походить бы я хотела", was eine totale Identifizierung zwischen ihr und Aphrodite zunächst auszuschließen scheint. Andererseits erinnert aber die Sch1lderung der Geburt der aus dem Meer emporsteigenden 'Tochter der Otter' an die Geburt der Schönheitsgöttin, vor allem auch durch die Betonung des bis zu den Füßen in Haar gehiullten Körpers (ebenda, 3.144), vas

Botticellis Bild "Die Geburt der Venus" ins Ged̈̈chtnis ruft. Stellt man die für Chlebnikov so typische Neigung, den Leser zur Entschlüsselung der vom Dichter gestellten Rätsel zu provozieren ${ }^{2}$ in Rechnung, so gewinnt die Zeile "походить бы я хотела" die Bedeutung der Einladung zu einem Rätselspiel:

1 Homer, Odyssee, übersetzt von J.H.Voss (Stuttgart, 1970), 8. Gesang, 307-311, S.110.

2 So sagt z.B. Henryk Baran:"...a most important element of Chlebnikov's poetic system" sei "the formation of deliberately ciphered texts, of poetic riddles." Henryk Baran, "Chlebnikor's Poem 'Bech'" in: Russian Literature, VI(1974), S.5-19; S.16. 
Der Leser wird dadurch sozusagen herausgefordert, die Identität der auf diese Weise präsentierten Gestalt zu erraten.

Die 'Tochter der Otter' ist also zugleich die Göttin der Liebe und der Schönheit, Aphrodite, Gattin des hinkenden Schmiedegottes Hephaistos und Geliebte des Kriegsgottes Ares, die den im Kaukasus gefesselten Prometheus befreit, indem sie seine Kette durchsägt.

Der vom Dichter in Klammern hinzugefügte Kommentar zur Befreiungstat - eine Art von "Regieanweisung"

(Освобохдаят его, перерезөя, как черкешенкя, цепь).

$$
\text { (ebenda, S.170) }
$$

Пушкин.

hat die Funktion, den orientalisierten griechischen Mythos in einen ausgesprochen russischen Kontext zu versetzen, und zwar dadurch, dâ er einen Bezug zwischen Prometheus und Puškins "Kaukasischem Gefangenen" (Kavkazskij plennik) herstellt. Der Verweis gilt wohl folgender Stelle bei Puškin:

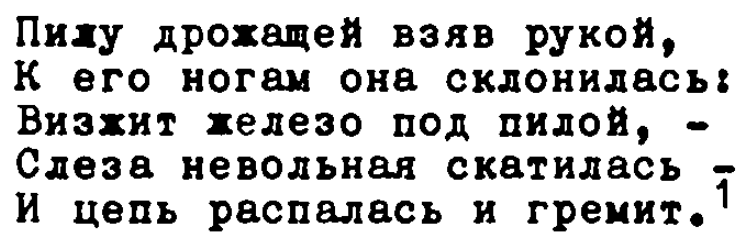

Loščic und Turbin haben darauf hingewiesen, daß Chlebnikov

mit Hilfe kodierter Axiome gedacht hat; beinahe jedes seiner künstlerischen Bilder ist eine verschlüsselte Entdeckung, die entweder in eine äußerlich zu selbstverständliche Sentenz, oder aber im Gegenteil - in eine scheinbar für niemanden verständliche Anhäufung von Bildern und Klängen aufgelöst wird.?

In Anlehnung an Lošcic und Turbin kann man also sagen, daß das "kodierte Axiom" in Chlebnikovs Behandlung der Prometheus

1 A. Fuśkin, Soćinenija v trëch tomach (Moskau, 1962), Bd.2, S. 02 .

2 Ju.Loščic und V.Turbin, a.a.0., S.148. 
-Legende sich aus der Darstellung des Titans ils'Kau'rasiscien Gefangenen' ergibt. Was ihn dem Kavkazskij plenril: von Puškin noch näherbringt, ist die Tatsache, daß sowohl der im Kaukasus an einen Felsen gefesselte Held der griechischen liythologie wie auch der in einem kaukasischen Dorf gefangengehaltene russische Offizier ihre Freiheit aus der Hand einer ö $s$ I i c h e $n$ r a $u$ erhalten: der Held Puskins durch die inn liebende tscherkessische Schönheit, der Held Chlebnikovs durch die 'Tochter der Otter', die im 1.Kapitel der Dichtung Deti Vydry als Schwester der "Geister mit schrägen Nongolenaugen" erscheint (ebenda, S.142f), die also nicht nur, wie bereits gezeigt, eine Verwandtschaft mit Aphrodite hat, sondern auch zugleich die Merkmale einer Orientalin trägt. Vielleicht ließ Chleonikov sich hier von der Tatsache inspirieren, daB die Gattin des Prometheus Asia hieB. Laut Herodot hat der Kontinent von ihr seinen Namen erhalten. 1

Zusammenfassend läßt sich sagen, àab Chlebnikov schon in dem frühen Werk Deti Vydry eine Identitätsbeziehung zwischen der Göttin Aphrodite, der Gestalt einer Asiatin und der Idee der Freiheit (die 'Tochter der Otter' als Befreierin) schafft.

D.A es sich bei Chlebnikov bei der Umarbeitung des Anhrodite-Mythos nicht um ein isoliertes, auf Deti Vydry beschränktes Beispiel handelt, sondern um ein durchdachtes, menrfach verwandelt wiederkehrendes liotiv, zeigt auch das Gedicht $\mathbf{v}$ ètot den', das aus der späten Schaffensperiode ${ }^{2}$ Chlebnikovs stammt:

1 Siehe K.Kerenyi, Prometheus (Reinbek bei Hamburg, 1962), S.62.

2 Dieses Gedicht stammt aus der so3. "Grobbuchsammlung" (siehe Anmerkungen von Stepanov, II, Bd.3, S.377f), die die Periode zwischen 1920-21 unfaBt. Siehe auch Anmerkungen von A.Parnis und N.Stepanov zu O.Samorodova, "Poèt na Kavkazc" in: Zvezda, VI (1972), S.186-194; S.194. 


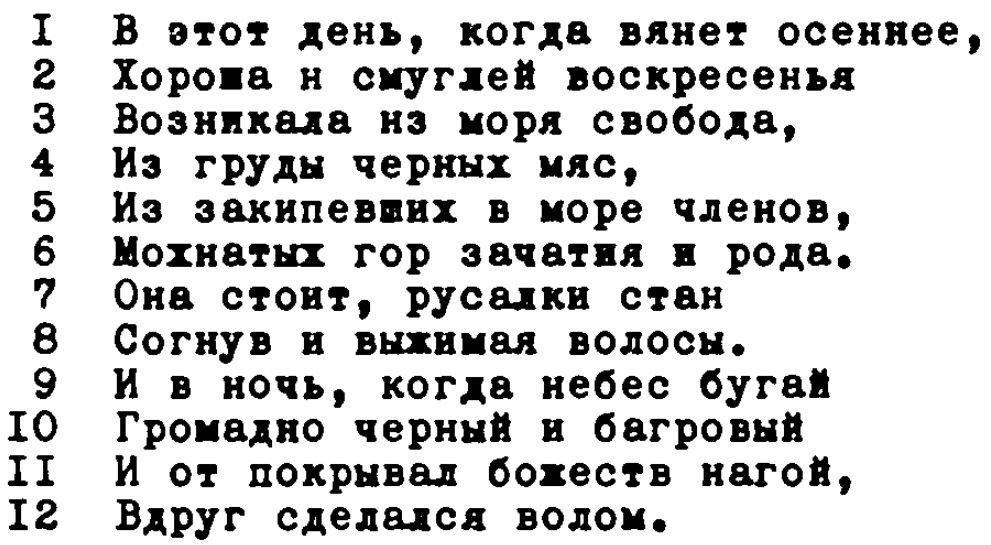

$$
(I I, B d \cdot 3, S .103)
$$

Die Zeilen 5 bis 8 gestatten die Annahme, daB der hier verarbeitete Mythos der der Geburt der Aphrodite ist. Diese Zeilen sind eine Anspielung auf den aus dem Mythos bekannten Zusammenhang zwischen der Geburt der Göttin und der Kastration des Uranos durch Kronos. Der Stier (oyran) wird zum Ochsen (вод). - Diesem Mythos zufolge warde Aphrodite aus dem ins Meer geworfenen männlichen Glied des Uranos geboren ("из закипевших в море членов"). "Закипевших в ropen ist dabei eine deutliche Anspielung auf den Schaum (griechisch "Aphros"), aus dem die Göttin emporstieg."

Der bereits in Deti Vydry angelegte Zusammenhang zwischen der Göttin Aphrodite und dem Akt der Befreiung wird in dem etwa zehn Jahre später entstandenen Gedicht $V$ ètot den' intensiviert und vertieft. Die Gestalt, die hier durch klare mythologische Anspielungen auf die Geburt der Aphrodite gekennzeichnet wird, ist die Freiheit: "Возникала из моря свобода."

In einem 1919 entstandenen autobiographischen Fragment schrieb Chlebnikov: "Mein Volk hat das lieer vergessen und, vergeblich nach der Freiheit greifend, vergaß es, daß die Freiheit die Tochter des Heeres ist."(II, Bd.4,S.118).

1 Hunger, a.a.0., S.419. Siehe auch H.J.Rose:"...from the member itself, as it floated in the sea and gathered foam (ápeós) about it, sprung the goddess Aphrodite." in: H.Rose, A Handbook of Greek Mythology (Iondon, 1965), S.22. 
Das "kodierte Axiom" 'Preiheit ist Tochter des Meeres' findet also seine dichterische Konkretisierung in der Darstellung der Göttin Aphrodite als Freiheit.

Wir werden nun weiter den Faden verfolgen, der die Gestalt der Befreierin des Prometheus in Deti Vydry mit der aus dem Meer steigenden Aphrodite als Verkörperung der Freiheit verbindet. Hierzu muB der Hinweis auf die Sonnenbräune der Göttin in der 2. Zeile beachtet werden. Die Göttin wird also als "sonnengebräunt" geboren, was als erster Hinweis auf inre orientalische Herkunft interpretiert werden kann. Es ist durchaus wahrscheinlich, daB Chlebnikov als ausgezeichneter Kenner der griechischen Mythologie wußte, daB der Aphrodite-Kult vorgriechischen Ursprungs war und aller Wahrscheinlichkeit nach aus Asien stammte. ${ }^{1}$ AuBerdem wird die Aphrodite in der Odyssee, auf die sich Chlebnikov in Deti Vydry bezieht (S.10), als die "goldene" bezeichnet, was ein zusätzliches Korrelat zu ihrer Sonnenbräune darstellt. Die merkwirdige Wortverbindung cyyrge воскресенвя in der 2. Zeile bereitet einige Interpretationsschwierigkeiten und kann nur in Bezug auf die erste Zeile verstanden werden, als eine Antithese zum "Verwelken des Herbstlichen". In diesem Zusammenhang gewinnt Bockpeceнbe die Bedeutung der Wiedergeburt des Frühlings, der Wiederkehr der Sonne, was ein neues Licht auf das Adjektiv смугле (also "sonnengebräunter") wirft: die neugeborene Göttin bringt den Frühling und die wiedergeborene Sonne mit sich.

Der Bezug zum "Verwelken des Herostlichen" in der ersten Zeile impliziert eine weitere mythologische Anspielung, und zwar auf die liebesbeziehung zwischen Aphroaite und Adonis, der im Herbst in die Unterwelt hinabsteigt (Persephone hat nach dem Tod des Adonis, der kein Gott, sondern ein Sterblicher war, auf Ersuchen der Aphrodite inm gestattet, sechs Monate im Jahr in der Oberwelt zu verbringen) und dessen herbstliches Trauerfest mit dem

1 Hunger, a.a.0., S. 44 .

2 Hunger, ebenda. 
Verwelken der Flora verbunden war. ${ }^{1}$

Die ersten zwei Zeilen des Gedichts bauen also eine stark betonte Antithese auf: einerseits herbstliches Verwelken der Natur, der Untergang des "herbstlichen" Adonis, andererseits aber die Geburt der ewig jungen Schönheitsund Liebesgöttin Aphrodite, die ja durch die Aufnahme des Aphrodite-lythos in die altrömische (altitalische) Mythologie zur Venus, also zur Göttin des Frühlings und der Gïrten wurde, deren heiliger Monat der April ist. ${ }^{2}$

Der suggerierte Zusammenhang zwischen der "sonnencebriunten" Aphrodite und der Wiederkehr bzw. dem Neuaufstieg der Frülingssonne stellt auch eine assoziative Beziehung zwischen Aphrodite und dem Osten, dem Bereich der aufgehenden Sonne her. ${ }^{3}$ Diese Beziehung ist in dem Gedicht $\mathrm{V}$ etot den' freilich anders gestaltet als in Deti Vydry, in beiden ierken jedoch finden wir dieselbe Verschmelzung der Schönheits- und Liebesgöttin mit der Idee der Freiheit und dem Osten wieder.

Die Vorstellung von der Preiheit als einer evig jungen Fruhlingsgöttin, die als Antithese zun herbstlichen Verwelken gesehen vird, inspiriert auch die folgende, zunïinst unverstindliche dichtcrische Fifur aus der Dichtung jadomir, die 1920, also etwa gleichzeitir, mit $\underline{\mathrm{V} \text { etot den' entstanden }}$ ist:

Идет свобода Неувяда,

Поднявши стяг рукою смело.

$$
(I, B d .1, S .192)
$$

1 Hunger, a.a.0., S.7. Daher auch die altgriechischen "Adonis-Gärtlein", in Blumentöpfe repflaizte, schnell aufscilieBende und welkerde Blumen. (ebenda)

2 Chlebnilov selbst machte 'ecinen Unterschicd zwischen Venus und Aplirodite. So in der Dichtun Saman i Venera - entstanden etwa zur gleichen Zeit wie Deti Vydry (T911-12) -,

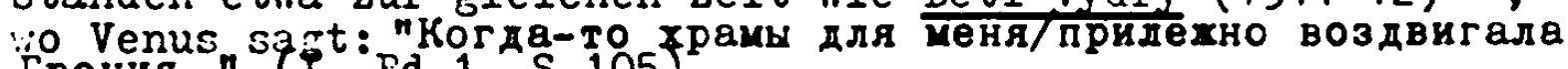
Tpeurs." sq. Ed.1, S.105).

$j$ Siehe K.Kerényi, Tüchter der Sonne (Zürich, 1944). In dem der "züldenen Aphrodite" gewidmeten Kapitel heiat es u.a.: "Es ist die Wirme und Ichtheit der Leidenschait, die das ilesen der Aphrodite ebenso durchgluht, wie das sonnenhafte Gold inre ganze Erscheinun:.." (S.160). 
Das Adjektiv Hеувяда , das auf die Freiheit angewendet wird, aktiviert die gesamten Konnotationen des oben analysierten Bildes der Geburt der Freiheit als Gegenpol zum Verwelken und zum herbstlichen Untergang.

Die komplexe Figur, die wir bis jetzt verfolgt haben, eine Frauengestalt, die in sich die Merkmale der griechischen Göttin Aphrodite mit den Merkmalen einer Orientalin vereint und die als Befreierin bzw. Personifizierung der Preiheit auftritt - erfährt eine weitere Modifikation in Chlebnikovs Dichtung, indem sie in einer Reihe von Gedichten als Personifizierung des Kontinents Asien (쇼교) erscheint. Man kann diese symbolische Frauengestalt als eine Art 'privaten Mythos' des Dichters bezeichnen. Nicht weniger als fünf Gedichte bzw. Fragmente sind der Gestalt Aazg gewidmet (II, Bd.3,S.122,123; III, S, 26,32,61).

Es ist bezeichnend für die dichterische Manier Chlebnikovs, daB die Personifizierung der Asus als Frau sich nicht auf der Ebene der einfachen Substitution abspielt (sodab man schlicht von einer Allegorie sprechen könnte), sondern da $B$ beide Bedeutungsebenen, d.h. Aзяя als Frau und Aзия als Kontinent, in diesen Gedichten zur gleichen zeit nebeneinander existieren. Es ist keine statische, sondern eine dynamische Koexistenz der beiden Bedeutungsebenen, die dieses Spiel Chlebnikovs mit dem iort Aзия kennzeichnet, etwa im Sinne der Definition, die Ju.Lotmen für den "Spieleffekt" (игровон эффект) herausgearbeitet hat:

Der 'Spieleffekt' besteht darin, daB die verschiedenen Bedeutungen eines Elements nicht unbeweglich koexistieren, sondern 'schimmern' ( Mepцanr). Jede Auslegung stellt eine separate Schichtung dar, bewahrt aber dabei die Erinnerung an die vorangegangenen Bedeutungen und die Möglichkeit der künftigen.1

Mit welcher Subtilität Chlebnikov dieses Zusammenspielen der "verschiedenen Bedeutungen eines Elements" durchgeführt hat, sahen wir bereits am Beispiel der zum Symbol der

1 Ju \&otman," Tezisy $k$ probleme 'Iskusstro $\nabla$ rjadu modelirujusćich sistem'n in: Teksty sovetskogo literaturovedćeskogo strukturalizma, Hrsg.K.Eimermacher (München, 1971), S.352367; S.363. 
Freiheit erhobenen Tochter des Meeres Aphrodite. In der Gestalt der Ааия im Gedicht O,Azija "schimmert" wiederum, um den Ausdruck Lotmans zu gebrauchen, die uns bereits in Deti Vydry begegnete Gestalt der Tscherkessin aus Kavkazskij plennik durch, also der asiatischen Frau als Befreierin bei Chlebnikov. Vergleichen wir die beiden Stellen:

Chlebnikov, im Gedicht 0,Azija:

0 еслиб волосами синих рек

Мне Азия покрыда бы колени,

И дева прошептала таинственне пени.

И тихая, счастливая рыдала,

КонцОМ косы гдаза сушв.

$$
\text { (II, Bd.3, S.123) }
$$

Puškin, in Kavkazskij plennik:

\begin{abstract}
Умодкла. Сдези и стенанья
Стесниди беднон девы грудь.

Уста без слов роптали пени.

Без чувств, обняв его колени,

Она едва могла дохнуть.1
\end{abstract}

Die Situation in beiden Gedichten ist analog: die orientalische Geliebte weint, sich an die Knie des Geliebten - der kein Asiate ist - stützend. DaB Chlebnikov in diesem Gedicht auf Puškins "Kaukasischen Gefangenen" anspielt, wird noch deutlicher aus der Verwendung des Puškinschen Reimwortpaars пени-кодени, wobei zu beachten ist, daß das Wort пени im Sinne von "Vorwurf", "Beschwerde" nicht einmal in der dichterischen Sprache des XIX. Jhs. sehr häufig vorkommt, was die Annahme naheliegend macht, dab Chlebnikov dieses Wort von Puškin libernommen hat. ${ }^{2}$

1 Puškin, a.a.0., Bd.2,S.89f

2 Siehe Slovar' jazyka Puškina (Moskau, 1959), Bd.III,S.291. Chlebnikov hat sich intensiv mit Puskin beschäftigt; im Jahre 1915 arbeitete er an einer Puskin-Biographie (IV,S.480). 
Das ungewönnliche Bild in dem Gedicint Chlebnikovs, das die beilen crsten Zeilen des angefuinrten Abschnittes enthalten ("О еслиб волосами синих рек/Мне Азвя покрыла быс"), stellt eine Erweiterung der ursprünglichen Situation dar: das Haar der vom Ich-Dichter erträumten Frau (das ganze Fedicht ist in honjunitivform abgefaßt) wird in der Gestalt der gewundenen Flüsse Asiens dargestellt, wobei die Frau Aзвя gleichzeitig als der Kontinent Asien präsentiert wird. Die Logik der Verbildichung ist klar: wenn Aзия eine Frau ist, dann sind die blauen Fäden der großen asiatischen Flüsse ihr Haar. (Es handelt sich sozusagen um eine Realisierung der i.letapher 'wellige Locken', 'gewelltes Haar').

Ein ähnliches dichterisches Verfahren, nämlich ảaß cir. Iild (in unseren Fall die Haare der Frau) aus ilementer. zusamnengesetzt wird, die einem anderen bz\%. fremden Konte:t entstammen (hier die Flüsse Asiens), hat Vjač.Vs,Ivanov fir das enigmatische Cinlebnikov-Gedicht lienja pronosjat na ilonovych (IV, S.259) festgestellt, das er auf eine Vorlaze aus der bildenden Kunst zuriickfiinrt. Ivanov zeigt, daL eine indische Miniatur als Schlüssel zun Verstündnis des wichtigsten Bildes dieses Gedichtes dient. 1 Die Iiniatux stellt den auf einem Elefanten sitzenden Gott Vishnu dar, wobei der Elefant sich aus einer Geflecist von Frauenjestalten zusamensetzt. Auch die hier untersuchte zusarnensetzung des Bildes des Frauenizares aus der Unrissen de: Pliisse ist in der Palcrei belegt, so z.D. in der Zeichnun des polnischen Jugendstil-ijulens idvars Olow, der 1301 fir die Zeitschrift "Chimera" das Eild eijen kaueriaen inau zeichnete, deren langes Haar in einen Fluß üvergeht, der die sie ungebende Landschaft durchfließt. ${ }^{2}$

Unser Gedicht, das, wie gezeigt, eine Anspielung auf Fuškins Kavkazskij plennik enthält, gehört zu einer ganzen Reihe von Gedichten, in denen Chlebnil:ov dieses Puškinsche

1 Vjac.Vs.Ivanov, a.a.0., S.379.

2 H.Fofstätter (Hrsg.), Jugendstil (Baden-Baden, 1973), S.270. 
Motiv, nämlich das der unglücklichen Llebesbeziehung zwischen einem asiatischen Mädchen und einem "weiBen" Fremden, verwendet hat. Es klingt bereits in einem sehr frühen Gedicht an, dem 1908 geschriebenen Alcak. Die Grundsituation ist die gleiche wie in 0 , Azija: ein trauriges Zwiegespräch ( zwischen ihm (dem Fremden) und ihr (einer orientalischen Frau):

\section{Один модчал, другая гдала. Один бнд бед, другая мало,

$$
(I, B d .2, S .50)
$$

Das Ende der Dichtung Puškins - der Selbstmord der liebenden Tscherkessin, die nach der Flucht des russischen Gefangenen sichins Wasser stürzt - wird von Chlebnikov an den Anfang seines Gedichts verlegt:

Как раньще темен длиннын берег, Где дева с звоном ддинных серег, С грустящим криком, с заломом рук, Кинулась в море, ринулась в звук Иссиня-светлых вод.

(ebenda)

Weiteren AufschluB über die vielschichtige Bedeutung, die der symbolischen Frauengestalt Азия in Chlebnikovs iverk innewohnt, gibt eine Untersuchung von A.E. Parnis zum Gedicht Ispaganskij verbljud. Parnis, den V. 'Markov "einen der besten Chlebnikov-Forscher" (III,S.XI) nennt, lieferte eine redigierte Fassung dieses in Persien entstandenen Gedichts.

$1 \mathrm{Vgl}$. bei Puškin: Bce мертво... На брегах уснувших Лить ветра сльшен легкий звук, И при дуне в водах плеснувших Струисти исчезвет круг.

$$
(a .0 .0 ., 5.93)
$$


In seiner Interpretation vertritt Parnis die Ansicht, daß

Chlebnikov das Wort A3gg als Kontamination von zwei Worten betrachtete. Das assoziative Denken Chlebnikovs zergliederte das Wort Азия in die Elemente: $\underline{A}-\underline{B}-\underline{G}$, wobei $\underline{A}$ vom Dichter einerseits als Synonym für 'Ich' (das altkirchenslavische Aa), andererseits als eine Chiffre (усдовнин знах), Chiffre der Freiheit $A_{3}$ verstanden wird.

arnis bezieht sich auch auf Viktor Gofman, der darauf inweist, daß in Ispaganskij verbljud die Vlorte mprapak A3a nit dem Wort 소표 auf dem Weg der "homonymischen Annähervng" in Verbindung gebracht werden. ${ }^{2}$ Außerdem macht Parnis darauf aufmerlisam, daB in den Glossalolija von Andrej Belyj eine phonetische Reihe angefuhrt wird, die dem Verfahren Chlebnikovs sehr nahesteht: :-Aa-Aзня. 3

Parnis verweist auf den von Chlebnikov selbst $z$ diesem Gedicht verfabten Kommentar, in dem der Dichter schreibt:

Az ist die befreite Persönlichkeit, das befreite 'Ich [...] Der Adler Chabich [ Anspielung auf den Freund Chlebnikovs Rudolf Abich f fliegt in das Iand Asien, das die freie Persönlichkeit aufgebaut hat, was ihn zuvor nicht felungen war, was aber den Heeresvölkern (рвморские

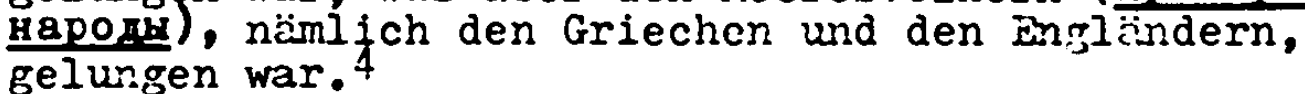
gelungen war.

De: Hinweis auf die Griechen als an ein leeresvol:, das "die freie Persönlichkeit auf jebaut hat", brinft uns zuf den liythos der Geburt der Aphrodite als Freiheit zuricl: ("внрастала во моря свобода"), auf die Wandlung ihrer Gestizt und inre Annäherung an die Gestalt der befreienden Tscher¿essin aus Kavkazskijplennik und schlieblich auf ihre iandlung zur Asar.

1 A.Parnis, "V.Chlebnikov $\nabla$ revoljucionnom Giljane" in: iarody Azii i Afriki, $V(1967)$, S.156-164; S.162. Diese These von Parnis stimmt im Prinzip mit der bereits angefühten These von Loščic und Turbin überein, derzufolge Cillebnikov "mit Hilfe kodierter Axiome gedacht hat"(S.11).

2 a.a.0., S. 163 .

3 3.a.0., s.164.

4. a.a.0., S.16.2. Korrel-turen folgen dem dem Chlebnijov -Original entnomnenen mext von Parnis. 
In dem von Parnis interpretierten Gedicht Ispagansk11 verbljud ist Asien das Land der VerhelBung, der Rettung ror dem trockenen "westlichen Rationalismus":

Шага⿱
Через пустыно Азия,
Где блещет призрак Аза,
Звоном зовет сухие рассудки.

(II, Bd.3, S.133)

Der von Parnis vorgeschlagenen Interpretation zufolge, die durch Chlebnikovs eigenen Kommentar gestutzt wird, wirde das $\underline{A 3}$ in der dritten Zeile "die befreite Persönlichke1t, das befreite 'Ich'n bedeuten.

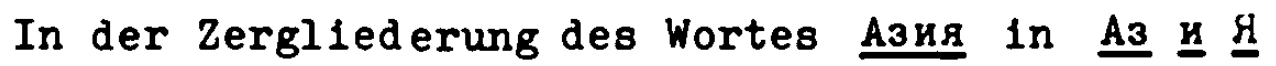
und der Verselbständigung der einzelnen Telle wird ein wesentliches Element der Poetologie Chlebnikovs sichtbar, nămlich die von inm entwickelte Theorie des "selbständigen Wortes" (самовитое слово), nach der die Totalitat der durch ein Wort zum Ausdruck gebrachten Bedeutungen sowohl in den Klängen wie in den inneren Beziehungen der einzelnen Wortteile enthalten ist. 1

Ein Ze1tgenosse, der Chlebnikor bei der Arbeit beobachtete, berichtet:

In der Regel spielte er mit irgendeinem Wort, indem er es wiederholt laut vor sich hin sagte [... I Er behauptete, daB wir das Wesen der Worte nicht bis zuende verstehen. In der lebendigen Sprache sel das Wort unorganisiert, zufällig. Der Dichter muB seine primäre Quelie, seine Grundlage entdecken, und danach strebt er sein Leben lang. 2

Von der Analyse Parnis' ausgehend, nämlich Азия als Zusammensetzung dreier Worte betrachtend, kann man feststellen, daB das Wort $\underline{\mathrm{A} и я}$ auch ein verschleiertes Palindrom 1st: A3 (alsog) 느므. Bedenkt man Chlebnikovs Vorliebe fir diese Gattung (er hat eine mehrere hundert Zeilen lange Dichtung, Razin, I,Bd.1, S.202-215, als Palindrom

1 Siehe z.B. den Aufsatz Naša osnova, III, S.228-243.

2 I.Berezark, "Vstreči s V.Chlenikovym" in: Zyezda. XIII (1965), S.173-176; S.175. 
geschrieben), so wird eine solche Interpretation als durchaus nicht $z u$ weit hergeholt erscheinen.

Eine Eintragung in Chlebnikovs Notizbuch lautet:

Die Worte sind besonders stark, wenn sie zwei Bedeutungen haben, wenn sie zu den lebendigen Augen für das Geheimnis werden, und wenn durch den Glimmer der alltäglichen Bedeutung ( "слода обикновенного сколла") eine andere Bedeutung hindurchleuchtet.1

(III,S.269)

Parnis ist in seiner Analyse des Wortes ㅆи bei Chlebnikov nicht auf das Problem der Personifizierung ( Азия als Frau) eingegangen. Wendet man aber seine Analyse auf die Азия-Gedichte an, so gewinnt die symbolische Frauengestalt Aзия eine zusätzliche Dimension, die die von mir oben aufgezeigten Zusammenhänge von neuem bestätigt. Die sprachliche Analyse, die Aзия als Synthese von "Ich" und der "Chiffre der Freiheit" versteht, verknüpt die Frauengestalt Азия auf eine andere Art mit der aus dem lieere steigenden Freiheit, der mythologischen Aphrodite, wobei die Beziehung der beiden Gestalten zur befreienden orientalischen Frau (der Tscherkessin) aus Puškins "Kaukasischem Gefangenen" wiederum die Verschmelzung von Scinönheit, Freiheit und Orient herstellt.?

Als AbschluBdieses Kapitels sollen hier àie verschiedenen Aspekte jener komplexen Frauengestalt, die sich zu einem eigentümlichen Mythos der orientalischen Frau verdichtet, noch einmal zusammengefaßt werden:

1 Damit ist im Wesen die gleiche Idee zum Ausdruck gebracht wie die von Ju.Lotman mit seiner Theorie des "Spieleffekts" (Siehe S.16).

2 Dieser ganze mythologische Komplex, der hier auf das entschlüsselte Chiffre-Wort A3ug bezogen wird, mag als Illustration zu der von Friedrich Scholz aufgesteliten These in Bezug auf die Dichtung des Futurismus dienen: "Das Thema soll sich aus dem Wort entwickeln. Das wort kann und soll so zum Schöpfer von llythen werden. Hier hat besonders Chlebnikov Beachtliches geleistet." Aus:F.Scholz, "Die Anfünge des russischen Futurismus in sprachwissenschaftlicher Sicht", in: Poetica, Bd.2,H.4(Okt.1968), S.477-500; S. 495 . 
Aphrodite kommt aus dem Meer als Verkörperung der Freiheit ( $V$ etot den') -.-.- Aphrodite ist auch 'Tochter der Otter', Schwester der 'Geister mit schrägen Mongolenaugen' und damit eine orientalische Schönheit (Deti Vydry) ----sie ist Befreierin des in Kaukasus gefangengehaltenen Prometheus (Deti Vydry) -..-- die Befreiungstat der Aphrodite ist analog zu der Tat der Tscherkessischen Schönheit in Puškins Kavkazskij plennik (Deti Vydry) -.--- die tscherkessische Frau "schimmert" durch die symbolische Frauengestalt des personifizierten Kontinents A3Ag (0, eslib Azija, Alcak, 0, Azija) hindurch -..- Asдg entschlüsselt sich als Zusammenfügung von $\underline{A}$ 토 으, der Formel des befreiten Ichs, der "befreiten Persönlichkeit" ( 0, Azija, 0 , eslib Azija, Ispaganskij verbljud).

Diese Zusammenfassung ist nicht als Ausdruck einer linearen Entwicklung zu verstehen; kein Gedicht enthält die Gesamtheit der hier angefuhrten Komponenten. Sie fügen sich aber zusammen, wenn man die verschiedenen Gedichte, die verwandte Motive enthalten, paradigmatisch miteinander in Beziehung setzt.

Chlebnikovs poetologisches Vorgehen, das auf höchst verwickelten und eigenwillig realisierten, ja manchmal esoterischen hotivkomplexen beruht, macht es unentbehrlich, eine große Anzahl von Gedichten aufeinander $z u$ beziehen, um die volle Bedeutung der behandelten Motive zu ergrïnden. 
2.1.2. Die Verlegung der Genesis-Legende in die Randgebiete RuBlands

In vorigen Kapitel wurde gezeigt, wie Chlebnikov Elemente aus einer der beiden großen Traditionen, die die westliche Kultur bestimmt haben - nämlich Elemente aus der griechischrömischen Mythologie - in ein russisches Randgebiet verpflanzt hat. Im folgenden wird nun gezeigt, wie der Dichter Elemente aus dem zweiten Grundstein der westlichen Kultur, nämlich aus der jlidisch-christlichen ïberlieferung, gleichfalls an die Grenzen Rublands verlegt, und zwar nach NordPersien.

In dem am 5.5.1921, also drei wochen nach seiner Ankunft in Persien, in der Zeitung Krasnyj Iran veröffentlichten Gedicht Navruz Truda schildert Chlebnikov das Ncujahrsfest ("Nauruz" auf Persisch) in der Stadt Rescht."

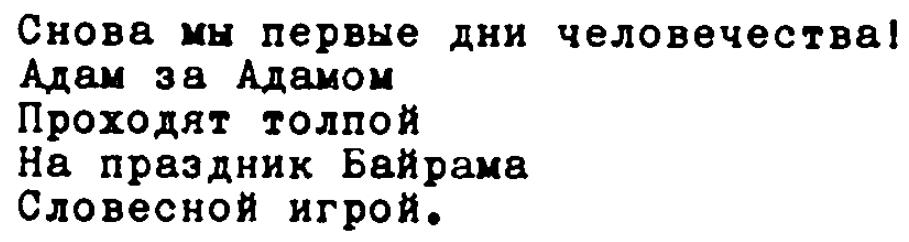

$$
(I I, B d .3, S .124)
$$

Diese Eröffnungsstrophe gewinnt ihren Sinn, :enn man daran erinnert, das 'Adarn' auf Persisch und in dem in Nordpersien gesprochenen Aserbaidschani-Dialekt das gleiche wie auf Hebräisch bedeutet, also 'Mensch' oder 'liann'.2 Die fünte Zeile erklärt sich daher von selbst: das "Wortspiel" besteht darin, daB man statt 'Adam' jeweils 'Mensch' oder 'Mann' lesen soll: die Männer marschieren einer nach dem anderen zum Neujahrsfest.

Da der persische Mensch nicht nur durch seine Zugehörigkeit zum menschlichen Geschlecht, sondern auch durch seine Benennung "Adam" ist, evoziert die Schilderung

1 Siehe Anmerkungen von N.Stepanov (II, Bd.3, S.378) und den Artikel von A.Kosterin, "Russkie dervisi" in: Moskva, IX(1966),S.216-221;S.218.

2 Kosterin, ebenda. 
der Peierlichkeiten des ersten Tages des persischen Neujahrs im Gedicht den Augenblick, in dem der biblische Menschenvater Adam die Weltbühne betritt: "Снова мы первие дни человечества!"

Dieses Zurükgreifen auf die biblische therlieferung der Genesis unter Verwendung des gleichen Wortspiels "Adam ist gleich Mensch" findet sich auch in der ebenfalls in Persien entstandenen Dichtung Truba Gul'-Mully. Hier wird der persische Mensch als Adam in seinen ursprünglichen Zustand, also ins Paradies vor dem Sündenfall versetzt:

Страна, где все доди Адамы,
Корни наруху небесного рая!

$$
(I, B d .1, S .239)
$$

Die Vorstellung Chlebnikovs, das biblische Paradies liege irgendwo im Gebiet zwischen dem Kaspischen und dem Schwarzen Meer, ist nicht erst während seiner Persien-Reise entstanden. Bereits seine erste Begegnung mit dem Kaukasus bedeutete fur inn die Evozierung der ersten Tage der Menschheit. Im Jahre 1903, nach der Beendigung des Gymnasiums, verbrachte Cnlebnikov einen Honat mit einer geologischen Expedition in dem kaukasischen Dorf Gunib. ${ }^{1}$ In einem sechs Jahre später geschriebenen Gedicht, Vam, in dem diese erste Begegnung Chlebnikovs mit dem Orient verarbeitet wurde, heibt es:

Неводьно числа я слагал, Как бы возвратясь ко дням творенья.

$$
\text { ( I, Bd.2,S.77) }
$$

Schon in dieser Zeit mag sich bei Chlebnikov die Vorstellung kristallisiert haben, dab in dieser Gegend am südlichen Rand RuBlands"die Wiege der Menschheit" zu suchen sei. 0. Samorodova scireibt in ihren Erinnerungen an Chlebnikov, er soll in einem Gespräch gesagt haben, "er betrachte Persien als die Wiege der Menschheit."2

1 Parnis und Stepanov, Anmerkungen zu 0.Samorodova,a.a.0.,S. 194 .

2 Samorodova, a.a.0., S.189. 


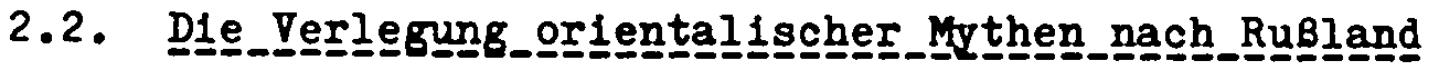

2.2.1. Der altägyptische Gott Ra(Rê) im Wolgagebiet

Die komplimentäre Bewegung zur Verlagerung'westlicher' Mythen nach Rußland besteht in der Verlegung östlicher bzw. allgemeiner gefaBt, orientalischer Mythen ebenfalls auf russischen Boden.

In der Erzälung 트, in der zahlreiche altägyptische Motive verarbeitet sind ( Amenophis, Amenhotep des IV.), findet sich folgender Satz: "лотос из устья Волги или Ра" (II,Bd.4,S.69).

Dabel 1st Ra der altgriechische Name der Wolga bel Ptolemäus,1 hier aber wird auch eine andere Bedeutung von Ra durch den Kontext assoziativ evoziert, nämlich die Bezeichnung des altägyptischen Sonnengottes $\mathrm{Ra}(\mathrm{Rê})$, dessen Verehrung als lebensspendende absolute Gottheit, der sog. "solare Monotheismus, von Amenhotep IV. (1370-1352 v.Ch.) eingefuhrt wurde. 2

Aus diesem Zusammenhang läßt sich der verborgene Sinn der folgenden Zeile aus dem Gedicht Nižnij erschließen: "Водга солнцу выходит молиться в часы зноя" (III, S.23). Im Hintergrund dieses Bildes steht das Wort'Ra' in seiner doppelten Bedeutung: Wolga, also der FluB Ra, betet die Sonnenscheibe an, also den Sonnengott $\mathrm{Ra}$, "In den Stunden der Hitzen, d.h. in den Stunden, in denen im Wolgagebiet "afrikanisches"(bzw. "altägyptisches") Wetter herrscht.3

In dem Gedicht Chadž1-Tarchan (1911-12 geschrieben, also fruher als die 1915 entstandene Erzählung $\mathrm{Ka}$ ) finden wir das erste Mal die Bezeichnung der Wolga als Ra.

1 Siehe "Wolga" in: M.Vasmer, Russisches Etymologisches Wörterbuch, III Bde.(Heidelberg, 1953), Bd.1, S.217.

2 S1ehe "Amenophis" in: Der GroBe Brockhaus (Wiesbaden, 1956), Bd.1, S.236. tber die Bedeutung von "Ra" siehe M.Lurker, Gotter und Srmbole der alten Ägypter (Bern/München/Wien, 1974), S.138.

3 Vgl. mit der späten Dichtung Azy i Uzy (1920-21): "и африкански зной в стране морозови (III,S.30). 
Настала красная пора

В низовьях мqаmегося $\mathrm{Pa}$.

$$
(I, B d .1, S .119)
$$

Das Gedicht 1st der Stadt Astrachan' gewidmet, die der Dichter bei inrem arabischen (auch tatarischen) Namen "Chadżi-Tarchan" nennt."

Auch in Chadzi-Tarchan, wie in Ka, dient die Evozlerung des altgriechischen Namens des Wolgaflußes, Ra, dazu, altagyptische Motive in das Gedicht einzubeziehen. DaB der ägJptische Sonnengott $\operatorname{Ra}(\mathrm{Re})$ wohl kaum etwas mit der altgriechischen Bezeichnung der Wolga zu tun hat, wird nicht berücksichtigt: die Homonymie dient als eine Art "ontologischer Beweis" für das Vorhandensein ägyptischer Merkmale in der mohammedanischen Stadt an der Wolga:

\section{Кольцом осохн закрнвал}

Рукав реки морскон Египет.

$$
\text { (a.a.0.,S.117) }
$$

Die Wolga(Ra) verwandelt sich in den Nil, und die russische Landschaft wird $z u$ einer afrikanischen:

\section{Другую хизнь узнал тот угол,}

Где смогрит Африкой Россия.

(ebenda)

Das afrikanische Thema in Chadzi-Tarchan wird gegen Ende des Gedichts mit der Erwähnung des Osiris abgeschlossen: "Но здесь когда-то был Озирис"(a.a.0.,S.121).

Die an sich absurde Logik funktioniert innerhalb des vom Dichter geschaffenen Systems einwandfrei: wenn die Wolga(Ra) zu einem afrikanischen FluB wird, dann hat auch der im Nil ertrunkene Osiris ${ }^{2}$ etwas mit dem russischen FluB zu tun,

1 Siehe "Astrachan" in: Vasmer, a,a.0., Bd.1,s.30.

2 Siehe "Osiris" in: Lurker,a.a.0., s.129f. 
zumal die Teile seiner zerstückelten Leiche dem Mythos zufolge in alle Richtungen zerstreut wurden, wodurch dem Dichter die Möglichkeit gegeben ist, ihn in der Gegend von Astrachan' an der Wolga wiederzuentdecken.

Osiris wurde im antiken Vorderasien als Sonnenheld verehrt. ${ }^{2}$ Es ist nicht auszuschließen, daß Chlebnikov auch von dieser Tatsache Kenntnis hatte, denn auf diese Weise wäre der Zusammenhang zwischen Ra, also der wolga, aber auch dem Namen des ägyptischen Sonnengottes einerseits und dem Sonnenhelden Osiris andererseits noch deutlicher.

Im Rahmen der Denkweise Chlebnikovs, die von "kodierten A:iomen", komplizierten Verschlüsselungen und der tberzeugung von dem Zusammenhang zwischen $\mathrm{Klang}$ und Bedeutung bestimmt ist, ist es fast selbstverständlich, daß die Identität der altgriechischen Bezeichnung der Wolga, Ra, mit der ersten Silbe des Namens von Stepan Razin, der im Wolgagebiet seinen großen Aufstand entfacht hat, auf eine innere Zusammengehörigkeit der beiden (Ra und Razin) hindeutet. In einem Gedicht der späten Schaffensperiode ("Grobbuchsammlung"h Ra, vira auf diesen Zusammenhang mit einer für Crlebnikov ungewöhnlichen Deutlichkeit hingewiesen:

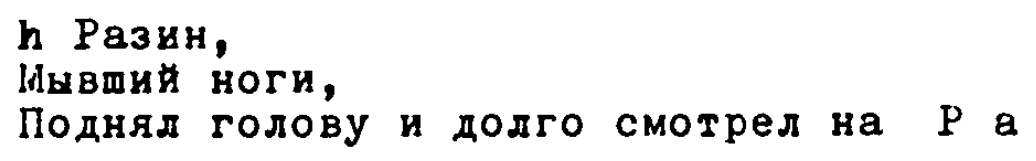

h Разин, Нившй ноги, Поднял голову и додго смотрел на $\mathrm{P}$ a

$$
\text { (II, Bd̉.j, S.158) }
$$

Das Wort "Ra" wird in der Leninfrader Ausgabe von ii.Stepanov in diesem Gedicht durchweg gesperrt gedruckt, was darauf schließen läßt, daß es auch im Manuskript hervorgehoben . wurde.

Von dem in das Wasser der Wolga schauenden Razin reibt es:

1 Uber die Zerstückelung und Zerstreuung der Leichenteile des Osiris siene 2.B. C.G.Jung, Symbole der Wandlung (01ten u. Freiburg, 1973), S.302.

2 Ausführliches über die Verehrung des Osiris als Sonnenheld siehe in:J.G. Frazer, The Golden Bough (London/Toronto, 1967), Kapitel XIII. "Osiris and the Sun", S.505-507. 
Волга гдаз

Тысячи очей - смотрят на него, тысячи зер и зин. (ebenda)

In diesen Zellen offenbart sich wiederum Chlebnikovs eigentulmliche Art, Silben und Klänge mit mehrdeutigen, vielschichtigen Inhalten zu fullen, um sie immer von neuem aufeinander zu beziehen. Зерв und зинш sind eine Dialektbezeichnung für "Augen"1 (hier зин - Gen.Pl. wegen тысячи). Die Zeile Bodra ralas ist daher eine Verschlusselung des Namens Razin: Bолra 1st auch $\mathrm{Pa}$, гда3 ist auch зин; also ist Boдra rдas gleich Pa-3ин.

Die hier erkennbare dichterische Intention besteht darin, dab der zur Entschlusselung aufgeforderte Leser erkennen soll, dab die historischen und geographischen Zusammenhänge, die zwischen Razin und dem Schauplatz seines Handelns (dem Wolgagebiet) bestehen, auch sprachliche Zusammenhänge sind, d.h. in der Sprache selbst realisiert sind.

Auch in Chadži-Tarchan befinden sich Anspielungen auf die Gestalt Razins (obwohl sein Name nicht erwähnt wird). Die Zeilen:

Чу! Слытен плач и стан княхны На руках гнется лиходея

$$
(I, B d .1, S .119)
$$

splelen auf die Ertränkung von Razins Braut an, einer persischen Prinzessin. Der Ausruf Сарынь на кичку! (ebenda,s.117) ist der Kampfruf Razins. An diesen Stellen also, die die Gestalt Razins evozieren, wird beim Leser wiederum die bedeutungsbeladene Silbe Ra evoziert( diesmal als die erste Silbe des Namens Razin), die einerselts, wie oben dargelegt, in diesem Gedicht bereits als Bezeichnung für Wolga aufgetaucht 1st, andererselts aber zugleich auf Afrika und das alte Ägypten hinweist.

1 Siehe Anmerkungen von Stepanor (II,Bd.3,S.380) und die Ausfuhrungen Chlebnikovs in dem Aufsatz Naša Osnova (III, S.228-243;S.229). 
In dem Gedicht Edinaja kniga, das im Jahre 1920, also fast ein Jahrzehnt nach Chadži-Tarchan, entstanden ist, läbt sich wiederum der verborgene Zusammenhang zwischen der Wolga und dem Nil erschließen. In diesem Gedicht wird u.a. eine Reihe von Flüssen aus verschiedenen Kontinenten aufgezählt, die sich im allgemeinen Kontext dieses Gedichts zu einer Art pantheistischer Einheit zusammenfügen (siehe Kapitel 5.3. dieser Arbeit, S.67ff). Wir werden uns aber in diesem Rahmen auf den Übergang von der Wolga zum NiI beschränken, die hier aufeinander folgen:

\section{Волга, где Разину ночьр порт, Жедтый Нид, где модятся соднцу}

$$
\text { (II, Bd.3,S.68) }
$$

Oben wurde schon gezeigt, wie sich die wolga in Chadzi-Tarchan in den Nil verwandelt. In Edinaja kniga ist es noch der Nil, an dessen Ufer man die Sonne anbetet, in Gedicht Nižnij aber wird das Sonnengebet in Zusammenhang mit der Wolga gebracht, ja es ist die Holga(Ra) selbst, die die Sonne (Ra) anbetet (III,S.23). Der Übergang von der Wolga zum Nil in Edinaja iniga beruht also auf einer inneren Verwandtschaft zwischen den beiden Flüssen, die auch durch die syntaktische Parallelität zwischen den beiden Zeilen unterstrichen wird. Diese syntaktische Parallelität (beide Male Jativ-Objekt im Nebensatz) ist um so auffallender, als man sinngemäß statt Paзинy doch Разина oder о Разине (z.B. das berühmte Razin-Lied "Из-за острова на стрехень") erwartet hätte, also Akkusativ bzw. Lokativ anstelle des Dativs. Dieser Dativ nun bringt Pазин in eine parallele Stellung zu coлнцy, (wodurch das Verb n000 die Bedeutung religiösen Singens, parallel zu модятcя, gewinnt), wobei die Silbe $\underline{\mathrm{Pa}}$ im Namen Paзин auf den Sonnengott $\mathrm{Ra}$ hinweist. Die vom Leser zu vollziehende Umkodierung der Wolga zu Ra und ebenso der Sonne zu Ra schafft die innere Verbindung zwischen den beiden Zeilen. 
In dieser dreifachen indirekten, verschlusselten Wiedergabe von 스 lst die erste einer geschichtlichen Quelle entnommen (Wolga als Ra bel Ptolemăus), die letzte ruhrt in die Mythologie hinein ( Morsres codshy, ale beten zum Sonnengott $R a$ ), das mittlere Bindeglied, die Silbe $\underline{R a}$ in Razin, beruht auf einem auf der semantischen Ebene festgelegten immanenten Zusammenhang zwischen dem Wort (hier: Name, Benennung) und dem Inhalt (hier: geographisch-historischer Wirkungskreis des Razin).

Zusammenfassend läbt sich sagen, das Chlebnikov ähn-

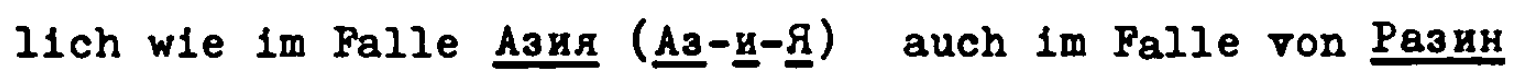
einen ganzen 'privaten' Wythos, nämlich den Mythos der inneren Verwandtschaft zwischen Wolgagebiet und Afrika, aus e1nem einzigen Wort entwickelt, aus Ra, das die geographische Gegend (die Wolga), den altägyptischen Mythos (den Sonnengott $\mathrm{Ra}$ ) und die herolsche Gestalt Razins in sich miteinander verknüpft.

Die Archaisierung des Namens des russischen Flusses hat eine doppelte Funktion. Einmal wird die tberleitung von Geschichte zur Mythologie geschaffen und zum anderen der Kontext erweitert, indem RuBland als ein Land mit stark orientallschen Merkmalen dargestellt wird.

2.2.2. Die kosmogonischen then der Orotschen in Det1 Vydary

Chlebnikov hielt die Legenden der Orotschen (oroči), eines im Gebiet von Chabarovik am Amur an der chinesischen Grenze lebenden Stames, "fur die altesten auf der Welt"." Seiner groBen Dichtung Det1 Vydry legte er die kosmogonischen Mythen dieses mongolischen Stames zugrunde, so z.B. die

1 Chlebnikov liefert Hinweise Uber die Bntstehung von Det 1 Vydry in einem Vorwort zu einer nicht erschienenen Ausgabe Srofasi (I, Bd.2, S.7-11; S.7). 
Legende der Tötung der zwei Sonnen (der schwarzen und der roten Sonne ${ }^{1}$ ) durch den mythologischen Helden der Orotschen, den 'Sohn der Otter', oder die tberlieferung, das die Erde sich "in einem feurigen Zustand" befunden habe (ebenda), bevor das Leben aus dem Wasser hervorstieg.

Chlebnikov begnügt sich aber nicht wit der thernahme der Orotschen-Legenden. Fr strebt in Deti Vydry elne vollkommene Synthese zwischen östlichen und westlichen Mythen an und flicht deshalb zahlreiche Motive aus der griechischen Mythologie in die Dichtung ein. Seine Verarbeitung der Mythen um Aphrodite und Prometheus in Deti Vydry wurde oben dargelegt. Hier sei ein weiteres Beispiel nur kurz erwähnt.

Die Handlung des zweiten Kapitels der Dichtung findet auf dem 0lymp statt, wo die den Orotschen-Legenden entnommenen 'Kinder der Otter' als Zuschauer dem heiteren Treiben der griechischen Götter und der Helden aus der "Illas" und der "Odyssee" beiwohnen. Im ersten Kapitel werden die beiden 'Söhne der Otter', die "Gelster mit schrägen Mongolenaugen", am Feuer sitzend gezeigt, wo sie ihre Wachsflugel zergehen lassen ( $I, B d .2, S .144)$ - eine deutliche, frellich ironisierende Anspielung auf den Ikaros-Mythos, denn einer dieser Brüder 1st ja derselbe, der die Sonne (die den Sturz Ikaros' verursachte) den Orotschen-Legenden zufolge besiegt hat.

In seinem 1916 geschriebenen "Brief an zwei Japaner" verlangte Chlebnikov, man solle "nicht an den griechischen, sondern an den asiatischen Klassizismus ${ }^{2}$ denken" (III, S.156). Tatsächlich aber nahm er in seine Werke beide therlieferungen auf, die altgriechische und die asiatische, und verknüpfte sie miteinander, wobel allerdings die orientalischen Mythen stärker in den Vordergrund traten.

1 Die gleiche Legende 1st in der Erzählung Oko (IV, S.291 - 293) verarbeitet.

2 Normalerweise wäre "Klassik" und nicht "Klassizismus" zu erwarten. Vermutlich einer der vielen lapsus linguae Chlebnikovs. 
3. RuBland und der Orient im geschichtlichen Denken Chlebnikovs

3.1. Die_Umorientierung der_geschichtlichen Perspektive und

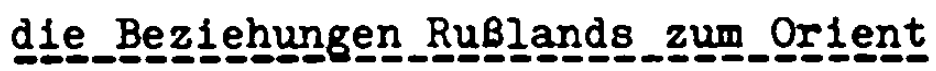

In dem im Kapitel 2.2.1. diskutierten Gedicht ChadziTarchan wird die Stadt Astrachan', die tatarische Stadt an der Wolga, mit ihren vielen Moscheen und spitzen Minaretten als Brutstätte fur die beiden gröBten Bauernkriege der russischen Geschichte dargestellt, den Aufstand Stepan Razins (1670-71) und Pugačërs (1773-75). Emel'jan Pugačër wird als Held des russischen Kampfes gegen die "Deutschen" präsentiert:

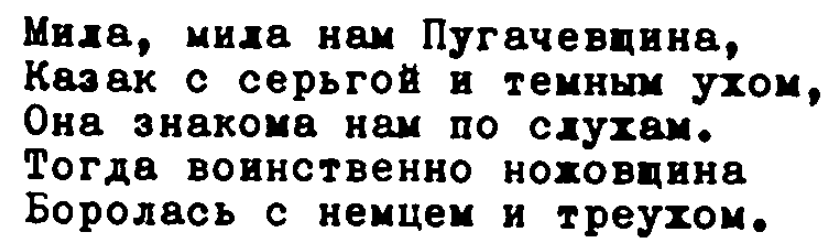

$$
(I, B d .1, S .117)
$$

Mit den "Deutschen" ist vermutlich die Kaiserin Katharina die GroBe - ursprïnglich Prinzessin von Anhalt-Zerbst gemeint, gegen deren Truppen die Aufständischen Pugacëvs in den Gebieten der Unteren Wolga gekämpft haben. ${ }^{1}$

Während die Deutschen als die großen Feinde geschildert werden, hebt der Dichter die Ähnlichkeit, Ja die Wesenseinheit der Russen mit den Mohammedanern, die im Heer Pugačëvs zahlreich vertreten waren ${ }^{2}$, hervor:

Ax, мусульмане, те те русские И русских мохет бнть Ислам. (ebenda,S.120)

1 V.Gitterman, Geschichte RuBlands 3 Bde. (Hamburg, 1949), $\mathrm{Bd} .2, \mathrm{~S} .180 \mathrm{f}$.

2 a.a.O., Bd.1,S.228f. 
Die historische Tatsache, daB Astrachan' in frühen Zeiten als Ausgangsounkt fur Handelsverbindungen zwischen RuBland und Indien gedient hat ${ }^{1}$, gibt Chlebnikov AnlaB, von dieser Stadt als vom "Fenster nach Indien" $z$ u sprechen:

\author{
Сквозь рУсских в Индио, В окно \\ Возили рухья и зерно \\ Купца суда. Теперь их нет. \\ А внуку враг и бохин свет. \\ (ebenda,S.118)
}

Es ist unverkennbar, daß Chlebnikov sich hier an Puskins "Ehernen Reiter" anlehnt, und zwar an die Schilderung der Errichtung von Petersburg als "Fenster nach Europa":

\title{
Природой здесь нам сухдено \\ В Европу прорубнть окно.2
}

Eine doppelte Tendenz läßt sich erkennen: RuBland wird einerseits gegen den Westen (das "Deutschtum") klar abgegrenzt und andererseits gleichzeitig mit einer Fülle orientalischer Merkmale versehen. Das umgeformte PuškinZitat ${ }^{3}$ dient also dem Ziveck der Umkehrung der geschichtlichen Perspertive: das "Fenster" als üffnung, als Weg aus der nationalen Isolation, soll nicht nach Westen (wie bei Peter dem Growen), sondern nach Osten, in Richtung Asien (Indien) aufgestoßen werden.

Der nächste Schritt ist die Darsteliung RuBlands als ein östliches Land, als eine Art 'Orient sui fgeneris':

"Нас перехенят на немках, клянусь."

Восток надел венок из зарев,

За честь свою восстала Русь.

(ebenda,S.119)

1 Siehe 2.B. N.V.Riasanovsky, A History of Russia (New York, 1963), S.312.

2 Puškin, a.a.0., S.250.

3 Eine Anspielung auf die gleiche Stelle im "Whernen Reiter" findet sich auch im Bericht Otkrytie Universiteta:

"...Aстрахань - окно в Индик"(IV,351).Ebenso im Gedicht Poluźeleznaja izba: "Прорубим на Кубань окно!" (II, Bd.3, S.50) 
Wie eng das Motiv der Verwandtschaft zwischen RuBland und Asien mit dem Motiv der Abgrenzung von Westeuropa zusammenhängt, läbt sich aus der 1914 zusammen mit B.Iivšic abgefaßten Protestschrift Chlebnikovs gegen den Besuch des italienischen Futuristen Marinetti in Petersburg ablesen:

Manche der Eingeborenen und die Italienische Sledlung an der Neva fallen heute aus eigensuchtigen tberlegungen Marinetti zu Füssen, den ersten Schritt der russischen Kunst auf dem Wege der Freihe1t und der Ehre verratend, und beugen den adligen Hals Asiens unter das Joch Europas.

$$
\text { (III,S.250) }
$$

Anstelle des"tatarischen Jochs" - ein wichtiges Motiv der russischen Geschichtsschreibung - tritt hier das "europälsche Joch" in den Vordergrund. Aber noch bezeichnender fir die Einstellung Chlebnikovs ist die folgende Stelle aus der Protestschrift:

Menschen der Freihelt halten sich fern. Sie kennen das Gesetz der Gastfreundschaft, aber ihr Bogen ist gespannt und inre Stirn ist zornig. Ausländer, achte das Land, in das du gekommen bist! 1

(ebenda)

Marinetti, der Europäer, ist also der Fremde, der Ausländer ( yухеземeg), während in Chadži-Tarchan demgegenüber die Mohammedaner den Russen gleichgestellt ( "Ax, мусудьмане re xe русские ${ }^{n}$ ) sind.

Die Umkehrung der historischen Orientierung RuBlands in Chadži-Tarchan - Ersetzung von "Fenster nach Europa" durch das "Fenster nach Indien", wie auch die Ersetzung des "tatarischen Jochs" durch das europäische in der Protestschrift - bestätigen die Tendenz: sowohl das Gesicht nach Asien zu wenden wie dem Westen den Rücken zu kehren.

1 In einem ebenfalls vom Besuch Marinettis handelnden Brief an Nikolaj Burljuk (2.2.1914) schrieb Chlebnikov: "Der Osten stellt dem hochmütigen Westen eine Herausforderung entgegen" (IV,S.368). 
Aus den Werken der fruhen Schaffensperiode Chlebnikovs (etwa 1906-1914) lassen sich zahlreiche derartige Beispiele anfuhren, in denen RuBland als vorwiegend asiatisches, mit dem Westen im Streit liegendes Land dargestellt wird. Damit 1st aber kelneswegs etwas Endgliltiges uber den frtihen Chlebnikov, geschweige denn über sein ganzes Werk gesagt. Wurde man es bei der Formel von der Abkehr vom Westen und der Zuwendung zum Osten belassen, so wäre die Haltung Chlebnikors mit einem enggefaßten Slavophilentum oder "Skythentum" gleichzusetzen. Sie ist es aber keinesfalls.

Chlebnikov war ein Dialektiker. Die Tiefe und Originalität seines dialektischen Denkens und der dichterischen Gestaltung läBt sich an der Art seiner Behandlung der Beziehungen ewischen RuBland und seinen asiatischen Nachbarn erkennen: Rubland ist nicht nur ein "asiatisches" Land, sondern auch ein Land, das sich mit dem Asiatentum bitter auseinanderzusetzen hatte. Das ausschlaggebende Element in den Bezlehungen zwischen RuBland und Asien in der Dichtung Chlebnikovs sind die jahrhundertelangen Kriege zwischen Russen und Asiaten.

\subsection{Das '_Gegetz_der_Vergeltung'_und_se1ne_dichter

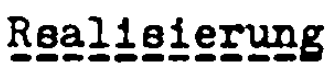

Die Geschichte der "Goldenen Horde", die Schlacht gegen Mamaj am Schnepfenfeld im Jahre 1380, der groBe russisch-Japanische Krieg von 1904-5, also die kriegerischen Auseinandersetzungen RuBlands mit den mongolischen Völkern, liefern das relche geschichtliche Material, anhand dessen Chlebnikor seine elgentumliche Geschichtsphilosophie entwickelt, d.h. seine Lehre von den "Gesetzen der Zeit" und seine Theorie der Vergeltung als das höchste Gesetz der menschlichen Geschichte. 
Chlebnikov vertritt in seinem Werk einen geschichtlichen Determinismus ganz besonderer Prägung. Seiner Theorie zufolge finden alle wichtigen historischen Ereignisse in ganz bestimten zeitlichen Abständen statt und sind auch dann kausal verknüpft, wenn sie äuBerlich gesehen gar nichts miteinander zu tun haben, wenn sie also z.B. zeitlich und räumlich sehr weit voneinander entfernt liegen. In einer muihsamen Arbeit, die sich uber die ganze Dauer seines schöpferischen Lebens hinzog, stellte Chlebnikov eine groBe Zahl von mathematischen Tabellen zusammen, die dem Ziel galten, die verborgenen kausalen Zusammenhänge zwischen den verschiedensten Ereignissen festzustellen. Diesen "Gesetzen der Zeit" (Законы времени) , wie sie Chlebnikov nennt ( $I, B d .2, S .10)$, liegt ein Ubergeordnetes Prinzip zugrunde, und zwar das Prinzip der Vergeltung.'

Den unmittelbaren AnstoB zum Beginn der Suche nach den "Gesetzen der Zeit" bekam Chlebnikov nach eigener Aussage durch den russisch-japanischen Krieg von 1904-5. In Svojasi schreibt Chlebnikov:

Das Versprechen, die Gesetze der Zeit zu finden, das ich auf eine Birke (im Dorf Burmakino, Gouvernement Jaroslavl') geschrieben habe, gab ich'beim Eintreffen der Nachricht von Tsuschima, und ich habe sie 10 Jahre lang gesammelt.

$$
(I, B d .2, S .10)
$$

Zur Zeit der Tsuschima-Schlacht (Mai 1905) stand Chlebnikor in seinem 20. Lebensjahr. Diese Schlacht, die die Niederlage RuBlands im Krieg besiegelte, wird sowohl in den frühesten uns bekannten Gedichten (z.B. Byli vešc̆i sliškom sini, 1906-8, I, Bd.2,S.31-33) wie auch in der im Jahre 1921, ein Jahr vor Chlebnikovs Tod, entstandenen Dichtung Perevorot $v$ Vladivostoke ( I, Bd.1,S.274-282) behandelt.

1 Siehe z.B. Chlebnikovs Ausführungen in den Sammlungen . tryvok iz dosok sud'by, Iist 2-j u. Iist 3-j (III,S.487520) 
In dieser Dichtung tritt der japanische Samurai als Krieger der tatarisch-mongolischen Horden von Khan Mamaj auf :

Глаза косые подымая

Достойным вонном Мамая,

Он проходил высоки горец. (I,Bd.1,S.276)

Und in Byli vešc̆i sliškom sini finden wir die Mahnung:

Бойесь, о бойтесь, монголн,

И тиитесь в будущем узреть Ниппон.

$$
(I, B d .2, S .32)
$$

Dadurch, daB Chlebnikov für die Japaner einerseits den therbegriff "Mongolen" im Sinne 'Angehörige der mongolischen Rasse' verwendet (wobei die Bedeutung des Wortes "Mongole" als Bezeichnung für das mongolische Volk, mit dem Rußland lange Kriege gefuhrt hat, mitschwingt), zugleich aber andererseits dieses Volk (eben die Japaner), das 1904-5 gegen die Russen rekämpft hat, einceutig als Nippon bezeichnet, kann der jichter die militäriscicen Auseinandersetzunger zwischen Rúland und Japars is die lange Reihe der russisch-mongolischen Kriere ei:rliadern. Wenn dem Dichter eine entsprechende Erveitcrung den historischen Perspektive als sinnvoll erscheint, macht. er nicht davor halt, eine Brücke zwischen den Japanern und dem Islam(!) zu schlagen. So in Perevorot $v$ Vladivostoke:

И ты, зедены плам пророка? Тебя забыл дол Владивостока! 1

$$
(I, B C .1, S .275)
$$

1 Gemeint ist der grüne Mantel des Propheten Mohammed. Auch in Chadži-Tarchan wird der Zusammenhang zwischen der grünen Farbe und dem Islam hervorgehoben:

Чалмы зеленые толпон/Здесь бродят в праздник мусульиан. $(I, B d .1, S .118)$ 
Also ist nicht nur die einzige konkrete Gestalt dieser Dichtung, die des japanischen Samurai, dem "stolzen MamajKrieger" gleichgestellt, sondern es wird auch die japanische Invasion in Vladivostok (April 1918) zum AnlaB genommen, die langen Kriege zwischen den Russen und den islamischen Steppenvölkern Südrußlands und Mittelasiens zu evozieren. Bezeichnend fur die dichterische Verarbeitung historischer Stoffe bei Chlebnikov ist die Vermischung geschichtlich und anthropologisch richtiger Tatbestände (Japaner gehören tatsächlich zur mongolischen Rasse) mit willkïrlichen assoziativen Feststellungen (hier eigentlich ein logischer TrugschluB oder ein Sophismus:"Wenn die Japaner zu den 'Mongolen', d.h. zur mongolischen Rasse, gehören und die Tataren, die mit den Mongolen eng verwandt sind, sich zum Islam bekennen, dann haben auch die Japaner etwas mit dem Islam zu tun").

Es handelt sich um eine mythologisierte Geschichte, in der objektive kausale Zusammenhänge durch die hermetischen Kausalitätsketten der sprachlichen Assoziationen ersetzt werden. Im angeführten Beispiel: Japaner -..--- mongolische Rasse -.--- Mongolen (als Volk) --.-- Tataren --.--- Islam.

Ein weiteres Mittel zur Vertiefung der historischen Perspektive ist die Archaisierung der dichterischen Sprache. So wird der Leser des ebenfalls dem Krieg von 1904-5 gewidmeten Gedicht Pamjatnik bereits durch die Eröffnungszeilen in frühere zeiten versetzt:

\footnotetext{
Далеко на острове, где русскон дерхаве

Вновь угрогал урок иль ущерб, Стал появляться призрах мехавыи, Стаи пугея робких нерп. $(I, B d .2, S .85)$
}

Auffallend ist hier die erhabene Diktion, die alte, streng poetische Art der Verbindung йлb.

Auch die Benennung der Realien wird einer Archaisierung unterzogen, wenn der Dichter bemuiht ist, daran zu erinnern, daB der russisch-japanische $\mathrm{Krieg}$ eine jahrhundertelange Vorgeschichte hat. Die Panzerschiffe der Russen und der 
Japaner, die sich in Kampfbereitschaft einander nähern, verwandelt der Dichter in altertümliche Boote ${ }^{1}$ :

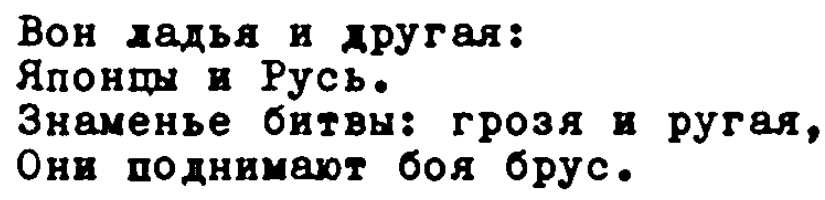

(ebenda)

Indem Chlebnikor den russisch-japanischen $\mathrm{Krieg}$ als Fortsetzung der alten russisch-mongolischen Kriege präsentiert, gibt er AufschluB liber seine Auffassung der Geschichte. Fï den Historiker Chlebnikor gibt es eine "entscheidende Schlacht" ebensowenig wie einen "entscheidenden Sieg". - Jede Schlacht ist nur ein Glied in der unendlichen Kette von Sieg, Niederlage und Vergeltung, einer Kette, die nur in der Utopie abgebrochen werden kann. ${ }^{2}$ So kann Chlebnikov die größte Rußlandverbundenheit, ja, einen ausgeprägten Patriotismus, mit seinem eigenartigen geschichtlichen Objektivismus vereinbaren.

Im 'Superpoem' Zangezi bezieht sich der Dichter auf den grimmigen Propheten des Panmongolismus Vladimir Solov'ëv, um die historische Rechtfertigung für die russische Niederlage bei Mukden zu finden. Auf diese Weise werden zwei mehr als funf Jahrhunderte auseinanderliegende Kriege kausal miteinander verknüpft, indem der eine als Vergeltung für den anderen aufgefaßt wird:

\section{Чем Кудихово было татарам, \\ Тем грогши Мукдев би дхя русских \\ B оqkax jqenoro пророкв \\ Eго ввдал a пвсьменвим стодом \\ Bладамар Содовьев.

$$
\text { (II, Bd.3,S.350f) }
$$

1 Den Hang Chlebnikovs zum altertümlichen Bild und zur archaischen Sprache verzeichnet Nikolaj Gumilër, ohne aber auf die Funktion dieser Archaisierung zu schlieBen. Siehe "Stat'i i zametki o russkoj poeziin" XXXI in: N. Gumilëv, Sobranie soćinenif $v$ detyrëch tomach (Washington, T962-1968), Bd,4,S.324.

2 Siehe das 5. Kapitel dieser Ábeit:"Chlebnikovs Entwarf einer Utopie und der Orlent." 
Die Akzeptierung der an die "Gesetze der Ze1t" gebundenen Vergeltung als das Prinzip, das die Beziehungen der Völker regiert, fuhrt bei Chlebnikov zu einer dualistischen Auffassung der Geschichte: wenn der Krieg eine mit mathematischer Genauigkeit voraussagbare Gegebenheit ist, dann ist der Krieg eine objektive Notwendigkeit und keiner ist daran "schuld". In der Dichtung Vlom Vselennoj, in der das bereits zitierte Versprechen, die"Gesetze der Zeit zu finden"(siehe S.37), in der Form eines Gedichts zum Ausdruck komnt, heibt es:

\section{Я дал обеданье все понять, \\ Чтоб простить всем и все

$$
(\mathrm{II}, \mathrm{Bd} .3, \mathrm{~S} .94)
$$

Die Geschichte wird als ein Modell von Aufstieg, Blüte und Niedergang konzipiert. Im dichterisch-geschichtlichen Bekenntnis Junosa Ja-Mir formuliert Chlebnikov seine Auffassung folgendermaßen:"Siegen, erobern, herrschen und sich unterwerfen - das ist das Gebot meines alten Blutes" (II,Bd.4,S.35). Die im Wesen gleiche Idee von Aufstieg und Niedergang wird auch mit Hilfe des "Gesetzes der Schaukel" (I,Bd.2,S.94) vergegenwärtigt: die Schwingung der historischen Schaukel setzt voraus, dab jede Seite ein Nal oben und das andere lial unten ist.

Die geschichtliche Dialektik Chlebnikovs zeigt sich nicht nur in seiner Behandlung der allgemeingültigen GesetzmäBigkeit, die die Geschichte beherrscht, sondern auch in den kuinstlerischen Nitteln, die er zur Gestaltung des geschichtlichen Stoffes wählt. Als zentrales Beispiel hierfür soll hier die Samural-Gestalt in einer der vollkommensten Dichtungen Chlebnikovs, Perevorot v Vladivostoke, dienen.

Der japanische Samural, der mit den Fingern die Augen seiner Feinde aussticht,"spielend" ihre Knochen bricht und Jiu-Jitsu-Schläge austeilt, ist die Verkörperung der Nemesis, 
der Vergeltung für die Niederlage des Mongolen Mamaj in der Schlacht am Schnepfenfeld im Jahre 1380:

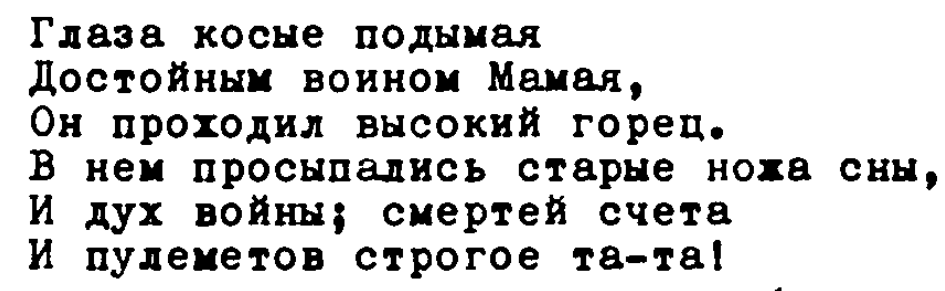

$$
(I, B d .1, S .276)
$$

Die aggressive Brutalität des japanischen Kriegers ist aber nur eine Seite in der dichterischen Gestaltung dieser Figur. Eine Reihe weiterer zentraler Bilder, die den Samura poetisch charakterisieren, ist durch eine polar entgegengesetzte Tendenz gekennzeichnet. Sie suggerieren edle Schönheit, Anmut, ja Zärtlichkeit. Die Bilder des Goldes, des Schmetterlings und des Kirschbaums, die sich auf den Samurai beziehen, stehen in krassem Gegensatz zu der Idee der Japaner als Erzfeinde Rußlands, die in dieser Dichtung ebenso zum Ausdruck gebracht wird, ja das eigentliche Thema des Gedichts ausmacht. Von einem solchen Gegensatz bzw. einer solchen Spannung zwischen der "Aussage" eines Gedichts unù den noetischen Bildern, die die "Aussage" modifizieren und relativieren, sagt Cleanti Brooks in seinem Artikel "The Heresy of Paraphrase":

... Whatever statemert we may seize upon as incorpo-
rating the 'meaning' of the poem, immediately the
imagery and the rhythm seem to set up tensions with
it, warping and twisting it, qualifying and revising it!

In Perevorot $\nabla$ Vladivostoke ist der Samurai mindestens genauso faszinierend wie bedrohlich. Seine gelbe Haut wird als Gold wiedergegeben: in den 14 Zeilen, die das Gesicht des japanischen Soldaten beschreiben, wird das Wort "Gold" $8 \mathrm{Mal}$ wiederholt. Es ist ein monochromes Gemälde von großer Schönheit:

1 C.Brooks, The Well Wrought Urn (New York, 1966), S.197. 
Зодотея бaбonxa

Приседа на гребень внсокин

Зодотого потопв,

ЗодотоН водны -

Это дицо.

Зодотая водна зодотото потопа

Сотнями брызг закипеда,

Набехвла на кручу

Зодотов пучинн.

Золотея бабочка

Тихо приселя на нен огдогнугь USW. ( I,Bd.1,S.279)

Das hier zur Schilderung des fapanischen Feindes verwendete Bild des Schmetterlings findet sich in der etwa zur gleichen Zeit wie Perevorot $v$ Vladivostoke (zwischen 1920 und 1922) entstandenen Dichtung Zangezi als Symbol des Ich-Dichters: "Мне, бабочке, залетевшен/ в комнату человеческон хизни" (II, Bd.3,S.324). Aber auBer dieser "poetisierenden" Funktion hat der Schmetterling bei Chlebnikov eine direkte Beziehung zum Osten. So in der Dichtung Vila i Lesij: "Kax мотылеx Bocrox nopras" (I,Bd.1,S.124). In dem im gleichen Jahr wie Perevorot geschriebenen utopischen Fragment Zakon moziestva caril ist die Rede von "Schmetterlingsgottheiten des Ostens"(II, Bd.4,S.302).

G.Chruslor hebt in seinem Aufsatz liber japanische Worte im Russischen hervor, daß der Name der durch die Puccini-Oper berühmt gewordenen Japanerin Cho-Cho-San in Rußland zum Symbol für alles, wie er sagt, "Pseudojapani sche" wurde." Cho-Cho-San ist aber ebenfalls als "Madame Butterfly" bekannt, und das bietet möglicherweise AufschluB über die Verwendung des Schmetterlingsbildes gerade für die Schilderung des Gesichts des japanischen Soldaten. Wichtig in diesem Zusammenhang ist das kleine Werk Cao, dem Chlebnikor die therschrift Tanka gibt, also die Bezeichnung der ältesten Gattung der Japanischen Literatur. ${ }^{2}$

1 G.Chruslov, "Japonskie slova v russkom jazyke" in: Russkaja reć', III(1971), S.124-130;S.126.

2 Cao(II, Bd.4,S.324-325) ist keine Tanka im traditionellen Japanischen Sinn - ein kurzes Gedicht aus 31 Silben (5-7-5-7-7) bestehend. Siehe "Japanese Poetry" in: J.T.Shipley, Dictionary of World Literature (Totowa, 1966), S.242f. Chlebnikov gab seínem Prosastück den Namen Tanka wohl wegen seines durch japanische Bilder geprägten Inhalts. 
Der Schmetterling beherrscht in diesem Werk, das bestimmte Elemente der Schilderung des Samurai aus Perevorot vomvegnimnt, weitgenend das Bild.

Die dialektische Spannung in der Schilderung des

"faszinierenden Erzfeindes" erreicht ihren Höhepunkt in der. Szene, in der sich der japanische soldat einer russischen Prau zu nähern versucht, die sich in ihrem Haus eingesperrt hat. Diese von einer erotischen Spannung gekennzeichnete symbolische Szene (Japan pocht an die Tiire Rublands) bringt am klarsten die Dialektik der geschichtlichen Auffassunf Cinlebnikovs zum Ausdruck: die Bedrohung durch die brutale Vergevaltigung vermischt sich mit einer siansüchtigen Arziehung. Der jananische Samurai ist eine ïischung aus Azoressivität und Zïrtlichkeit.

inerseits:

Он замер за дверью, лучте котов Прыжок на добычу сделать готов. (évenảa,S.280)

Uris andercrseits : піто он, в полночь? Только стук.
Нет ответа, нет вестей
деревцо випневое, щебетавтее "да",
Вишня в лучах золотого заката

(ebenàa,S.278f)

Das spezifisch japanische iesen des bier ver:venceten Symbols ist tiefer und konkreter als beim sild des scrmetterlings. Es ist aie aus der Malerei und aus der Dichtunf Janans wonl belannte Kirschblïte ("Sakura"), das Symbol des Friulings und der Liebenden. Daner deuter die letzten zivei Zeilen die löglichkeit einer llarmonie zwischen dem Japaner und der russischen Frau an - und auf symboliscier zbenc aic einer iamonie zischen cer. beiden einander bek:impfenden Völkern. 
Der Samurai bezeichnet seine Vergewaltigungsabsicht als Spiel, und seine Worte werden durch den bedeutsamen DichterKommentar abgelöst: " $\mathrm{x}$ двое, полузнакоми они" (ebenda,S.280). Es ist gerade diese aus der konkreten situation nicht ganz ersichtliche 'Halbbekanntschaft', die den Leser veranlaBt, nach der symbolischen Bedeutung dieses Bildes zu fragen. Da die Frau die Tür gar nicht aufmacht, bleiben ja sie und der Samurai einander völlig unbekannt. Was bedeutet also jene 'Halbbekanntschaft' zwischen der Russin und dem Japaner? Diese ist wohl nur auf der symbolischen Ebene zu suchen, und zwar als geheime Verwandtschaft zwischen den beiden Völkern. Was wïrde nun eine Vervollständigung dieser 'Halbbekanntschaft bedeuten? Etwa eine Vergewaltigung und Schändung RuBlands durch Japan? Der Dichter balanciert die Schilderung des Soldaten als Schänder und als zärtlicher Liebhaber sorgfätig aus. Die Frage bleibt bis zum SchluB der Dichtung ungelöst:

Небрехны рта цветок, гестокою чертой означен, На подбородок брошен был тирокин.Это воин востокв.

Пыли морскоћ̆ островов, пыли морен страннын посод, Стоял около двери, тихо стучв.

$$
\text { (ebenda,S.282) }
$$

Selbstverständlich wird die erklärte Absicht des Dichters dadurch nicht aufgehoben, die Japaner werden als Feinde und fremde Eindringlinge dargestellt:

"Идите прочь" - неслась пальбы суровой речь,
Речь, прогремевшая в огне вамl
(ebenda,S.274)

Wie wir gesehen haben, stimmen die vom Dichter verwendeten Bilder und Metaphern hier aber nicht mit den vordergründigen Absichten des Gedichts uberein. Nehr noch, sie füren oft in die entgegengesetzte Richtung, indem sie Schönheit und Zärtlichkeit evozieren. 
Wie auch V.Markov zu dieser Dichtung bemerkt:

What at first seemed to be a purely descriptive poem becomes a psychological and symbolic study. Everything grows from the inside; images link to one another, and move in this manner. 1

Aber gerade diese Ansicht läßt die folgende Schlußfolgerung Markovs als fragwirdig erscheinen:

Ideologically, the poem presents an interesting aspect of Khlebnikov's Asiaticism. Japan, unlike the rest of the Orient, had never aroused his enthusiasm; as early as 1912, in 'Pamyatnik' ('The Monument'), he had written vindictively about Japan because of the defeat of the Russian fleet at Tsushima. As a presentation of Oriental evil, 'Perevorot $\nabla$ Vladivostoke' may be considered a pendent piece to 'Truba Gul-mully.' 2

Wir haben aber gesehen, dab eine genaue Untersuchung der Bilder dieser Dichtung Ziveifel an der Behauptung über Chlebnikovs mangelnden "Enthusiasmus" für Japan erwecken muk. Woch fragwiirdiger ist die Darstellung der Dichtung als "presentation of Oriental evil"(was im übrigen für Iruida Gul'-lilully ebenso wenig zutrifft).

Eine Lösungsmöglichkeit des Widerspruchs zwischen den vom Dichter gebrauchten Bildern und Metaphern einerseits und der unmittelbaren Intention des Gedichts andererseits letztere veranlaßt Narkov $z u$ seiner Behauptung über die Beziehung Chlebnikors zu Japan ("Oriental evil") - könnte etwa der allgemeine Hinweis von Cleanth Brooks bieten, da $B$ in einem Gedicht "the unity is achieved by a dramatic process, not a logical; it represents an equilibrium of forces, not a formula." 3

Ein "dramatischer Proze B" ist aber, wie mehrmals gesagt, auch das historische Denken Chlebnikovs. Die in Perevorot $\nabla$ Vladivostoke festgestellte 'Halbbekanntschaft' zwischen dem japanischen Samurai und der russischen Frau

1 llarkov, a.a.0., S.193.

2 ebenda.

3 C.Brooks, a.a.0., s.20\% . 
bzw.auf der symbolischen Ebene zwischen Rußland und Japan ist eine Folge der langen russisch-mongolischen $\mathrm{Krlege,}$ vom Schnepfenfeld bis Tsuschima, die bis zur "Vollendung des Kreises ${ }^{1}$ von Sieg, Niederlage und Vergeltung weitergefuhrt werden müssen.

Durch die mittels der Bilder und Metaphern evozierte Hervorhebung der edlen Schönheit des gewalttätigen Samural wird die tberzeugung von der inneren Dialektik des geschichtlichen Prozesses auf der sprachlich-dichterischen Ebene zum Ausdruck gebracht: die unerbittliche GesetzmäBigkeit der Vergeltung ist nicht nur grausam und blutig, sondern die poetischen Bilder implizieren zugleich, daB der Nemesis auch eine eigentümliche, schreckliche Schönheit innewohnt.

Der Pazifist Chlebnikov, der eine Welt des Friedens und der Brüderlichkeit erträumte ${ }^{2}$, betrachtet das Gesetz der Nemesis als eine unabänderliche Gegebenheit:

Кто изнемог под тяхестьр возмездин

И хизнь печальную оглянет,

Тот пред дицом немых созвездий

Своего предкв проклянет.

$$
(I, B d .2, S .163)
$$

In einem der letzten Werke Chlebnikovs, Zarëj venčannyj (geschrieben am 16.1.1922), wird der religiöse Ursprung seiner Nemesis-Lehre sichtbar: es ist der der Heiligen Schrift entnommene Satz "Denn die Rache ist mein, Ich werde vergelten" (V.Buch Mose, XXXII, 35), den Chlebnikov als die "einfache und grausame Formel" der Vergeltung bezeichnet (III, S.474).

1 In der späten Dichtung Carapina po nebu (1920) heiBt es von Khan Batyj (Batu), dem Begründer der "Goldenen Horde" an der Unteren Wolga:" Усатын бог степно, /Сам не зная того, разрутая Россио,/Выполял начертанве круга,/ Как плясунья пера готовальниу (II, Bd.3, S.77).

2 Die Frage des idealen Staates ohne Kriege wird eingehend im finften Kapitel dieser Arbeit behandelt. 
Und dennoch gibt es für Chlebnikov einen Ausweg aus dem scheinbar ewigen Kreis von Krieg, Sieg, Niederlage und Vergeltung, einen Ausweg, der notwendigerweise das quasiwissenschaftliche Denken des Dichters aufhebt und in den Bereich der Chlebnikovschen Utopie hineinfürt. Bevor wir aber auf seine 'Lehre von der Zukunft' kommen, soll kurz das Problem der Zeit im Werk Chlebnikovs umrissen werden. 
4. therleitung: Chlebnikovs Konzeption der zeit und der Orient

Auf den engen Zusammenhang zwischen Chlebnikovs Auffassung der Zeit und dem Orient haben bereits Loščic und Turbin hingewiesen. 1 Die dichterische Realisierung dieses Zusammenhanges sehen die beiden Autoren in der "metaphorischen Reihe 'Stein-Baum-Zeit'", wobei der Stein die in der Steppe verstreuten heidnischen Idole (Kamennye baby, II,Bd.3,S.32ff) - laut Loščic und Turbin ndie Vergangenheit des Orients" symbolisiert, während der Baum als Symbol der "werdenden Gegenwart Asiens" verstanden werden soll. 2

Diese Festlegung ist mangelhaft sowohl in Bezug auf die Metapher selbst (bei weitem nicht jeder Stein und nicht jeder Baum in den Gedichten Chlebnikovs hat etwas mit der orientalischen Thematik zu tun), als auch in Bezug auf die Auffassung der Zeit bei Chlebnikov, deren wichtigstes Nerkmal in dem Verzicht auf eine Unterscheidung zwischen Vergangenheit,Gegen:art und Zukunft als selbständigen analytischen Kategorien besteht.

Im klaren Gegensatz zu dem, was Lǒšcic und Turbin behaupten, strebt Chlebnikov eine neue, und zwar mit dem orientalischen Denken und Lebensgefuhl verwandte Definition der Zeit an, die keine abstrakte Trennung zwischen der Vergangenheit, der Gegenwart und der Zukunft kennt.

Man kann die westliche Auffassung der zeit in allgemeinen Zügen als eindimensional, linear, evolutionär und historisch bezeichnen. 3

Dem östlichen Zeitbegriff, wie William S. Haas ausfuihrt,

[...]fehlt eine innere Beziehung zur Evolution und zur evolutionären Zeit.[...] Die Welten treten aus dem Brahma in unvorstelibaren, aber endlichen Äonen hervor und kehren zum Brahma in einer endlosen Wiederholung zurück. Wenn man sie [die östliche Zeitstruktur], wie

Toscic und Turbin, a.a.0., S.152.

2 ebenda, S. 155 .

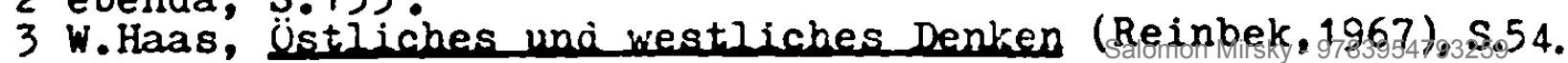


es geschehen muB, gegen diesen Hintergrund betrachtet, verlieren Evolution, Verwirklichung und Fortschritt inre Bedeutung. 1

Chlebnikov baut in seinem Werk ein in allen Einzelheiten durchdachtes System auf, durch das die westliche Konzeption der linearen zeit aufgehoben wird. Aus der freien Bewegung auf der Achse der zeit und aus der Konzeption des zyklischen Ablaufs der Geschichte ergibt sich zusammengenommen die Möglichkeit, die Vergangenheit in die Zukunft $z u$ verlegen und vice versa. In einem Brief an A.Kručenych vom 31.8.1913 schrieb Chlebnikov: "Das was später war, war früher. Am Anfang Greise, dann Säuglinge.[...] Wer jung ist, ist Vater der Menschen"(IV,S.367). Erst die konsequent durchgefuhrte 'Umkrempelung' der Zeitperspektive im Werk Chlebnikovs erlaubt es dem Dichter, das bereits Geschehene (die Vergangenheit) als das Bevorstehende (die Zukunft) zu erleben:"Wir kommen aus der Zukunft, aus der Ferne der Jahrhunderte"(III,S.259). "Wir" sind selbstverständlich "wir, die Dichter" (in diesem Falle Velimir Chlebnikov und sein Freund Grigorij Petnikov), die in dem von Chlebnikov erbauten System nicht nur die Funktion der Wissenschaftler und Herrscher, sondern auch die der Propheten erfüllen. ${ }^{2}$ Der Dichter Zangezi sagt von sich:"Ich kann vorwärts und rückwärts durch die Jahrhunderte schreiten"(II,Bd.3,S.359). Auf diese Weise kann auch der Mythos in die Zukunft verlegt werden. Im theoretischen Zyklus Kol iz buduśčego, dessen Aufsätze die Zeit zwischen 1914 und 1922 umspannen, wird diese Idee am klarsten zum Ausdruck gebracht:

Sind Märchen die Erinnerung eines Greises oder nicht? Oder kindliches Hellsehen? Mit anderen Worten, ich dachte: hat es die Sintflut und den Untergang ron Atlantis schon gegeben oder werden sie erst kommen? Eher war ich geneigt zu glauben, dab es noch bevorsteht.

$$
\text { (II,Bd.4,S.286) }
$$

1 Haas, a.a.0., S.1201.

2 Siehe Kapitel 5.1. dieser Arbeit. 
Der nächote Schritt ist die totale Aufhebung der herkömmlichen Begriffe der Zeit. Davon spricht Chlebnikov in dem Brief rom 14.3.1921 an den Maler P.Miturič(III,S.324). Besonders interessant ist in dieser Hinsicht die späte Chlebnikov-Dichtung Vlom Vselennof:

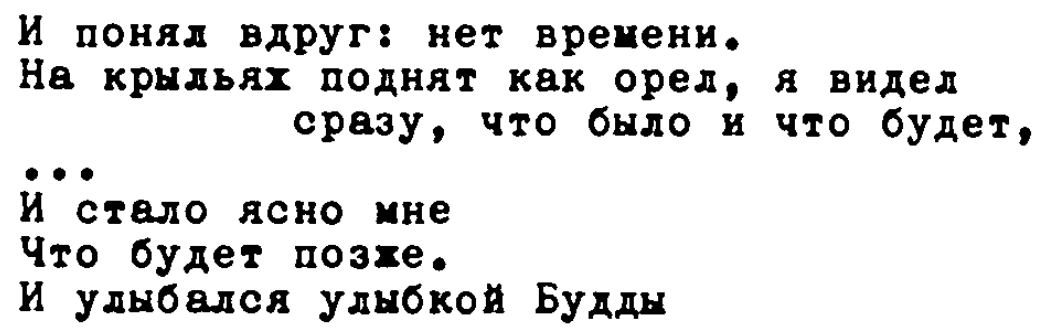

Der Verzicht auf die Auffassung der Zeit als lineare, evolutionäre Fortbewegung bedeutet nun aber keinesfalls die Zerstörung des geschichtlichen Gefühls bei Chlebnikov. In Anlehnung an die von Ju.Lotman vorgeschlagene Typologislerung von Texten nach den Merkmalen von "Anfang" (z.B. Weltschöpfung, Geburt einer Kultur) oder "Ende" (z.B. eschatologische Texte) ${ }^{1}$ kann man sagen, daß für Chlebnikov die Konzeption der, wie Lotman sie nennt, "richtigen geschichtlichen Entwicklung"2 nicht zutrifft: der Gang der Geschichte ist bei inm weder "progressiv" noch "regressiv". Für Chlebnikov trifft vielmehr die von Lotman formulierte alternative Auffassung $z u$, der in Anlehnung an Rousseau sagt, daB

... die ideale Ordnung der gegenwärtigen Zeit weder vorangeht, noch ihr künftig folgen wird. Diese Ordnung ist als ideale Norm in der Natur der Dinge verborgen und sie dient als Ausgangspunkt nicht chronologisch, sondern typologisch.j

Chlebnikovs Beschäftigung mit dem Phänomen Zeit ist von seinen geschichtlichen Forschungen nicht zu trennen:

1 Ju.Lotman,"O modelirujuščem značenii ponjat1j 'konca' i hačala' v chudożestrennych tekstach" in: Teksty sovetskoro

2 ebenda, S.310.

3 ebenda 
die geschichtlichen Erelgnisse sind für Chlebnikor die sichtbar gewordenen "Gesetze der Zeit". Seine historischen Forschungen führten ihn zwangsläufig zu einer intensiven Beschätigung mit den asiatischen Aspekten der russischen Geschichte. Da aber Chlebnikov die Ergebnisse seiner Forschungsarbeit auf die Zukunft projizlerte, trägt auch sein erträumter Idealstaat wesentlich orientalische Merkmale.

Mit den oben angefuhrten "Gesetzen der Zeit" glaubte Chlebnikov, seinem Anspruch auf wissenschaftliche Objektivität gerecht $z u$ werden. Da aber in einer nach diesen Gesetzen lebenden Welt das größte Ubel, der Krieg nämlich, nicht zu beseltigen wäre (im Gegenteil, er ist auf ewig festgelegt in dem Gesetz vom Kreislauf Krieg - Sieg Niederlage - Vergeltung), suchte Chlebnikov ein Instrument, das die Iraft seiner eigenen Gesetze aufheben würde. Dieses Instrument fand er in der Kraft der Prophezeiung. Der mit mathematischen Formeln ausgerüstete Wissenschaftler weicht letzten Endes vor dem Propheten. Auch das Prophetentum Chlebnikovs fand seinen wahren Nährboden in seinem Orientalismus. 1

1 Mit dem Thema dieses Kapitels, "Chlebnikors Konzeption der Zelt und der Orient", befaBt sich auch u.a. ein wichtiger Artikel von Vjăc.Vs.Ivanov, der mir während der Vorbereitung dieser Arbeit leider nicht zur Verfügung stand. Siehe: Vjač.Vs. Ivanov, "Kategorija vremen $1 \mathrm{~V}$ iskusstve $i$ kul ture $X X$ veka" in: Structure of texts and semiotics of culture, Hrsg. J.van der eng und M.Grygar (Den Haag/Paris, 1973), S.103-150. 
5. Chlebnikovs Bntwurf einer Utopie und der Orient

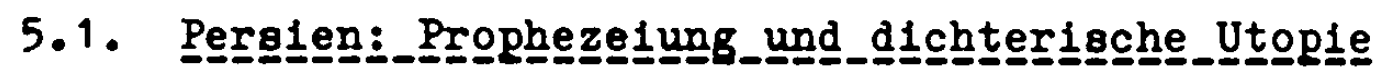

Sicherlich war Chlebnikov als Historiker, um den Ausdruck Prledrich Schlegels zu gebrauchen, "ein rückwäts gekehrter Prophet". 1 Aber da die Geschichte bei Chlebnikov immer eine mythologisierte Geschichte ist und der Mythos eine "Vergangenheit, Gegenwart und zukunft umspannende Dauerstruktur" bildet, ${ }^{2}$ so könnte man Chlebnikor ebenso in Umkehrung des Satzes Schlegels - einen "nach vorwärts gekehrten Historiker" nennen.

Das Thema der Prophetie setzt bereits sehr frïh im Schaffen Chlebnikovs ein. Als Neunzehnjahriger schrieb der Dichter 1904 in einer autobiographischen Aufzeichnung: "Er träumte begeistert davon, ein Prophet zu sein" (IV, S.318). Chlebnikov verstand sich in zwelfacher Hinsicht als Prophet, nämlich als Verkiinder seiner elgenen dichterischen Sprache der Zukunft und als 'Entdecker' der "Gesetze der Ze1t", die es inm ermöglichten, die kuinftigen Erelgnisse vorauszudeuten. Um das Jahr 1912 schrieb er in Učitel i učenik: "Soll man nicht im Jahre 1917 den Sturz eines Staates erwarten?" (III, S.179, Anm.S.348; siehe auch III, S.406, Anm.S.524). In Baku lieB sich Chlebnikov eine beglaubigte Bestätigung ausstellen, die bezeugt, da $B$ er in einem Vortrag uber die "Reinen Gesetze der Zeit in Natur und Gesellschaft" die Proklamierung der Sowjetrepublik in Aserbaidshan auf den Tag genau vorausgesagt hatte (III, S.531). In seinen "Vorschlägen" (1915-16) schrieb Chlebnikov rom "FIug zum Mond als Zeichen zur Beendigung des groBen Krieges" (III, S.157), und in einem Brief an Nikolaj Burljuk (2.2.1914) propheze1te er wiederum ein "Duell im Kanonendonner zwischen einem italienfsch-deutschen Bund und den Slaven" (IV, S.368).

1 Athenaeum, Nachdruck der Berliner Ausgabe von 1798-1800 (Darmstadt, 1970), Bd.1, s.196.

2 C.Lévi-Strauss, siehe S.6 dieser Arbeit. 
Bei Chlebnikovs großem Interesse und seiner Empfänglichkeit für alles Östliche ist es kaum verwunderlich, daß er die Heimat der wahren Prophetie im Orient sah. Buddha, Mohammed, Mazdak, Zarathustra, Aschoka, Mirza-Bab und andere orientalische Propheten und Geisteslehrer kehren in seinen Gedichten immer wieder.

Eine große Steigerung dieses Themas bringt der kurze Aufenthalt Chlebnikovs in Persien mit sich, wo er Mitte April 1921 mit einer Einheit der Roten Armee in der Stadt Enzeli (heute Pachlevi) in der Provinz Gilan an der südwestlichen Küste des Kaspischen Meeres landete. ${ }^{1}$

Aus einem an die Schwester des Dichters, Vera, gerichteten Brief, den Chlebnikov am Tag seiner Ankunft in thzeli (14.4.1921) schrieb, wird ersichtlich, dab er sich bereits während der Vorbereitungen für seine Reise mit dem persischen Propheten Mirza-Bab beschäftigte und in Gilan für Perser und Russen einen Vortrag über "Mirza-Bab und Jesus" halten wollte(III,S.320). Noch bevor er das persische Festland betreten habe, so heißt es weiter in dem Brief, habe er in den vor. Schnee bedeckten Berggipfeln Persiens "aie Augen des Propheten hinter aen Augenbrauen der Wolken versteckt" gesehen(III,S.319). Der Brief an die Schwester schließt mit den Worten:"Den Persern habe ich gesagt, daß ich ein russischer Prophet bin"(III,S.321). Diese exzentrische Aussage Chlebnikovs bringt seine Überzeugung zum Ausdruck, daß Persien das Iand sei, in dem die Prophetie noch immer zuhause sei und dal es deshalb eigentlich seine Berechtigung habe, wenn einer sich den Persern als Prophet vorstellt. Diese Auffassung von Persien als vom Land der lebenden Propheten gibt auch Aufschluf über das Thema der Prophezeiung, das leitmotivisch seine Gedichte des persischen zylius durchzieht. In dieser Hinsicht ist vor allem die in Persien angefangene und nach seiner Rückkehr nach

1 N.Stepanov, Anmerkungen zu O.Samorodova, "Poèt na Kavkaze", a.a.0., S.193f; Parnis, a.a.0., S.157. 
Pjatigorsk vollendete Dichtung Truba Gul'Mully von Bedeutung. ${ }^{1}$ Bereits die Eröffnungszeilen dieses Gedichts stellen die Ankunft des Dichters in Persien als die Ankunft eines Propheten dar:

$0 \times !$

OK!

Это горнын пророк; 2

Eine interessante Möglichkeit der Interpretation bietet in dieser Hinsicht die Vermutung des russischen Iranisten Vasilif Nikitin ${ }^{3}$, der in einem Brief an V.Markov

1 Wir beziehen uns hier hauptsächlich auf die zweite, in der Minchner Ausgabe nicht enthaltene Fassung dieser Dichtung. Der Text, der im Vergleich zu der ersten Fassung (I, Bd.1, S.233-245) wesentliche Unterschiede aufweist, wurde von N.Stepanov in die Sammlung V.Chlebnikov, Stichotvorenifa i poemy (Leningrad, 1960), S.339-354 aufgenommen. S.339.

2 In der ersten Passung folgt auf den doppelten Ausruf Ok! Ok! das Bild des verwundeten Schwanes, der, wie Markov ausfihrt, "das Symbol eines verwundeten Dichters" darstellt (Markov, a.a.0., S.161). In der ersten Fassung wird also der Zusammenhang zwischen Ok! Ok! und Mpopok nicht sofort sichtbar: Ok! Ok! wird zunächst als der Schrei des Schwanes verstanden, in weiteren aber (bereits in der zweiten Strophe) wird auch in dieser ersten Passung der Zusammenhang zwischen dem Ausruf und dem Propheten hergestellt: Siehe I, Bd.1, S.233.

3 V.P.Nikitin, Verfasser mehrerer orlentalistischer Arbeiten, lebte lange Zeit in Persien. Er veröffentlichte über Truba Gul'Mully einen Artikel in der in Teheran auf Persisch erscheinenden Zeitschrift Jaghma; siehe dazu die Besprechung von Franciszek Machalski In der polnischen Zeitschrift fiur Orientalistik Przeglad Orientalistyczny, IV (1956), S.15. Auf den persischen Artikel von V.Nikitin bezieht sich auch Parnis, a.a.0., s.157. Von Nikitin stand mir auferdem ein unveröffentlichter Artikel über den historisch-politischen Hintergrund der Persien-Reise Chlebnikovs zur Verfügung: V.P.Nikitin, "Russkif dervišn (persidskif period $v$ zizni v.Chlebnikova). 
vom 19.1.1956 die Nieinung äuBerte, bei kㅡ! Ok! könne es sich um die russische Wiedergabe von "Hak! Hak!", den "ublichen Ausruf der persischen Derwische",der 'Wahrheit' oder 'Gott' bedeutet, handeln.' Die Vermutung von Prof. V.Nikitin gewinnt noch mehr Glaubwirdigkeit, wenn man den Anfang des 2. Kapitels ${ }^{2}$ betrachtet:

Это пророки

Сбехвлися с снежных гор.

Сбежалися с гор

Встречать чадо Хлебникова,

Eму радуясь!

Саул, вдам

Веры Севера.

Сауд тебе

За твор звезду

OK!

$\mathrm{OK}_{\mathrm{K}}$

(ebenda, S.340)

$\underline{\text { Ok}}$ ! Ok ! wird also konsequent als Ausruf und Kennzeichen der Propheten präsentiert. Hier melden sich die persischen Propheten zu Wort, und sie bedienen sich offensichtlich der gleichen Sirache vie der anjommende "russische Prophet" (siehe oien den Brief an die Schwester Chlebnikovs, Vera). So wird der Ausruf 0l:! Ok:! zu einer lrt Kennwort für beide Seiter. huf dieses Zeremoniell des gergenseitigen Erkennens folgt dann der Jubel iber die Ankunft des Propheten, in den nicht nur die "Priester der Berge" einfallen, sondern an dem die ganze Natur Persiens teilnimst:

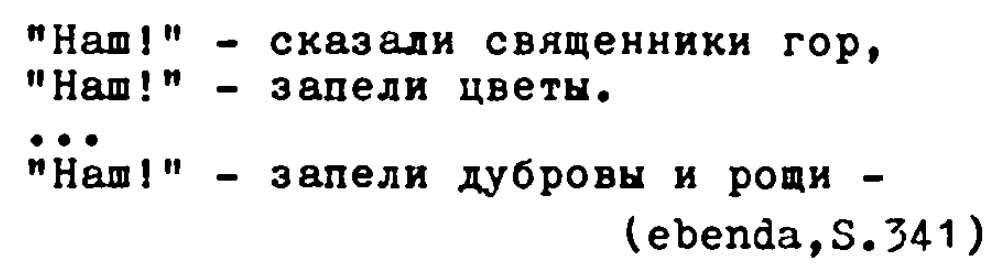

1 Die unveröffentlichten Briefe des inzwischen verstorbenen V.P.Nikitin wurden mir liebenswürdigerweise von Prof.Dr. Vladimir ilarkov von der University of Los Angeles in Kalifornien zur Verfügung gestellt, und ich nehme die Gelegenheit wahr, i:m für diese Briefe sowohl wie für das anregende Gespräch und für die Beschaffung sonst schwer zupänflicher Artike] über Chlebnikov meinen aufrichtigen Dani: auszusprechen.

2 Oder die 2. Strophe der Minchner Ausgabe (I,Bd.1,S.233) 
Die Ankunft Gul'-Mullas ('Priester der Blumen' auf Persisch, Anm. I,Bd.1,S.319) wird also zur Rückkehr des Propheten in seine Heimat. Dieses Thema durchdringt die meisten der persischen Gedichte Chlebnikovs:

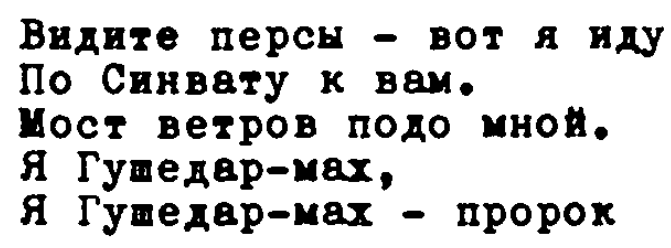

(III,S.85)

Oder :

Я видед рнопу пророхв, Припавпего х стеклянни волосам десного водопада. (II, Bd.3,S.305)

Es ist jenes Gefühl der Verwandtschaft, ja der Ebenbürtigkeit mit den Menschen (und Propheten) Persiens, von dem Ju. Tynjanov sagte:"In 'Truba Gul'-Mully' gibt es keinen europäischen Osten: weder herablassendes Interesse, noch überflüssice Ehrfurcht." 1

Die liunktion des orientalischen Propheten, wie er in Chlebnikovs Dichtung vorkommt, läbt sich von Anfang an klar erkennen: der aus dem Osten kommende Prophet wird der grö3ten Plage der lienschheit, dem Krieg, ein Ende setzen. In der pazifistischen Dichtung Vojna $\nabla$ myšelovke (entstanden zwischen 1915 und 1917, also lange vor Chlebnikovs Persien-Reise), die äußerst plastische Schilderungen der Greuel des Krieges enthält, wird die Vision der künftigen welt, in der es keine Kriege mehr geben wird, durch den Hinweis auf Buddha und Allah eingeleitet:

1 Tynjanov, a.a.0., S.593. 
Я веро, я веро, что некогда "Маћна!" Воскликнет Будда или Алдат.

$$
(I, B d .2, S .249)
$$

Mit seinem Hang zum sprachlichen Eklektizismus läßt Chlebnikov den Propheten oder den Gott des Orients sich der Matrosensprache bedienen: Mă̈на! ist ein Ausruf, der bei Hafenarbeiten als Signal zur Senkung der Last gebraucht wird. Hier ist Maнha! das Zeichen zur Abschaffung des Krieges, etwa in der Bedeutung Долоњ вонну! ('Nieder mit dem Krieg!'). In der erträumten Zukunft wird also der Krieg mit Hilfe der Weisheit des Orients (der Lehren Buddhas und Allahs) aus der Welt geschafft.

Damit dies aber geschieht, muß die für Chlebnikov zentrale Voraussetzung erfullt werden, da $B$ eine für die ganze Welt gemeinsame Sprache geschaffen wird, was folgerichtig die Aufhebung aller existierenden Sprachen bedeutet. Auch in diesem Bereich spielt der Orientalismus Chlebnikovs eine gewichtige Rolle.

1 Siehe"Манна" in: Slovar' morskich i rednych terminov (Moskau, 1955) S.197. 


\subsection{Die_Weltsprache_und_die_dichterigche_Utople}

Immer wieder komt Chlebnikov in seinen Werken darauf zurück, daß die einzige Möglichke1t,einen Weltkrieg zu vermelden, die Schaffung elner Weltsprache se1. "Was 1st besser, eine Weltsprache oder ein Weltgemetzel?"(III,S.266),so lautet eine Eintragung in seinem Notizbuch.

Der Idee der Schaffung einer Weltsprache ging der Gedanke der "panslavischen Sprache" voraus. In elnem Brief an Vjačeslav Ivanov (31.3.1908) spricht der junge Chlebn1kov von der Ablösung des modernen Russischen durch eben diese "panslavische Sprache" ( всесдавянскии яавх, IV,S.354). In diese Perlode fällt auch die intensive Beschäftigung Chlebnikovs mit den Ideen des kroatischen Gelehrten Juraj Križanić (1617-1683), der eln Apostel sowohl des Panslavismus wie der Schaffung einer für alle Slaven gemeinsamen Sprache war. ${ }^{1}$

In den Jahren 1915-16 1st es dann schon nicht mehr die panslavische Sprache, sondern die "gemeinsame wissenschaftlich aufgebaute Schriftsprache der Arler" (III,S.157) die dem Dichter als Ideal vorschwebt.

Im Laufe der Jahre erweitern sich aber die Grenzen der Sprachutopie Chlebnikovs. Der Panslavismus und die "Sprache der Arier" weichen vor der Idee der "Weltsprache" zurück. In der obenerwähnten Dichtung Vojna $v$ mǒ̀elorke ist die Vision einer Welt ohne Kriege mit der Vision der einen einzigen, fur alle Menschenrassen gemeinsamen Sprache verkonlipft.

И черды, бөдие, гөдтие Забыла про дан̈ п про наречья.

$$
(I, B d .2, S .258)
$$

1 Uber Chlebnikovs Interesse für Križanić slehe: Markov, a.a.0.,S.88. Križanie wird in Učitel' 1 učenik erwähnt (III,S.182). 
Dieses Motiv der einen Sprache begleitet beinahe jedes Werk, in dem der Dichter sein kosmisches Programm der Zukunft der Menschheit entwickelt. So z.B. in der Dichtung Ladomir:

И переден земди наречья

В едннви смертных разговор.

$$
(I, B d .1, S .186)
$$

Die existierenden Sprachen werden $z u$ jenem Faktor erklärt, der "die Menschheit trennt"(III,S.216), und werden schlieblich als ein Rudiment, als "der Nagel am Flügel der Vögeln(III,S.265) zum Untergang verdammt.

Die Vorstellung einer Weltsprache ist für Chlebnikov, zumindest in einigen zentralen Aspekten, von der Ideenwelt des Orients geprägt. In der autobiographischen Erzählung $\underline{\mathrm{Ka} 2}$ schreibt er uber den "erregenden panasiatischen Verstand, der aus der Sackgasse der Dialekte hinausführen soll"(III, S.126). Zu diesem Aspekt bemerkt V.Markov:"Wenn Chlebnikov von der Weltsprache träumte, entfaltete sich die Welt für ihn in Richtung Asien." 1

Diese Feststellung bedarf allerdings einiger Einschränkungen. Chlebnikov entwickelte nie eine kohärente, konsequent durchgeführte Theorie der "einen Weltsprache", sondern beschäftigte sich vielmehr mit mehreren Möglichkeiten zur Verwirklichung dieses Ideals, wobei nicit alle dieser Möglichkeiten unbedingt in Richtung Asien führten. Im folgenden sollen die wichtigsten Richtungen, in denen Chlebnikov seine Suche nach der "einen Weltsprache" geführt hat, kurz dargelegt werden.

5.2.1. Die Suche nach der gemeinsamen Schriftsprache

In dem Artikel Chudožniki mira (1919) plädiert Chlebnikov für "eine gemeinsame Schriftsprache, die für

1 V.Narkov, "0 Chlebnikove"(Popytka apologii i soprotivlenija) in: Grani, XXII(1954),S.125-145;S.132. 
alle Völker des dritten Satelliten der Sonne [gemeint ist wohl die Erde]gemeinsam wäre"(III,S.216).

Es ist bezeichnend, dab inm als Vorbild für diese Aufgabe die Völker Chinas und Japans vorschwebten, die "in hundert verschiedenen Sprachen sprechen, aber nur eine Schriftsprache lesen und schreiben"(ebenda). Eine derartige Schriftsprache wïde das Menschengeschlecht vereinigen ( "собиратедь человеческого рода", еbenda).

5.2.2. Der Buchstabe und der Klang als Vermittler von Inhalten

Der Suche nach diesem Weg ist eine große Anzahl der Werke Chlebnikovs gewidmet. ${ }^{1}$ In Svojasi formuliert Chlebnikov sein Vorhaben als den Versuch, "die Einheit der Sprachen der Welt $z u$ finden, die aus den Einheiten des Alphabets besteht.[...] Der Weg zur transrationalen Weltsprache" (I,Bd.2, S.9). Das ist der Weg, den Viktor Gofman als einen Versuch Chlebnikovs bezeichnet,

die historisch bedingte 'Kluft' zwischen der sprachlichen Technik des Ausdrucks und dem ausgedrückten Inhalt, zwischen der lautlichen Form und dem Bedeutungsinhalt $z u$ überwinden.2

Was C.Lévi-Strauss von den antiken Philosophen sagt, trifft in vollem Maße für Velimir Chlebnikov zu:

Die antiken Philosophen redeten über die Sprache wie wir noch heute über die Mythologie. Sie konstatierten, dab in jeder Sprache gewisse Lautgruppen bestimmten Sinngehalten entsprechen, und suchten verzweifelt zu begreifen, welche innere Notwendigkelt diese $S i n n g$ e $h$ a $l t e$ und diese $I a$ u $e$ verbinden. 3

1 Siehe z.B. Slovo o El'(II,Bd.3,S.70-72); Carapina po nebu (II, Bd.3,S.75-86); weite Teile von ZangeziT(I,Bd.3,S.317368), sowie mehrere Aufsätze:III, S. T71-182; S.187-190; $198-210$.

2 V.Gofman, "Jazykovoe novatorstvo Chlebnikova" in: Zvezda, VI(1935) S.209-236;S.215.

3 Lévi-strauss, a.a.0., S.26. 
5.2.3. Die Zahl als Grundeinheit der Weltsprache

Diese utopische Theorie wurde u.a. aus den Schriften der deutschen Romantik, genauer aus denen Novalis' übernommen. 1 "Novalis, Pythagoras, Amenophis IV. ahnten den Sieg der Zahl über das Wort", schrieb Chlebnikov(III,S.446f). Diese Vorstellung ist für Chlebnikov wiederum stark mit dem Orient verbunden.

In dem "Brief an zwei Japaneṛ"(1916) schließt die Aufzählung der Themen, die zum Diskussionsgegenstand der "asiatischen Versammlung" werden sollten, mit dem Vorschlag, "die Zahlensprache des Kranzes Asiatischer Jünglinge" zur Debatte zu stellen(III,S.157). Die Zahlen sind für den Dichter Namen für Dinge( чисдоимена ,III,S.210), die Zahlensprache (чисдоречь) jene Sprache, mit Hilfe deren man "jede Handlung, jedes Bild bezeichnen kann"2(III,S.157), und die Zahl, also die Grundeinheit dieser Sprache, gehört $z u$ den Heiligtümern des Orients. In Carapina po nebu betet der "bärtige Mongole", Khan Batu, "die Zahl als Gott an" (II,Bd.3,S.77). Im Jahre 1920 hielt Chlebnikor in Char'kov einen Vortrag, den er "Koran der Zahlen" nannte(III,S.316).

Für Chlebnikov ist die "echte Mathematik", wie für Novalis, nur "im Morgenlande[...] zu Hause"; in Europa sei sie "zur bloßen Technik ausgeartet." 3

1 Chlebnikovs engster Freund Grigorij Petnikov übersetzte die "Fragmente" von Novalis(1914) und die "Lehrlinge zu Sais"(1920) ins Russische. Siehe die bibliographischen Angaben zx "Novalis" in: Literaturnaja enciklopedija, Red.A.V.Lunačarskij (Moskau, 1934) Bd.8,S.113. S1ehe auch folgende Erwähnung bei Chlebnikov in Ljal ja na tigre: "Petnikov hat Novalis herausgegeben"(III,S.214). Den ersten Hinweis auf Petnikovs Beschäftigung mit Novalis verdanke ich Frl.Dr.J.R. Döring.

$2 \mathrm{Vgl}$. bei Novalis in den "Fragmenten und Studien 17991800": "Zahlen sind, wie Zeichen und Worte, Erscheinungen, Repräsentationen kat exochen." In: Novalis, a.a.0.,S.542.

3 Novalis, ebenda, S. 543. 
Eckhard Heftrich führt in seinem Buch uber Novalis in dem Kapitel "Zahl und Wort" aus:

Unter morgenländischer Mathematik dürfte jede Art von Zahlenmystik zu verstehen sein, sei sie nun pythagoräisch, neuplatonisch oder kabbalistisch orientiert. Aber wo immer man auch dieses Morgenland suchen mag, wirklich zu finden ist es nur im Utopia des künftigen Reiches. 1

Die folgende Formulierung Heftrichs kann schlieblich einen Einblick in den inneren Mechanismus gewähren, der auch Chlebnikov dazu bewegt hat, die Weltsprache der zukunft von der Mathematik abzuleiten:

Die 'Wunderbarkeit' der Mathematik, eines noch zu unendlicher Perfektion fähigen Instrumentes, liegt im Verhältnis von Zeichen und Bezeichnetem begründet. 2

In der liathematik nämlich ist der Unterschied zwischen $s i g n i f i n t$ und $s$ ig $n$ if i $b$ '(im Sinne der Kategorien de Saussure's) aufgehoben. Daher vrüde eine direkt aus der llathematik abgeleitete Sprache durch die Vereinigung von Zeichenkörper ( $\mathrm{s}$ i $\mathrm{g} \mathrm{n}$ i $f i$ a $n$ t: Bezeichnendes) und Bedeutung ( $\mathrm{i} g \mathrm{n}$ i $f$ i $k$ : Bezeichnetes) direkt auf den Sachverhalt (bei de Saussure $c h \circ s$ e $)^{3}$ schlieben lassen und daher für alle Menschen verständlich scin, ungeachtet ihrer natürlichen Sprachen.

Chlebnikov will diesen Universalismus der Mathematik zur Schaffung seiner Weltsprache in Dienst stellen: "ведь осязание числа есть велики переводчик не имещих никакого родства языков"(IV,S.311). Oder an anderer Stelle: "слова суть лишь слышимые числа нашего бытия"(IV,S.321).

1 E.Heftrich, Novalis. Vom Logos der Poesie. (Frankfurt, 1969), S. 147.

2 ebenda

3 Siehe z.B. K. -D. Büntinf, Einführung in die Linguistik (Frankfurt, 1972), S.33. 
5.2.4. Die Aufhebung der Sprache

Der nächste Schritt auf dem Weg der Einigung der Menschheit ist die totale Abschaffung der Sprache. Der Zustand der vollkommenen Harmonie wird an eine durch nichts vermittelte apriorische Verständigung zwischen allen Lebewesen - sowohl Menschen wie Tieren - geknüpft. Der Traum von der Rïckkehr (wohlgemerkt im romantischen Sinne, also "Rlickkehr nach vorne"1) zum Urzustand, zum vorsprachlichen Stadium der Menschheit, wird bereits in der Fruhdichtung Deti Vydry voll zum Ausdruck gebracht:

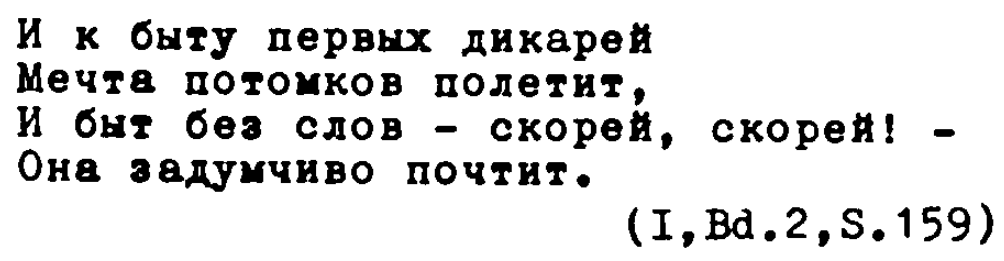

Die Paradoxie dieses Wunsches ist offensichtlich: ein Dichter beschwört eine "Zeit ohne Worte" herauf. Die Erklärung hierfür ist wohl in Chlebnikovs Beeinflussung durch die Ideen der deutschen Romantik zu suchen.

Der Bruch zwischen Mensch und Natur, wie ihn die deutsche Romantik uberwinden wollte, stellt sich fur Chlebnikov als Bruch zwischen dem Ding und seiner Benennung dar. Durch die Auflösung der Sprache wäre es somit möglich, diese Kluft zu uberwinden und also die Harmonie von Mensch und Natur wiederherzustellen.

1 Die Wiederkehr des vergangenen Goldenen Zeitalters und die Wiederherstellung der verlorengegangenen Naivitat, d.h. des Zustands, in dem die Gegensätze zwischen erkennendem Subjekt und dem Objekt, zwischen Bewußtse in und Natur aufgehoben werden, waren ein zentrales Thema der romantischen Bewegung. (Siehe z.B. Ren' Wellek, "Romanticism Re-examined" in: Romanticism Reconsidered, Northop Frye, Hrsg. (New York/London, 1963) S.107-133). Chlebnikov steht, was diese Problematik anbelangt, unter dem starken EinfluB der romantischen Tradition, wobei er die wichtigsten Anregungen vermutlich von Novalis bekommen hat. (Siehe S.62 dieser Arbeit). 
Der Orient mit seinem fü Chlebnikov organischen, ungespaltenen Wesen schien dem Dichter viel näher an die Verwirklichung dieses Ideals heranzureichen als der sich immer weiter von der Natur entfernende "rationalistische" Westen.

Aus dieser Perspektive heraus läßt es sich erklären, warum Chlebnikov die in seinen Werken oft vorkommende Situation einer direkten Kommunikation zwischen Mensch und Tier meistens in einem orientalischen Kontext oräsentiert. In der Erzählung Esir ist ein derartiges Gespräch onnc Worte zwischen dem Inder Krischnamurti und einem Schwan dargestellt(II,Bd.4,S.91). Von der Hauptọerson dieser Erzühlung, dem Wolga-Fischer Istoma, der von asiatischen Räubern gcfangengenommen und nach Indien verkauft wird, heibt es, er lätte mit der zeit gelernt, "den Ameisenhauien $z u$ verstehen" (ejenda,S.100).

imartungsgemäl ist zuch Persien ein Land, in dem zwischen lienschen und den sonstigen Jieberesen eine gemeinsame Sprache existiert. Das zentrale Erlebnis im Gedicht Ioc'v Pensii ist eine mystisch wirkende Verständi gunj zwischen dem Ich-Dichter und einem Kiffer:

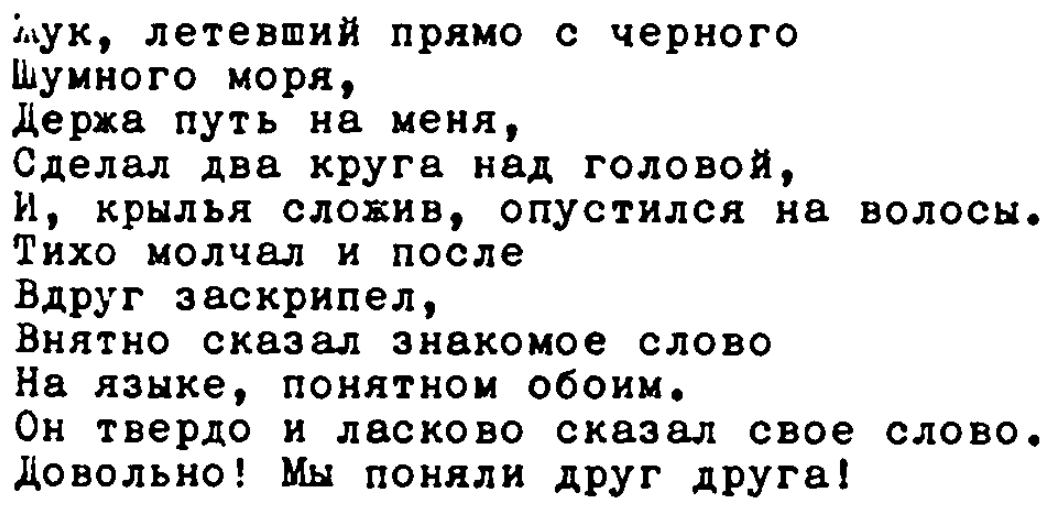

Ebenso neibt es vom Inder und rom Sch:/an in der obenerwïnten Erzbilung Esir: "оба поняли друг друга" (II,Bd.4, S.91). 
Die hier dargestellten Wege der Suche Chlebnikovs nach einer Weltsprache - die Schaffung einer für die ganze Menschheit gemeinsamen Schriftsprache, deren Einheit entweder durch die Aufdeckung der universalen Bedeutung der Einheiten des Alphabets oder durch die Zahl (Mathematik) erreicht werden soll, und schlieblich die Auflösung der Sprache als höchste Stufe der Harmonie und der Vereirigung mit der Natur - schaffen die Voraussetzung zum Verständnis eines wichtigen Symbols der Dichtung Chlebnikovs, des Symbols des 'Einen Buches' oder des Buches schlechthin. 


\subsection{Das 'Eine Buch'}

Zwar geht die Bedeutung dieses Symbols uber die orientalische Thematik in der Dichtung Chlebnikovs hinaus, dennoch aber scheint es - freilich hier in sehr beschränktem Rahmen - gerechtfertigt, dieses Symbol zu untersuchen, da es besonders häufig gerade in jenen Gedichten auftritt, die man dem großen Bereich der Gedichte mit orientalischer Thematik zuordnen kann.

In seinem Brief an Vjačeslav Ivanov (10.6.1909), in dem Teile der Meistererzählung Zverinec (IV,S.285-288) enthalten sind, schrieb Chlebnikov:"Im ruhigen Gesicht des Kamels las ich ein aufgeschlagenes buddhistisches Buch" (IV,S.356). 1 Das ist die früheste uns bekannte dichterische Außerung Chlebnikovs, in der das Buch - an sich ein Produkt menschlichen Geistes bzw. BewuBtseins - als Zeichen für die verborgene Weisheit der Natur vorkommt. Im Laufe der Jahre verselbständigte sich die Buchmetapher in der Dichtung Chlebnikovs zu einem äuBerst komplizierten Symbol, das wichtigste Merkmal jedocin blieb unverändert: es ist das große Buch der Natur, das sich jedem Leser weit öfnet, der sich die Mihe giot, die Snrache der Zeichen zu erlernen, in denen dieses Buch geschrieben worden ist.

Die ganze sichtbare Welt ist fü den Dichter ein Buch: der näcintliche Himmel (IV,S.145), das menschliche Gesicht (IV,S.168), der Sumpf (II,Bd.4,S.150) und die Stadt (II,Bd.3,S.288). Im Gedicht Azija wächst die Buchmetapher bis ins Kosmische hinein; die ganze Erdkug్l ist cin riesiges Buch:" $\mathrm{T}_{\text {н }}$ поворачиваешь страницы книги тон,/Где почерк был нахим руки морен"(II,Bd.3,S.122).

Das retaphorische Buch wird dem realen Buch gegenübergestellt, und dabei wird das letztere verworfen:

1 Die vorliegende Ausgabe enthält zwei Fassungen der Erzählung Zverinec (II,Bd.4,S.27-30 und IV,S.285-288), die allerdings nur relativ geringfügige Unterschiede aufweisen. Ich beziehe mich hier auf die letztere, da sie einer späteren Ausgabe, nämlich der von ii.Chardžiev aus dem Jahre 1940,entnommen ist. 
"Das beste Buch sind weiBe Seiten - das Buch der Natur" (II, Bd.4,S.103). In dem zwei Jahre nach Zverinec geschriebenen Gedicht Pesn' me (1911) ist diese Absage an die Buicher bereits zum klaren Bekenntnis geworden:

В Век книг

Воскдиквуд я: "Мы тодько зверям Bepнu I" 1

$$
\text { (IV,S.205) }
$$

Die Ablehnung des herkömmlichen Buches wird erst im Lichte der Sprachtheorien Chlebnikovs verständlich. Da ein Buch ja sozusagen vergegenständlichte Sprache ist, machen die Bekämpfung und Auflösung der Sprachen (" н бнт без слов ckope甘, cxopell"- siehe S.64) es erforderlich, auch den Büchern den Kampf anzusagen. Die Buicher werden ebenso wie die Sprachen, die die Menschheit spalten, zu Faktoren erklärt, die den Krieg verewigen. In dem 1917 geschriebenen Gedicht Tol'ko my, svernuv vaši tri goda vojny werden die kriegführenden Staaten mit Verlagsanstalten bzw. mit Kaufhäusern verglichen:

[.. ]мы отрицаем господ, Именуоцих себя правителями, Государствами и другими книгоиздательствами И торговния домами Война и $\mathrm{K}^{\circ}$

$$
\text { (II,Bd.3,S.21) }
$$

Das fuhrt nun direkt zum Problem der Buchbekämpfung, nämlich zu dem mehrfach antauchenden Motiv der Bücherverbrennung.

In der frühen Erzählung Razgovor dvuch osob (1912) wird das Motiv eingeleitet:"Ich sehne mich nach einem großen Scheiterhaufen aus Büchern"(III,S.183). Sechs Jahre später, an einem von Chlebnikov genau fixierten Tag (der 26.1.1918), löste die persönliche Erfahrung der Verbrennung eines Buches eine intellektuelle und

1 Vgl. mit Zverinec: "Сад, где взгдяд зверя больше значнт, чем груды прочтенных книг." (IV,S.286) 
seelische Reaktion aus, die sich in dem bedeutenden Gedicht Edinaja Kniga niederschlug. Am genannten Tag, wie Chlebnikov in der autobiographischen Aufzeichnung Nikto ne budet otricat' ausführt (II, Bd.4,S.114-117), las er Flauberts Roman "Die Versuchung des Heiligen Antonius" ("La Tentation de Saint-Antoine"), als das Licht plötzlich ausging. Der Dichter riB eine Seite aus dem Buch heraus, zündete sie an und benutzte das licht dazu, die nächste Seite zu lesen, die dann ihrerseits dem Feuer zum Opfer fiel, bis das ganze Buch gelesen, d.h. zu einem Häufchen Asche verwandelt war. Der Vorgang wird so geschildert: "Der Name Jesu, der Name Mohammeds und Buddhas flackerten in der Plamme, wie das viles eines Schafes, das ich im Jahre 1918 geopfert habe"(ebenda,S.116). Und in dem zwei Jahre später geschriebenen Gedicht Edinaja Kniga wird ein Verbrennungsritual geschildert, bei dem die "schwarzen Veden, der Koran und das Evangelium" geopfert werden (II, Bd.3, S.68).

Das Ziel dieser einem östlichen Ritual nachemprundenen zeremoniellen Opferdarbietung ist es, die Ankunft des "Einen Buches" zu beschleunigen. Dieses "Eine Buch" ist das uns bereits bekannte "Buch der Natur", das alle vom lienschen geschaffenen Bücher ablösen soll:

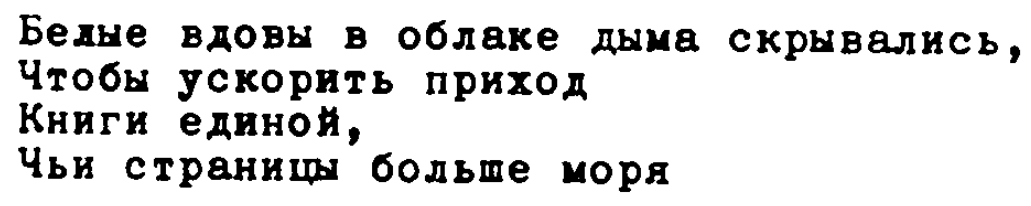

$$
(I I, B d .3, S .68)
$$

In den Kapiteln 5.2.3. und 5.2.4. haben wir bereits auf eine mögliche Beeinflußung Chlebnikovs durch die Schriften Novalis' hingewiesen. Auch das hier vorliegende Motiv der Bücherverbrennung könnte mit einiger Wahrscheinlichkeit auf Novalis zurückgehen. Im zweiten Kapitel ("Die Natur") der von Petnikov, dem Freunde Chlebnikovs, ins Russische libersetzten Novalis-Erzählung "Die Lehrlinge zu Sais" füht der Weg zur Genesung des Hyazinth uber 
die Verbrennung des Buches ${ }^{1}$, wobei Hyazinth durch diese Tat auf den Weg der Erfahrung verwiesen wird. ${ }^{2}$ Bei Chlebnikov wird die Nachwirkung der Verbrennung des Flaubert-Romans die "Versuchung des Heiligen Antonius" folgendermaken beschrieben:

Erst als ich das Buch in Asche verwandelt und plötzlich eine innere Freiheit gewonnen hatte, habe ich begriffen, daB es irgendein Feind von mir war.

$$
(I I, B d .4, S .117)
$$

Es ist von Interesse, auch dem Zusammenhang zwischen dem Motiv der Buchverbrennung und dem Inhalt des Romans "Die Versuchung des Heiligen Antonius" selbst nachzuspüren. Die Verbrennung des Buches wurde von Chlebnikov im Nachhinein als ein symbolisch-ritueller Vorgang empfunden, als ein Weg zu einer Art Erlösung durch die Befreiung vom "Feind". Im Buch selbst nun besteht eine der gröBten Versuchungen des Heiligen Antonius in der Vernüntelei und dem kalten Rationalismus, zu denen der Teufel (Hillarion) ihn verführen will, von denen Antonius sich aber befreit. Daher kann man in der Verbrennung des Buches durch Chlebnikov eine Art symbolischer wiederholung der Absage des Heiligen an die Vernunft des Teufels sehen: das Buch als Sinnbild "teuflischer Vernunft". Der Heilige wird erlöst erst nachdem er u.a. der Versuchung einer Bekehrung $z u$ fremden Religionen, also $z u$ 'feindlichen Büchern', widersteht, um am Ende des Werkes den Weg zur wainren Erlösung zu finden.

Bei Chlebnikov in Edinaja Kniga ist das neue "Eine Buch", das die dem Feuer geopferten Heiligen Schriften der Weltreligionen ersetzt (also sozusagen die 'neue Bibel') - das große Buch der Natur, das gleichzeitig von der ganzen lienschheit gelesen und verstanden wird:

1 Novalis, a.a.0.,s.110.

2 Siehe Anmerkung zu "Die Lehrlinge zu Sais", ebenda,S.683. 
"Род человечества - книги читатедь//И на облогке Надпись творда" (II, Bd.3,S.69).

Im Rahmen einer anderen Arbeit wäre es interessant, der Frage nach dem hier sichtbar werdenden Zusammenhang zwischen dem Antiintellektualismus Chlebnikovs (die Heraufbeschwörung einer "Zeit ohne Worte") und seiner Sehnsucht nach urwichsiger Naturverbundenheit nachzugehen. Was aber im Bezug auf das liotiv der Bucherverbrennung aus der Perspektive unserer Arbeit besonders von Belang scheint, ist die Darstellung dieses Aktes als eines östlichen Rituals. In Edinaja Kniga wird das Autodafé der Bücher mit einem Feuerritual der kalmückischen Frauen verglichen: "Как это дедабт калмихи кахдон зарен" (II,Bd.5,S.68).

Das Reich der kunftigen (also auch der ehemaligen) Harmonie ist bei Chlebnikov stets mit dem Osten verbunden, und deshalb ist die Flamme, also jenes Element, das durch Läuterung zur völligen Verschmelzung der Gegensätze fünrt ${ }^{1}$ und alle "Buchreligionen"2 vereinigt, zugleich die Flamme eines orientalischen scheiterhaufens. 3

Die neue vollkommene Einheit, das große 'Buch der Natur' ist selbstverständich in einer ganz anderen Sprache als die sonstigen Bücher geschrieben. Die Zeichen dieser Schrift sind überall in der Natur verstreut. Es sind die Vögel im Himmel("Застыли сказочными птицами/Отцов письмена в поднебесьи",II, Bd.3,S.37), die Häuser eines persischen Dorfes ("казвлись сакли/Буквами нам непонятнон речи ",II,Bd.3 S.135), die Flecken auf den Schenkeln eines Frosches ("Внимательно читао весенние мили бога на узоре пестрых ног хабн". III,S.66) und die Zeichen auf den Leibern der Ochsen ("Волы лехали в степи подобно громадным могидьным

1 tber die psychologische Bedeutung der Feuerzubereitung als Ausdruck der Anamnesis, der Rückerinnerung und Wiederentdeckung des Urbildes siehe C.G.Jung, a.a.0.,S.214.

2 Siehe Mircea Eliade, Das Heilige und das Profane (Hamburg, 1957), S.95.

3 Auch das 'Buch der Natur' ist ein östliches (buddhistisches) Buch. Siehe die obenerwähnte Stelle aus Zverinec (S.67 dieser Arbeit). 
камням, темнея кондом рог. Искалвсь на нвх надпвсь благочестивого apaбa" (I,Bd.2,S.153)!

Diese Beispiele, von denen noch erheblich mehr beigebracht werden könnten, mögen hinreichen als Beleg für die Tendenz zum Verzicht auf die Mittel der herkömmlichen geschriebenen Texte zugunsten einer ursprüglichen Sprache der Natur.

Von der von Lotman aufgestellten Klassifikation ausgehend, die die Kulturen nach dem Prinzip der Unterscheidung zwischen "Text "und "Nicht-Text" einteilt", könnte man im Werk Chlebnikovs eine doppelte Tendenz feststellen: einmal die Tendenz zur MiBachtung der zu seiner Zeit und in seinem Wirkungskreis akzeptierten Kriterien zur Definition eines Textes, was sich vor allem darin manifestiert, daB er ständig auf der Suche nach neuen Ausdruckweisen, ja nach einer neuen Sprache (und zwar im buchstäblichen Sinne des Wortes) war, um dann in dieser neugeschaffenen Sprache neue Texte bilden zu können; zum anderen die Tendenz zur

$1 \mathrm{Vgl}$. mit dem Beginn der "Lehrlinge zu Sais": "Mannigfache Wege gehen die Menschen. Wer sie verfolgt und vergleicht, wird wunderliche Figuren entstehen sehn; Figuren, die zu jener großen Chiffernschrift zu gehören scheinen, die man überall, auf Flügeln, Elerschalen, in Wolken, im Schnee, in Kristallen und in Steinbildungen, auf gefrierenden vlassern, im Innern und Æ̈uBern der Gebirge, der Pflanzen, der Tiere, der Menschen, in den Lichtern des Himmels, auf beruhrten und gestrichenen Scheiben von Pech und Glas, in den Feilspänen um den Magnet her, und sonderbaren Konjunkturen des Zufalis, erblickt. In ihnen ahndet man den Schlüssel dieser Wunderschrift, die Sprachlehre derselben, allein die Ahndung will sich selbst in keine feste Formen fügen, und scheint kein höherer Schlüssel werden zu wollen." a.a.0., S.95.

2 Ju.Lotman und A.Pjatigorskij, "Tekst 1 Funkcija" in: Teksty sovetskogo literaturovedćskogo strukturalizma, a.a.0.,S.483-491;5.486. 
Aufhebung aller vorhandenen Texte, um auf diese Weise zum "Urtext", dem "Einen Buch", dem "Buch der Natur" zurückzukehren. Diese doppelte Tendenz könnte man mit Lotmans und Pjatigorskijs Begriffen als "Bewußten Bruch mit einem bestimmten Typ der Kultur" bezeichnen. 1 Wenn Chlebnikov in "Brief an zwei Japaner" schreibt, er "würde eher einen jungen auf Altjapanisch sprechenden Japaner als manche der Russisch sprechenden Iandsleute verstehen"(III,S.155), so ist diese Aussage sicherlich nicht wörtlich $2 u$ nehmen (Chlebnikor konnte kein Japanisch, geschweige denn Altjapanisch). Die Aussage kann aber sehr wohl als Ausdruck seines Unbehagens an dem von seinen Zeitgenossen gebrauchten sprachlichen Apparat betrachtet werden, dessen radikale Transformation er stets angestrebt hat. Und zugleich kommt hier wieder seine Neigung zum Ausdruck, dle Grundlage für die neue von ihm angestrebte Weltsprache im Orient zu suchen(siehe Kapitel 5.2. dieser Arbe1t).

Es muß aber mit Nachdruck betont werden, da $B$ ein Versuch, Chlebnikov als 'Zerstörer der Sprache' darzustellen, viel zu einseitig ist, um seinen mannigfaltigen Bemuihungen Genüge zu tun. Gleichzeitig mit seinen utopischen Vorschlägen, sämtliche Sprachen abzuschaffen, entstanden seine kiinnsten Experimente in der Suche nach neuen, bisher unerforschten Möglichlseiten des sprachlich-dichterischen Ausdruclis ("Sternensprache", "Zahlensprache", "Metalogische Sprache" usw). Ja, in seiner Forderung die Sprachen aufzuheben, bedient sich Chlebnikov paradoxerweise oft einer durchaus traditionsgeprägten dichterischen Sprache, die zuweilen sogar bis in die Metrik hinein von der Dichtune der russischen Klassik, vor allem von Puškin, beeinflußt ist. Sein eigentliches Anliegen war nicht, die Sprache "zu zerstören", sondern sie durch tberschreiten ihrer eigenen Grenzen zu transformieren.

1 ebenda, S.189. 
Das fuhrte allerdings manchmal dazu, daB er die Grenzen des (zwar nur schwer definlerbaren) "Mitteilbaren" uberschritt. Roman Jakobson hat noch zu Chlebnikovs Lebzeiten (Ma1 1919) geschrieben:

An einer Reihe von Beispielen sahen wir, wie das Wort in der Dichtung Chlebnikors zunkchst seine Gegenstandlichke1t [ pequerностb] verliert, dann die innere und schlleblich sogar die äuBere Form.1

1 R.Jakobson, Novejšaja Russkaja Poèz1fa, Nabrosok I: V.Chlebnikov (Prag, 1921), S.68. 
5.4. Der_orient_und__der___taat_der_Zukunft

5.4.1. 'Ijudostan' und 'Ladomir' - die harmonische Welt

Die politische Utopie Chlebnikors läßt sich von seiner sprachlichen Utopie nicht trennen. Auf diesen Zusammenhang hat schon Osip Mandel's'tam hingewiesen: "Chlebnikov begriff die Sprache als einen Staat, nur nicht im Raum, nicht geographisch, sondern in der Zeit."1

Wie aus den oben dargelegten Zeitvorstellungen Chlebnikovs abgeleitet werden kann, hat es wenig Sinn, hinsichtlich seiner sprachlichen Theorien und ihrer Verwirklichung entscheiden $z u$ wollen, ob Chlebnikov tatsächlich Futurist oder, wie manche Forscher behaupten, eher 'Passeist' war. ${ }^{2}$ Ebenso wenig läbt sich das Wesen der politischen Utopie Chlebnikovs eindeutig als 'ruickwärtsgerichtet' bzw als 'zukunftsorientiert' klassifizieren, wie sich ja überhaupt Utopia in gleichem Maße auf das in der Vergangenheit liegende "Goldene Zeitalter" wie auch auf die Zukunft orientieren vann.3

$\mathrm{Da}$ b Chlebnikov zumindest oberflächlich mit den Ideen der platonischen Republik, dem Urbild aller Utopien, vertraut var, ist aus dem Anhang zum"Brief an zwei Japaner" ersichtlich, in dem der Dichter seine Vorschläge zur Tagesordnung des "Asiatịschen Kongresses" unterbreitet. In Anlehnung an die gesellschaftlichen Stände in platons "Politeia" sieht auci der Dichter seinen Staat in Stände unterteilt: in die "Erfinder" (изобретатеди) und die "Ern:erber" (приобретатеди) . Die "Erwerber", die sich

1 0.Mandel'štam, Sobranie sočinenij 3 Bde. (Washinfton, 1964-1969), Bd.2,S.390.

2 Siehe vor allem V.Gofman, a.a.0.,S.220 und K.Zelinskij, "Na velikom rubeze (1917-1920). Dervis russkoj poézii" in: Znamja XII(1957),S.143-152;S.151.

3 Siehe "Utopias of escape" und "Utopias of reconstruction" im Kapitel "Utopian literature" in: J.Shipley, a.a.0., S.432f. 
aus den Angehörigen der "höheren Alterstufen" zusamensetzen, haben eine Funktion "im Handel, in der Familie und im Erwerbn(III,S.157). Sie entsprechen etwa den "Krämern" von Platon.1 Die "Erfinder" nehmen für sich die Bereiche "der Kunst und des Wissens" in Anspruch (ebenda).2 Die Dichter werden also im Unterschied zur Republik von Platon nicht aus dem idealen Staat ausgeschlossen. Im Gegenteil, durch die Verknüpfung von Kunst und Wissen sind sie zum Stand der Herrscher, der Philosophen ausersehen, die ja bei Platon als "Sehende Hüter" und als "Fuhrer des Staates" fungieren. 3 so wird auch die innere Logik des von Chlebnikov und seinen Freunden mit großem Aufwand getriebenen Spiels sichtbar: sie ermennen sich nämlich selbst zu den "Vorsitzenden des Erdballs" ("Председатеди Земного шара"). Es sind die Dichter, die sich zu den Fihrern der kinftigen, noch im Werden begriffenen Welt proklamieren. 4 .

Die Erhebung der Dichter zum regierenden Stand bestimmt Chlebnikors Auffassung des idealen Staates als eines dichterischen Staates, eine Vorstellung, die aus der deutschen Romantik wohlbekannt ist. 5

E's soll ein Staat ohne Krieg sein, die Aufhebung der Kriege aber kann, wie mehrmals gesagt, erst nach der iberwindung der Vielfalt der Spracinen, d.h. erst nach der Schaffung einer Weltsprache geschehen. So muß der utopische

1 Platon, Sämtliche Werke, 6 Bde. (Leck, 1959), "Politeia" Bd.III,2, Kap.12, 317b-d, S.108.

2 Hehr über die "Erfinder" und über die "Frwerber" siehe in Truba marsian (III,S.151-154).

3 Platon, a.a.0., S.200.

4 Siehe z.B. den von Chlebnikov und Petnikov unterzeichneten Aufruf Vozzvanie Predsedatelej Zemogo Sara (III, S.162-164) und Oktjabr na Neve (II,Bd.4, S.105-113)

5 Siehe z.B. bei Novalis:"Ein sehr geistvoller staat wird von selbst poetisch sein - je mehr Geist, und geistiger Verkehr im Staat ist, desto mehr wird er sich dem poetischen nähern...." Aus:"Vermischte Bemerkungen('Blütenstaub') 1797-1798', a.a.0., S.351. 
Staat nach der Schaffung einer Weltsprache folgerichtig ein Weltstaat werden.

Im utopischen Essay Lebedija buduščego (1915-16) wird dieser Weltstaat der Zukunft als "Соединенние Станн Aзй" bezeichnet(II,Bd.4,S.287). Hier wendet sich Chlebnikov gegen die Utopie von Vladimir Solov'ëv, der in den "Drei Gesprächen" (Tri razgovora) für das XXI. Jahrhundert einen europäischen Völkerbund "Европейскне соединеннве штати" vorausgesagt hat. 1

Hierin komnt wieder die gleiche bewußte Umkehrung der Perspektive zum Vorschein, wie wir sie bereits in Kapitel 3.1. dieser Arbeit dargelegt haben: Asien tritt an die Stelle von Europa.

In der großen Dichtung Ladomir, die zu den zentralen und bekanntesten Dichtungen Chlebnikors zählt und die ideale Welt der Zukunft zum Thema hat, heiBt der künftige Weltstaat Додостан (I,Bd.1,S.188). Es ist ein Neologismus Chlebnikovs, der sich aus dem Kollektivum Jlog und dem Wort cran zusammensetzt, wobei eine wirksame Imitation der Bezeichnung asiatischer Staten oder Gebiete entsteht: Afghanistan, Pakistan, Turkestan, Kasachstan u. ̈...

zwischen den Worten Jодостан (die Bezeichnung des liinftigen Staates) und Ладомир (die Bezeichnung der Welt der Zukunft) kann man eine Reihe von komplizierten semantischen und morphologischen Parallelen feststellen, die wesentlich sind für das Verstindnis der Dichtunf, Ladomir.

Zuerst einmal sind Людостан (Люд-о-стан) und Ладомир (Лад-о-мир) morphologisch gesehen ganz parallel gebaut, indem sie die gleiche Abhängigkeitsstruktur der Teile des jeweiligen Kompositums aufweisen ( $\underline{\text { Jngостан }}$ im Sinne "Staat der Menschen", Ладомир im Sinne "Welt der Eintracht").

1 V.Solov'ëv, Pri razgovora (New York, 1954), S. 198. Chlebnikov geht in Zangezi direkt auf Solov'ëv ein (II,Bd.3,S.350f). Die Vision (der russisch-japanische Krieg), auf die sich cer Dichter Zangezi bezieht, ist im gleichen Kapitel der "Drei Gesvräcine" enthalten wie die Prophezeiung über.: die Schaffung der "Vereinigten Staaten Europas". 
Da cran im Russischen auch als eine Bezeichnung für 'Menschengruppe' 1 aufgefasst werden kann, entsteht innerhalb des Wortes Jодостан eine Art innerer semantischer

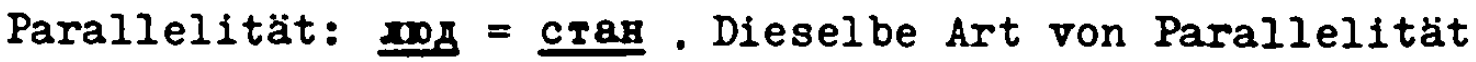
weist auch das Wort Jадомиp auf, wenn man yas in der Bedeutung von 'Priede', 'Eintracht' heranzieht: IES = Mup. Es besteht also eine 'horizontale' Parallelität zwischen Jrogocraн - Iagomgp, indem in den beiden Worten die beiden Bestandteile der Komposita in einem synonymen Verhältnis zueinander stehen.

Außer dieser 'horizontalen' Parallelität zwischen Лодостан und Ладомир besteht auch eine 'vertikale' Beziehung zwischen den beiden Worten. Ias und I0s sind ein paronomastisches Paar, gebildet nach den von Chlebnikov formulierten "Gesetzen der Inneren Flexion" ( Bнутреннее скдоненве), wie sie z.B. in seinem diskursiven Aufsatz Učitel' i učenik (III,S.171-182) expliziert sind. Den Beispielen Chlebnikovs in diesem Artikel folgend kann man folgendermaben argumentieren: a und $\underline{\mathbf{a}}$ sind Genitiv-bzw. Dativendungen des maskulinen 0-Stammes. Auf diese Weise entstehen Chlebnikov zufolge Wortpaare, die einerseits einen ähnlichen Klang und eine tiefe Beziehung zueinander haben, andererseits aber in einer spannung zueinander stehen (wie die von Chlebnikov als Beispiele angefuhrten

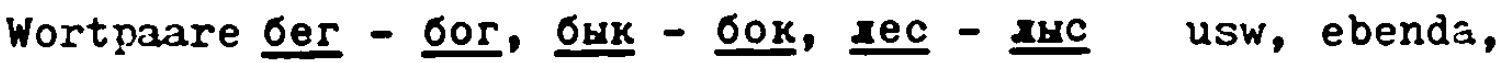
S.171f). In unserem Falle bezieht sich die innere Spannung zwischen den Worten, die durch die "innere Flexion" miteinander verbunden sind, auf die zentrale Idee der Utopie Chlebnikovs, die erst nach der Aufhebung des größter. Übels unserer Welt, des Krieges, verwirklicht werden kann:in unserer Welt leben die Menschen (표) nicht in Eintracht (I8I) miteinander - was durch die Spannung ausgedrückt wird, die Chlebnikovs "Gesetzen" zufolge unbedingt zur "inneren Flexion" gehört (ebenda,S.171). Die Utopie besteht für Chlebnikov vor allem in der tberwindung eben dieses Spannungsverhältnisses zwischen IDS und Ias.

1 Siehe "craн" in : Tolkovyi slovar' Velikorusskogo jaryka Vladimira Dalja (Moskau/Petersburg, 1903), 3Aufl. IV Bde. Bd.2, S.505. 
Die 'vertikale' Beziehung zwischen I0I0cras und Iaxомap erstreckt sich auch auf den jeweiligen zweiten Teil dieser Komposita: Mup und crax stehen in einer engen Beziehung zueinander, wenn man uap als traditionelle russische Bezeichnung für das 'Treffen der Mitglieder einer Dorfgemeinde' 1 und cras als 'Lager einer zusammenreisenden Gemeinde' 2 versteht.

Diese mehrfache gegenseitige Widerspiegelung der Namen Jagomap - mit seinem starken slavischen Klang 3 und einer ebensolchen assoziativen Wirkung-und Jogocras, ein Wort, das, wie bereits gezeigt, morphologisch den Namen mehrerer asiatischer Staaten nachempfunden ist, bringt die wichtigste Idee der politischen Utopie Chlebnikovs zum Ausdruck: RuBland ist Ausgangspunkt fiir die Schaffung des idealen Staates der Zukunft, dieser Staat aber wird ausgeprägt asiatische (weiter gefaßt: orientalische) Züge tragen.

In Anlehnung an den Staat der Zukunft Iogoczar nennt Chlebnikov die künftige Stadt (Topos 6yaymero) - CoxнuecraH (II,Bd.3,S.63). Cоднцестан ("Stadt der Sonne") weist auf das altägyntische Heliopolis zurück. Wie im Kapitel uber den llythos gezeigt wurde (siehe besonders Kapitel 2.2.1.), hat sich Chlebnikov intensiv mit dem Mythos des Sonnengottes $\mathrm{Ra}(\mathrm{Re})$ befaßt, und Heliopolis war bekanntlicin das Zentrum des sog. solaren Monotheismus. 4

1 Siehe "myp" in: Dal', ebenda, Bd.2,S.863.

2 Siehe "craн", ebeñá, Bd.2,S.505.

3 Niarkov, a.a.0., S.146.

4 Lurker, a.a.0., S.31. Siehe auch:

"Amenophis" in:Der GroBe Brockhaus, 3.a.0., Bd. 1, S.236. 
5.4.2. Der Sieg über den Tod und die Reinkarnation

In der idealen Welt der Zukunft, in der Welt von ladomir, wird der Tod besiegt sein ("смерть смерти будет ведать сроки", I,Bd.1,S.185), eine Idee, die das Bild des idealen Staates bei Chlebnikor fast immer begleitet. Dieses Motiv - so V. Markov - verbindet Chlebnikov mit den Ideen des russischen Philosophen Nikolaj Fëdorov. 1 In Chlebnikovs Utopia sind, wie oben angeführt, die Dichter, die zur gleichen Zeit Wissenschaftler sind, der herrschende Stand der Gesellschaft. In Anlehnung an die Gedanken Fëdorovs postuliert Chlebnikov, daB es im Staat der Zukunft die Aufgabe der Wissenschaftler sein werde, den Tod $z u$ überwinden, wobei die Iuftfahrt als littel zur Überwindung der Gesetze der Schwerkraft eine entscheidende Rolle spielen würde. Diesen Gedanken bringt Chlebnikov in einem Brief an M.Matjušin (18.6.1913) zum Ausdruck, in dem er die End guiltigkeit des Todes bezweifelt und dazu bemerkt:"Wenn die Schwerkraft vieles lenkt, dann sind aie Luftfahrt und die relative Unsterblichkeit miteinander verbunden"(IV,S.365).

Die Vorstellung vom Weg zur Unsterblichkeit ist bei Chlebnikov durch eine eigenartige Synthese von wisserschaftlichem Denken und dem Glauben an die buddhistische bzw. hinduistische Leire von der Reinkarnation geprägt.

1 Markov, a.a.0.,S.148. Ausführlicheres uber Chlebnikovs Beeinflussung durcin Fëdorov siehe in den Anmerkungen, ebenda, S.224.

Fëdorov (1828-1903), Autor der "Philosophie der gemeinsamen Sache" ( Философия общего деда") sah in dem Sieg über den Tod die höchste Aufgabe der lienschheit und glaubte, man könne dieses Ziel mit der Hilfe der Wissenschaft erreichen. Außerdem hat er sich viel mit den asiatischen Aspekten RuBlands befaßt. In seinem geschichtlichen Denken nahm der Begriff Turan, also eigentlich das innerhalb der Grenzen Rußlands liegende Turkestan, als Bindeglied zwischen RuBland und Asien eine wichtige Stelle ein. Auch auf dieser Ebene ist also ein EinfluB Fëdorovs auf Chlebnikov anzunehmen. zum Begriff Turan bei Pëdorov siehe z. B. seine Briefe an V.A.Kożevikov: "O Turkestane", in: Vërsty, III(1928), S.278-288 . 
In einem Brief an Petnikov schrieb der Dichter: "Wir haben es vor, mit dem Wissen um die Sekunde unserer zweiten Geburt zu sterben"(III,S.314). In dem Fragment otryvok iz p'esy wird gleichfalls dargestellt, wie man mit Hilfe wissenschaftlicher Forschungen die Zeit der eigenen Geburt, des Todes und der Wiedergeburt berechnen kann. Einer der Teilnehmer am Dialog sagt, daß er seine wissenschaftliche Arbeit "nach dem zweiten Tod, im dritten Leben" fortsetzen wird (III,S.142). Nian beacinte auch den Hiniveis auf den "Tag des blauäugigen Gangi", der als Geburtstag eines der beiden Gesprächspartner angegeben wird (ebenda), was die Frage der Wiedergeburt in einen buddhistischen bzw. hinduistischen Kontext stellt. ${ }^{1}$ Die Straße, auf der dieses Gespräch stattfindet, das die Wiedergeburt als eine durchaus alltägliche Angelegenheit behandelt, wird als die "Straße der zukunft" bezeichnet (ebenda).

Die Vorstellung von der Ubervindung des Todes bei Chlebnii:ov sciöoft also aus zwei grundverschiedenen Quellen: aus dem westlichen wissenschaftlichen Denten und dem östlichen Glauben an die Reinkarnation. Daher trägt auch Chlebnikovs Utopie, der Weltstaat der zukunft, in dem es :eder Kriege noch Tod geben wird, bestimmte Züge, die von der buddhistischen Vorstellungswelt geprägt sind. Den Gesetzen der Reinkarnation ist ja alles Lebende, nicht nur lienschen, sondern auch Tiere unterworfen. Daher entsteht im utopischen Werk Lebedija buduščego die bruderliche Gemeinde von Kenschen und Tieren:

1 Vjać.Vs.Ivanov liefert wertvolle Hinweise zu dieser Frage und belegt Chlebnikovs Interesse an der buddhistischen Lehre mit für uns zum Teil unzugänglichen Wcrken des Dichters. (Ivanov, a.a.0.,S.385f). Aus Ivanovs Ausfuihrung folgt, das Chlebnikov das Buch von V.A. Koževnikov Buddizm kannte. Siehe unsere Anmerkung auf 5.80 über Fêdorovs Briefe an V.A.Koževnikov. 
Es wurde als Regel bestimmt, da $B$ kein einziges Tier verschwinden darf. [...] Der beflügelte Schöpfer ging sicheren Schrittes zur Gemeinde nicht nur aller Menschen, sondern aller lebenden Geschöpfe der Erdkugel uberhaupt.

$$
\text { (II, Bd.4,S.289) }
$$

Buddha ist für Chlebnikor die Idealgestalt eines Menschen, der für das Leben eines Tieres genauso viel Achtung hat wie für das menschliche Leben. Im Gedicht Azija heibt es:

\section{Зхесь снн царя прославил нищету \\ И робох опустить на муравья пяту \\ И годит ниция в лопани.}

$$
\text { (III,S.27) }
$$

Der Königssohn, der die Armut pries und zur Schonung aller Tiere aufrief, ist selbstverständlich Buddha.

Chlebnikov muB bereits sehr früh auf die von der Lehre Buddhas beeinflußte Idee der harmonischen Gemeinschaft zwischen Menschen und Tieren gestoßen sein. Im Jahre 1904, also im Alter von neunzehn Jahren, schrieb Chlebnikor in seinem "Testament":

Er sah keinen Unterschied zwischen der menschlichen Art und den Arten der Tiere und trat für die Ausdehnung des Gebotes 'Liebe Deinen Nächsten wie Dich selbst' auf die edlen Tierarten ein.

$$
\text { (IV,S.318) }
$$

Wesentlich für das Verständnis der Utopie Chlebnikovs ist daher das Motiv des Staates der Tiere. So in Azija: "Ты разрешила обезьянаи/иметь правительства и королеи" (III,S.27). Und im Brief an V.Ermilov (3.1.1921):"Es kann sein, daB es im Staat der Pferde begabtere Schuller geben wird als im Staat der Menschen"(IV,S.385). In Ladomir gehört die Gleichberechtigung der Tiere zur idyllischen Welt der Zukunft:"Я виху конские свободв/и равноправне коров" (I,Bd.1,S.193). 
Nun ïbernimmt Chlebnikov nicht nur die Vorstellung der Eintracht zwischen Mensch und Tier aus dem Buddhismus. Sogar Ideen wie Gleichheit und Brüderlichkeit sind für ihn an erster Stelle nicht etwa mit der französischen Revolution, sondern bezeichnenderweise mit der Lehre des indischen Königs Asoka verbunden. Eine 1915 geschriebene symbolische Skizze wird mit dem Satz eröffnet:"Ich ging $z u$ Asoka und erbat bei inm leihweise Gedanken uiber Gleichheit und Brüderlichkeit"(IV,S.317). Asoka war der König, auf den die Einführung des Buddhismus als Staatsreligion in Indien (im III. Jh. vor Christus) zurückgeht. 1

Die Konzeption des idealen Staates ist bei Chlebnikov auBerdem stark von der romantischen Vorstellung der sogenannten "politischen Biologie" ${ }^{2}$ geprägt: er versteht den Staat als einen perfekt funktionierenden Organismus, als einen Makroanthropos. Am klarstenwird diese Idee im dichterischen Bekenntnis Junoša Ja-liir zun Ausdruck gebracht:"Ich bin eine zelle von dem Haar oder vom Hirn eines großen lienschen, dessen Name Rußland ist"(II,Bd.4, S. 35). Jieses alte allegorische Bild (der Staat als Körper, in dem alle Teile und Funktionen aufeinander abgestimnt sind und der Ganzheit dienen) ist in der Dichtung Chlebnikovs derartig ausge prägt realisiert, da $B$ beide Komponenten àer Allegorie gegeneinander vertauscht werden können: nicht nur wird der Staat als Organismus, als ein lebendiger körper durgestellt, sondern auch der Körper, und zwar der Kürper des Ich-Dichters, wird zum Staat proklamiert. Auf diesen Sachverhalt in der Dichtung Chlebnikovs hat auch der Dichter Nikolaj Zabolockij aufmerksam gemacht, der in einem Brief an Konstantin Ciolkorskij, den Pionier der Raumfahrt in Rußland, folgendes schrieb:

1 Haas, a.a.0., S.223.

2 Utber den Staat als Makroantinropos bei Novalis siehe z.B. Hans Keiss, Politisches Denken in der deutschen Romantik (Bern, 1966). Dort heibt es:"Der Staat hat bei Novalis also organischen Charakter. Er ist weder Kunstwerk noch Maschine; er ist ein großes Individuum, das alle Individuen umfaßt. Der Staat ist ein Makroanthropos:" (S.34). Vgl. mit der Theorie der "politischen Biolo
bei Schleiermacher in: Reiss, a.a.0., S.67. 
Sich als einen Staat zu fiuhlen ist offensichtlich eine neue Errungenschaft des menschlichen Genies. Dieses Gefihl, das in Ihren Werken einen derartig klaren Ausdruck fand, war dem genialen Dichter Chlebnikov bekannt, der im Jahre 1922 gestorben ist. 1

Anschließend zitiert Zabolockij den Text des ChlebnikovGedichts Ja i Rossija (II,Bd.3,S.304), in dem der Dichter den eigenen Körper als einen Staat feiert.

Daraus ergibt sich natiurlicherweise die Frage nach dem Wesen des Ichs in der Utopie Chlebnikovs. Wenn der Staat ein "Makroanthropos" und das Individuum eine Art "Mikropolis" ist, dann gehen die beiden ineinander über: die Möglichkeit der künftigen gesellschaftlichen Harmonie wird unmittelbar aus der Erfahrung des eigenen Körpers abgeleitet, das Ich muB aber in die Ganzheit zurückkehren. Zu einem ähnlichen SchluB kommen auch Loščic und Turbin, die allerdings nicht auf die "politische Biologie" eingehen:

Das Verschwinden in Strom der Geschichte ist die Form der Wahrung des 'Ichs', des Einmaligen und Unwiederholbaren. Und Asien war fü den Dichter [ für Chlebnikov] nicht nur deshalb unentbehrlich, weil es sicin irgendwo in der liäie befindet, nicht nur weil es geheimnisvoll und exotisch ist, sonder. Asien zor inn an als begehrte irginzung zu den, was wir Europëier vissen, als Schule, die vir zbsolvieren missen.2

Was in der angefïhrten Feststellung unzusgesprochen bleibt, ist der Hinweis darauf, daB der Dichter im großen Bereich

1 A.Pavlovskij,"Iz perepiski N.A.Zabolockogo s K. $\dot{E}$. Ciolkovskim", in Den' Poèzii (Leningrad, 1964), S.227232 ; 5.230

2 Iościc und Turbin, a.a.0.,S.148. Vjač.Vs.Ivanov bestreitet die Feststellun; von Loscic und Turbin vom "Verschwinden im Strom der Geschichte" als "Form der ialurung des Ichs" bei Chlebnikov. (Ivanov, a.a.0.,S.38.4). Ivanov scheint aber dabei Chlebnikovs Auffassung vom kosmos als einem geschlossenen system, in dem alle Teilelemente, darunter aucin das Ich, gleichzeitig ein Teil der Ganzheit und eine Ganzheit sind, die alles andere in sich beinhaltet, $z u$ verkennen. 
der asiatischen Philosophie und der Geisteslehre eben jene Idee fand, mit deren Hilfe das Ich, das sich auf dem Wege der Wiederverkörperung (Reinkarnation) immer von neuem in den Kreislauf der Natur integriert, zur Unsterblichkeit gelangt.

Die späte Dichtung Vlom Vselennoj beginnt mit der Vision einer Todesgefahr fur ein ganzes Volk als Folge der Gefährdung eines einzigen Insekts, eines Marienkäfers (II,Bd.3,S.93). Daher gleicht seine Errettung aus dem Wasser der Erlösung des ganzen Volkes (ebenda,S.99). Auch die einzelnen im Marienkäfer verkörperten menschlichen Individuen sind den Gesetzen der Reinkarnation untemorfen:

\section{Мы вздетим на небо \\ И через многие тхсячи тет \\ Вернемся на земдо \\ Непонятным прахом.}

$$
\text { (ebenda, S.98) }
$$

Die viederkehr zur Erde in Form von непонятиын прar impliziert also die Reintegration dessen, was einmal gelebt hat, in einen neuen Lebenskreis, wobei aus dem "Staub" möglicherweise auch neue Menschengenerationen geschaffen werden können. Hier wird also sichtbar, auf welchem subtilen Wege der Dichter die biblische Konzeption der Unsterblichkeit der Seele und der Rückkehr des 'Staubes zum Staube' mit dem buddhistischen Glauben an die Reinkarnation vereint. Dieser Glaube ist nur eine Komponente in einem großen von Chlebnikov erarbeiteten synkretistischen System, in dem die neuesten wissenschaftichen Erkentnisse (Chlebnikov hatte z.B. Kenntnis von den Arbeiten Albert Einsteins, III,S.101) mit den Grundsätzen nehrerer Religionen zu einer eigenartigen Ganzheit zusammengeschmolzen werden.

Im Zeichen dieses Synkretismus steht auch die politische Utopie Chlebnikovs. Auch sie trägt Merlmale seiner 
eigenartigen ost-westlichen Synthese. Diese Synthese wird am deutlichsten in den Gedichten der persischen Periode sichtbar. Im Gedicht Dub Persii z.B. findet sich der Zusammenklang", die Harmonie von Mazdak und Marx: "Шумит созвучие / С Маздаком Марксв" ( II,Bd.3,S.1ว4). lazdak, der persische Reformator (um 500 n.Chr.), erarbeitete das Ideal "einer auf Religion gegriindeten kommunistischen Gesellschaft." 1 Daraus wird ersichtlich, mit welchem aiel in dem Gedicht Chlebnikovs Mazdak in Zusammenhang mit Karl Marx genannt wird: es ist die Suche nach dem gemeinsamen Nenner orientalischer und abendländischer Visionen der idealen künftigen Weltordnung.

Wie im Kapitel uber Chlebnikovs Auffassung der Geschichte mehrfach gesagt worden ist, findet in seinem ilerk eine Umorientierung der gesamten kulturgeschichtlichen Perspektive statt. Seine Version des "ex Oriente lux" ïberträgt sich natürlicherweise auch auf die Utopie der Zukunft. Diese Welt der Zukunft ist aber weder Orient noch Okzident: es ist ein komplexes Konflomerat aus beiden Kulturrelten. Und da Rußland seiner geographischen Iare, seiner Geschichte und seines kulturellen Erbes vegen Ost und West in sich vereinigt, ist Rußland in den Wer:en Chlebnikovs der Ausgangspunist der Vision der idealen vereinigten Welt.

1 Haas, a.a.0., S.138. 


\subsection{Der_Orient_und__der_vol_zkommene_Mensch}

Die Schaffung des idealen Staates setzt die Schaffung des vollkommenen Menschen voraus. In der Utopia Chlebnikovs ist dieser Mensch selbstverständlich ein Russe, der wiederum sehr viele orientalische Züge trägt.

In der Analyse der utopischen Welt der Zukunft (Ladomir) haben wir darauf hingewiesen, da $B$ im idealen Staat die Rolle der Herrscher den Dichtern zuteil wird. Wie wir weiter dargelegt haben, ist es eine genaue Umkehrung der Verhältnisse, wie sie in der Republik Platons entworfen werden, da $B$ die Dichter $z u$ "Vorsitzenden des Erdballs", zu Fürern der Menschheit werden gerade weil sie, im Gegensatz zu den erwerbenden Konsumenten ( пряобретатедя ), nichts besitzen und ihre Aufgabe in der Suche nach neuen Wegen sehen. Deshalb sieht Chlebnikov die "Erfinder" als die wahren, freien und vollkommenen lienschen. Da die Freiheit, die freie Persönlichkeit bei Chlebnikov nämlich durch Азия als 'Chiffre der Freiheit' (siehe S.20 dieser Arbeit) vertreten wird und es Азия ist, die "die freie Persönlichkeit aufgebaut hat"(ebenda), ist die Vision der küftigen freien welt und ihrer freien rienschen unbedingt im Zusammenhang mit Asien, also mit Chlebnikovs Orientalismus zu sehen.

Die Freiheit allein schafft aber noch nicht den vollkommenen Menschen: das Ideal für Chlebnikov ist eine Synthese zwischen ungehinderter Spontanitit (die "Freiheit Asiens") und einem analysierenden, ordnenden Intellekt (der "Rationalismus des Westens"). Daher wird also das Ost und West in sich vereinende RuBland zur Geburtsstätte des vollkommenen lienschen bei Chlebnikov. Es ist der Dichter selbst, der sich zum Vorboten dieses Ideals proklamiert, wobei seine eigenartige Synthese lautet:"я Разин со знаменем Лобачевского" (I,Bd.1,S.202). 
Wie immer in der Dichtung Chlebnikovs verbirgt sich auch hinter dieser auf den ersten Blick bizarren und paradoxen Zusammenfügung zweier so verschiedener Gestalten (Razin, der Anfuhrer des Bauernaufstandes im XVII.Jh, und Lobačevskij, 1792-1856, der Begründer der neuen, nichteuklidischen Geometrie) ein in allen Details durchdachtes System: Razin löste eine populäre, durch soziale Akzente gekennzeichnete Massenbewegung in RuBland aus und ging als Revolutionär in die Geschichte ein. Lobačevskij bewirkte eine Revolution in der Geometrie. Beide waren mit der Wolga verbunden: Razin zog mit seinem Heer Wolga-aufwärts, Lobačevskij war von 1827 bis 1846 Rektor an der Universität von Kazan' an der Wolga, wo Chlebnikov im Jahre 1903 Mathematik studierte.

Die Wolga verbindet im System Chlebnikovs die Schicksale dreier Gestalten: Razin, als Verkörperung der Freiheit, Lobačevskij, als Verkörperung des Intellekts, und den Dichter Chlebnikov, der an der Wolga geboren wurde und der sich als Synthese der beiden versteht, als ein ungestümer Rebell und Freiheitskämpfer, der mit wissenschaftlichen Erkenntnissen ausgerüstet ist. (Der Dichter bei Chlebnikov ist ja immer sowohl Wissenschaftler wie auch Revolutionär, ein Veränderer der Welt).

Das angefihrte Bekenntnis des Dichters "Я Разин со знаменем Добачевского", das als Notto der Dichtung Razin ( $I, B d .1, S .202-215)$ vorangestellt ist, wird in der Dichtung Ladomir erweitert und erscheint nun explizit in einem revolutionären Kontext:

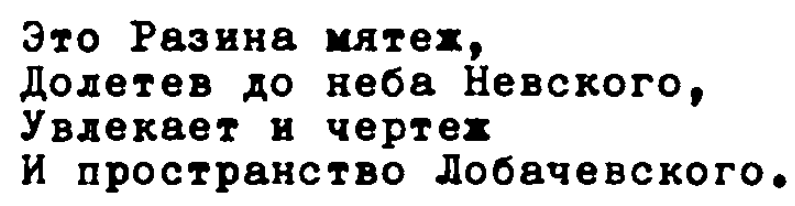


Die in der Gestalt des idealisierten Ich-Dichters erreichte Synthese entspricht Chlebnikovs Ideal des vollkommenen Fienschen. is ist eine Synthese zwischen der Idee der strengsten Formgebung - Lobacievskij als Symbol der geometrischen Gestaltung des Raumes - und der Idee der rücksichtslosen, ja zerstörerischen Freiheit, wie Stepan Razin sie verkörpert. Die beiden sind für Chlebnikov wie gesagt in der Gestalt des Dichters vereint, und zwar in der Gestalt des Dichters Velimir Chlebnikov, der in seiner Dichtung einerseits um Eormgebung bemiiht ist, andererseits die Zerstörung cier traditionellen Poesie anstrebt. Die Synthese zwischen Lobac̉evs':ij und Razin ist gleichzeitig eine Synthese zwischen dem vorwiegend europäischen, auf zatio ausgerichteten und dem vorwiegend asiatischen, in seiner Freiheit ungehinderten russischen Rebellen.

Zwar tritt das Lobačevskij-Motiv auch in anderen Gedichten Chlebnikovs auf (z.B. in Vlom Vselennoj, II, 3d.j, 5.93 oder in Pesn' mne, IV,S.207), dennoch aber jleibt gie Gestait des großen liathematikers re:rissermaben "flach", sie wird nicht entuickelt uno jowinnt keine besoniere Tiefe. Entschieden anders steht es mit dem Razin-Motiv, einem der ausgeprägtesten, aber auch kompliziertesten Votive der Dichtuz; Chiebnilovs. 


\section{Das Razin-Motiv in der Dichtung Chlebnikovs}

Im Kapitel über die Mythologie (2.2.1.) wurde das Razin-Motiv in seiner mythologischen Dimension bereits behandelt, hier aber wollen wir seine Entwicklung auf anderen Ebenen weiter verfolgen.

Was vom Standpunkt unseres Themas besonders wichtig erscheint, ist die Steigerung des Razin-Motivo im Zusamenhang mit Chlebnikovs Persien-Reise. Truba Gul'-Mully (I,Bd.1,S.233-245), Ustrug Razina (I,Bd.1,S.246-251), die Erzählung Razin, dve Troicy (II,Bd.4,S.146-150), das Gedicht Ėto parus rekača (II, Bd.3,S.202-205) und andere, kleinere Dichtungen, in denen dieses Motiv eine zentrale oder mindestens wichtige Stellung einnimmt, wurden während Chlebnikovs kurzen Persienaufenthaltes oder nach seiner Rückkehr aus Persien nach RuBland vollendet.

Chlebnikov begriff seine Reise nlich Persien gewissermaßen als eine symbolische Wiederholung des beruhmten Persienzuges von Razin, der in den Jahren 1668-9 die Provinzen an der kaspischen Küste Persiens plünderte ${ }^{1}$ und mit dem persischen Khan in der Stadt Rescht verhandelte ${ }^{2}$, also in der gleichen Stadt, in der Velimir Cnlebnikov 250 Janre später, im April 1921, mit einer Einheit der Roten Armee landete.

Die im Januar 1922 vollendete Erzählung kazin, die den Untertitel Dve Troicy trägt, ist eine durch viele Abschweifungen und fü Chlebnikov typische komplizierte Verschlüsselungen gekennzeichnete Beschreibung zweier Pfingstfeierlichkeiten: die eine fand 1905 in der stadt Perm' im Uralgebiet statt, die andere 1921 in Chalchala in Nordpersien (II,Bd.4,S.149). Die Verbindung zwischen

1 Gitterman, a.a.0., Bd.1,S.292.

2 Siehe "Razin" in: Binciklopedičeskif slovar' Brokgauz i Efron, 82 Bde.(Petersburg, 1890-1904), Bd.51, S.160. 
den beiden Orten (der eine in RuBland, der andere in Persien) wird durch die Gestalt Razins vermittelt. Nordpersien wird als "Родина раннего удвлого дедв Раздна" (II,Bd.4,S.149) dargestellt. Dabei sind die Frlebnisse des Dichters, der seine eigenen Erfahrungen und Gefuhle bei den Pfingstfeiern in RuBland und in Persien schildert, durch seine Identifikation mit der Gestalt Razins gekennzeichnet.

Der Ich-Erzähler nennt Razin seinen Doppelgänger: " Эн! Двониак Раздн, садись в лодку меня - "(ebenda,S.147). Bereits in dem frihen Gedicht Pesn' mne (1911) kündet der Dichter seine Ankunft als die des Schattens von Stepan Razin an: "я npuxоху к ваи теньр Paзнна" (IV,S.208). In Dve Troicy konkretisiert sich die Selbstdarstellung des Dichters als des "Schattens Razins", indem Razin, wie gesagt, zum Doppelgänger des Dichters wird, und zwar zu seinem $n$ e $g$ a $t i v$ e $n$ Doppelgänger: "Orрицательнын годубон Двониик Рвзин, пепел зөклятин сыпдется на тебя из мовх рук." (II,Bd.4,S.147).

Dieses Motiv des negativen Doppelgängers soll hier weiter verfolgt werden, weil es m.E. nicht nur zur Klärung der Razin-Gestalt im Werk Chlebnikovs beitrager. wird, sondern auch bestimmte methodische Schlüsse uber die Art der Motiventwicklung bei Chlebnikov zulässt.

Das Motiv Razin als "negativer Doppelgänger" wird in der Dichtung Truba Gul'-jully im vollen Umfang sichtbar:

\section{И в звездноН охоте \\ Я звезднын скакун, \\ Я Разин напротив, \\ Я Разин навыворот.}

$$
(I, B d .1, S .234)
$$

Hier begreift sich also Chlebnikov als den "umgekehrten Razin" und führt aus, worin diese Umkenrung besteht, indem er Geivalt und Dichtung, Vernichtung und Schaffen 
gegenübergestellt. Die Aussage dieser Strophe wird durch die Erwähnung der beruhmten Episode der Ertränkung der persischen Prinzessin durch Razin weitergefürt:

Разин деву

В воде утопид.

Что сдедар я? Наоборог? Cпасу!

$$
\text { (ebenda,S.235) }
$$

Das ebenfalls in Persien entstandene Gedicht Ja videl junošu proroka enthält eine variation auf das gleiche Thema:

Он Разиним покдядся бить напротив.
Ухеди снова бросит в море княхну? Противо-Разин грезит.

$$
\text { (II, Bd. } 3, \mathrm{~S} .305)
$$

Es ist also die vorgestellte 'Umkehrung' von Razins Tat durch den Dichter, die Razin zum negativen Vor- und Doppelpänger des Dichters macht. Das ist der erste, und zwar inhaltliche Aspelit der negativen Spierelung des Dichters in der Gestalt Pazins.

Die zweite, und zwar lautliche spiegelbildliche Verkehrung ergibt sich aus der Umkehrung des $y$ or $t$ e $s$ Pазин , wobei das Wort Низарf) entsteht. Dieses Wort hat die Bedeutung 'Bewohner des Unterlaufes eines Flusses' 1 und wird oft zur Bezeicinnung eines lenschen, der von der Unteren Wolga komnt, gebraucht. Chlebnikov, der in der Nähe von Astrachan' zur Welt kam, war ja selbst ein Huзарь , ein "umfelsehrter Razin". (So schliebt die Dichtung 年azin mit der Zeile "Мы, ннзари, детеди Разиным" , I, Bd.1,S.215).

Indem Chlebnikov nach Persien fährt, bewegt er sich in Richtung Süden und damit in dic entgegengesetzte Richtung wie sein "negativer Doppelgänger" Razin, der ja mit seinen Truppen in die umgekehrte Richtung zog,

1 Siehe "низ" in: Dal': "Ha Bолге все rорода нихе

Симбирскв зовут, ,низовыми,", a.a.0., Bd.2,S.1413. 
von Persien ${ }^{1}$ wolgaaufwärts, und Moskau zu erreichen beabsichtigte. In Razin. Dve Troicy verdeutlicht Chlebnikov diesen Gedanken, indem er von sich sagt, dab er im geographischen Sinne in die ungekehrte Richtung wie Razin sich bewegt (II,Bd.4,S.146).

Wie so oft bei Chlebnikov wird auch diese Metapher von der Bewegung in der umgekehrten Richtung dichterisch, auf der sprachlichen Ebene realisiert: der historische, geographische und moralische Gegensatz zwischen dem Dichter und seinem "negativen Doppelgänger" fuhrt zur Anwendung einer dichterischen Form, die sich auch "in die andere Richtung bewegt", nämlich zum Palindrom. Die Zeile "я Разин навиворог" ergibt nicht nur Hизарь als Hinweis auf den bei der Wolgamindung geborenen Dichter, sondern verweist auch auf die ein Jahr vor Truba-Gul' Mully (also 1920) als Palindrom geschriebene, über 500 Zeilen lange Dichtung Razin (I,Bd.1,S.202-215). In der zweiten Fassung dieser Dichtung, die sich im Besitz von A.Kručënych befand, trägt das Gedicht den Untertitel "Beschwörung durch den doppelten Strom der Rede, doppeltkonvexe Rede" ("Заклятье двонным течением речи, двояковыпуклая речь", I, Bd.1,S.318). So ergibt sich die Form der als Palindrom geschriebenen Dichtung Razin direkt aus dem inneren, inhaltlichen Gegensatz zwischen dem Dichter und dem von ihm besungenen Helden.

1 Diese Umkehrung der Bewegungsrichtung bei Chlebnikov sollte vor dem Hintergrund gesehen werden, daB die Persien-Züge Razins in der Folklore lebendig geblieben sind. So werden z.B. in manchen Volksliedern Razin und seine Genossen als "Perger" bezeichnet: "Kax не белье дебедочки содеталися/Как не ясные соколочки сопорхалися/Соходилися музурушки персидскне" oder:

"Соходились, собирались добры молодш/За славнне музурувки персидские" in: Pesni, sobrannye P.V. Kireevskim, VII.Ausg. (Moskau, 1868). 2itiert nach: I.S.Septaev, "Pesni razinskogo cikla i pesni o Ermaken, in: ocerki po istorii russkoj literatury, Leningradskij Gosudarstrenny j pedagogiceskij institut im. Gercena, učęnye zapiski (Leningrad, 1966) Bd.309,S.3-24;S.22. 
Damit nun sind die verschiedenen Bedeutungsbezüge der Gestalt Razins in der Dichtung Chlebnikovs nicht erschöpft. Der Name Razin - der eine konkrete historische Figur bezeichnet (Razin und die Geschichte seines Aufstandes), der als Ausgangspunkt für einen neuen Mythos (Wolga - Ra - Ra-zin) dient und der als morphologisches und moralisches Spiegelbild des Dichters (der "negative

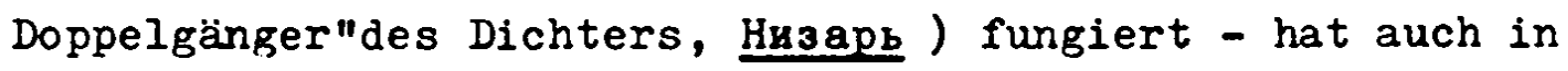
einem mathematischen Bezugsrahmen eine Bedeutung.

Die Erzählung Razin. Dve Troicy beginnt mit dem zunächst enigmatisch wirkenden Satz:" Нa ropдом уструге нет-единдшы плыть по душе Разина по широким волнам, будто по широкон реке...." (II,Bd.4,S.146). Aus dem Titel der Dichtung Ustrug Razina(I,Bd.1,S.246-251) und aus dem Kontext der Erzählung selbst können wir entnehmen, аa $B$ уструг нет-единищ mit уструг Разина identisch ist. Was bedeutet aber нет-единищв?

Razin ist, wie bereits gezeigt, der "negative Doppelgänger", die "Umkehrung", also das Spiegelbild des Dichters, die Umkehrung seines Ich als Person, als $E$ i n $z$ e $l$ n e r. Razin läßt sich zudem als ein eigenarti.zes Possessivum, als wort der Zugehörigkeit (Mask.Sg.), abgeleitet von pas im Sinne einer Quantitätsangabe beim Zählen ( "раз, два, три..." usw), verstehen. Da pas der Zahl один aquivalent ist, unà da Razin das "negative", "umgekehrte" Ich des Dichters ist, also eine negative Einheit bezeichnet, so bestätigt sich der Sinn der entschlüsseiung von уструг нет-единици als yструг Pазина.

Das in der Erzählung geschilderte symbolische Ereignis ist eine Reise des Dichters durch die Zeit mit dem Ziel, über die Jahrhunderte hinweg zu Razin, dem Vor-und Doppelgänger zu gelangen.

Jetzt können wir uns an die Deutung eines der schwierigsten Sätze der Erzählung machen: 
Не даром гогочут голмая "Сарннь на кичкуI", и Осн, корни из мнимон "нетп иа единищ русалок протягивартся к "да" единидам.

$$
\text { (II, Bd.4,S.146) }
$$

Die Hügel an den Wolga-Ufern tragen als Zeugen der ehemaligen Taten Razins seinen gefürchteten Räuberruf " Сарннь на кичку!" 1 durch die Jahrhunderte. Der Widerhall dieses Rufes schafft die überzeitliche Verbindung die Achsen ( $\underline{o c u}$ ) als geometrische Geraden, die zwei Punkte verbinden - zwischen dem Dichter ("да" единица ) und seinem "negativen Vorgänger" Razin ("нег" еднница ). Das Wort корни hat direkten Bezug zur geschilderten Situation: die Suche nach dem Vorgänger, Razin, ist auch die Suche nach den eigenen Wurzeln. AuBerdem hat das Wort корни eine unmittelbare mathematische Bedeutung. Chlebnikov, der Mathematikstudent, beschäftigte sich in seinen quasi-mathematischen, quasi-dichterischen Arbeiten mehrmals mit dem Problem der Quadratwurzel aus -1 . So in dem 1916 geschriebenen "Mysterium" Skuf'iz Sieifa:

Я знал, что $\sqrt{-1}$ нисколько не менее вещественно, чем $1 ;[\ldots .$.$] Пора научить людей$ извдекать вторичные корни нз себя и из отрицательных людей.

$$
(\mathrm{II}, \mathrm{Bd} .4, \mathrm{~S} .84)
$$

Die'Wurzel aus $-1 '$, eigentlich ein mathematisches Paradox, ist eine imaginäre Größe. So heiBt es in einem mathematischen Buch:

Das Wort 'imaginär' ist zuerst von Descartes gebraucht worden:'Die Wurzeln einer Gleichung sind nicht immer reell, sondern manchmal blOB eingebildet (seulement imaginaires) [...] Eine Größe heift imaginär, wenn sie weder prößer als Null, noch kleiner als Null,

1 Siehe Anmerkungen Stepanovs in: V.Chlebnikov, Stichotvorenija i poémy , a.a.0., S. 384 . 

noch gleich Null, ist. Das ist etwas Unmögliches
wie $2 . \mathrm{B} \cdot \sqrt{-1} \cdot{ }_{1}$

Nach dem ersten Buchstaben dieses Wortes "imaginär" wird die 'eingebildete Quadratwurzel aus -1 ' mit "in bezeichnet. 2

Chlebnikov, der, soweit bekannt, als erster nach Lewis Carroll (1832-1898), 3 dem englischen liathematikprofessor und Verfasser von "Alice in Wonderland", die liathematik $\mathrm{zu}$ einem integrierten Bestandteil seiner Dichtung machte, befabte sich immer wieder mit der Idee der imaginären Größe, der $\sqrt{-1}$. So in der Erzählung $\mathrm{Ka}^{2}$ (Iies: Ka-Quadirat):

А вы знаете, что природа чисед та, что там, где есть да чисда и нет чнсда (подогитедьные и отрицатедьные) судества, там есть и мнимые $\sqrt{-1}$ ? Вот почему в настониив хотед увидеть $\sqrt{-1}$ из человекв и единицу, делимую на человека. И его дицо пресдедовало меня вспду в туме удид. 4

$$
\text { (III, S. 127) }
$$

1 H.Gericke, Geschichte des Zahlbegriffs (Nannheim/Wien/ Zürich, $19707,5.66$.

2 Siehe: "мицмая единица," числоі, квадрат которого равен отрицатедьно единице; таким обрвзом, $i=\sqrt{-1}$. In: Enciklopedičeskij slovar', 2 Bde. (lioskau, 1964), Bd.2, S. 40.

3 Siehe Bibliographie der Werke von Lewis Carroll in: The Annotated AIice, M. Gardner Hrsg. (Harmondsworth, T972),5.347-349.

4 Im Rahmen dieser Arbeit ist es wichtig darauf hinzuweisen, daB das hier thematisierte Motiv des unsichtbaren Doppelgängers im Zusammenhang mit der altägyptischen Mythologie zu sehen ist, wie aus dem Titel der Erzählung Ka2 hervorgeht. Siehe M. Lurker, a.a.0.,S.96:"Als eine Art Doppelgänger begleitet der $\mathrm{Ka}$ den Mienschen; stirbt dieser, lebt der $\mathrm{Ka}$ weiter." In der ein Jahr vor $\mathrm{Ka}^{2}$ (also 1915) geschriebenen Frzählung Ka (II,Bd.4, S.47-69) verarbeitet Chlebnikov diesen Mythos und geht auf die Bedeutung des $\mathrm{Ka}$ im alten Ägypten ein: "Ich hatte einen $\mathrm{Ka}$... Ka ist der Schatten der Seele, ihr Doppelgänger." (ebenda, S.47). 
Die spätere Erzählung $\underline{\mathrm{Ka}}^{2}$ gibt auch Aufschluß über die Frage der ambivalenten Bedeutung der "Negativität" einer Person, wie sie in unserem Fall in der Gestalt Razins behandelt wird, sowie uber die Bedeutung der Quadratwurzel aus -1 . "Negation" ist eine "geliebte, erwartete, aber abwesende Person"(ebenda). Mit anderen Worten, "negativ" ist auch ein verstorbener Mensch, "negativ" in dem Sinne, dab es ihn als Einheit, als Individuum nicht mehr gibt, d.h. er gleicht -1 . Die Quadratwurzel aus -1 wird dagegen als"fremd" und "feindselig" bezeichnet:

Впрочем, скоро я понял, что если любимый, охидаемьһ, но отсутствующи человек отрицательное существо, то кахдое врахдебное постороннее собранио (не присутствуошее в нем) будет $\sqrt{-1}$, судеством мнимым.

(ebenda)

Vienn wir diesen Schlüssel aus der Erzählung $\underline{\mathrm{Ka}}^{2}$ auf den auf Seite 95 angefuhrten schwierigen Satz aus der Brzählung Razin. Dve Proicy anwenden, so ergibt sich, dak die Hassernymphen - die imaginären, mythologischen ieser. ("оси, корни из мнимо "нет" из единицы русалок"), :elche nach den "Plus-Einheiten" greifen, also nach den leberdigen Wenscher, die im Boot über die Wolga fainren "fremde, der Versammlung nicht angehörende", scheinhafte Wesen sind.

Durch die Wassernymphen, die nach den im Boot sitzenden Menschen greifen, wird eine assoziative Verbindung zur Geschichte des Odysseus und den verderblichen Sirenen geschaffen. (Chlebnitor hat sich, wie bereits gezeigt, intensiv mit Homer beschäftigt). In unserem Kontext aber ist es eine Odyssee, die rückwärts durch die Zeiten zu Stepan Razin führt:

[...] до истоков хизни молодого донца в Соловках, перерезавшего поперек вск Россию, чтобь подслушать северные речи, увидеть очи северного бога, бога севера.

$$
\text { (II, Bd.4,S.146) }
$$


Die aus dem Wasser nach dem Boot greifenden Nymphen, -die"fremden Wesen", werden daher in die Nähe der von Razin in der Wolga ertränkten persischen Prinzessin gerückt, ein Motiv, das Chlebnikov äuberst stark beschäftigt hat. So auch in Truba Gul'-Mully:" Разин деву/В воде утопил" (I,Bd.1,S.235) oder in der frühen Dichtung Chadzi-Tarchan:"Чу! Слышен плач, и стан княхны/На руках гнется лиходея" (I,Bd.1,S.119). In der

Dichtung Nočnoj obysk ertönt das berühmte Sten'ka Razin Lied Iz-za ostrova na strežen' ( I, Bd.1,S.267), in dem besungen wird, wie Razin die Prinzessin ertränkt hat; das gleiche liotiv finden wir auch im Gedicht Ja videl junošu proroka (II,Bd.3,S.305); der Tod der Perserin in den Fluten der Wolga bildet auch den Höhepunkt der Dichtung Ustrug Razina (I,Bd.1,S.246-251).

Selbstverständlich kann man die Frage stellen, ob sich der Aufwand, mit dem die Entschlüsselung eines einzigen Satzes verbunden ist, liberhaupt lohnt. Die Frage nuL jedoch in zweifacher Hinsicht positiv beantwortet werden: einmal hilft uns die hier vorgenommene entschlüsselungsarbeit, eine bestimmte Dimension in der dichterischen Jehandlung der Gestalt Razins, eines der wichtigsten Hotive der Dichtung Chlebnikovs, zu erkennen. Zum anderer. sind solche oder ähnliche, manchmal noch kompliziertere Verfahren unumgänglich in der Behandlung einer besonders "dunklen" Stelle in einem Gedicht, das an sich weder mit der "metalogischen Sprache" ( noch mit seiner kabbalistischen Zahlenmystik viel zu tun hat.

Ein gutes Beispiel für eine äuberst komplizierte Verschluisselung der Gestalt Razins bietet die späte Dichtung Ladomir, von der V.liarkov sagt:"A commentator would have the time of his life finding sources for the many images Khlebnikov used in this poem." 1

1 larkov, The Longer Poems of Velimir Chlebnikov, a.a.0., S.146. 
Der im folgenden zitierte Abschnitt aus Ladomir bildet m.E. eine relativ in sich abgeschlossene Einheit, aus der sich die Zeilen 9 bis 16, auf die es in unserem Vorhaben ankommt, nicht ohne weiteres herauslösen lassen. Deshalb das ganze Zitat:

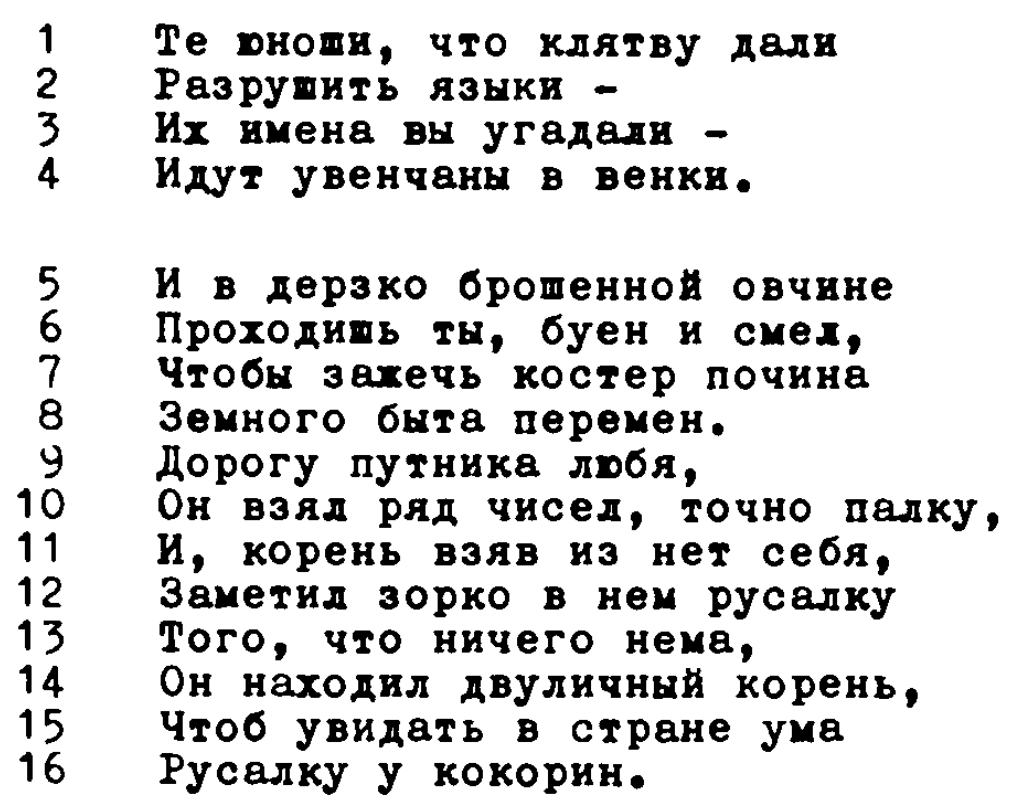

$$
(I, B d .1, S .193 f)
$$

Die anhand der Erzählung Razin. Dve Troicy und anderen Gedichten geleistete Vorarbeit erlaubt es uns, zu dem Schiur. zu kommen, daB es sich in diesem Abschnitt aus Ladonir um ein stark verschlüsseltes Razin-Notiv handelt, und zwar viederum um Razin als den "negativen Vorgänger" des Dichters.

Die "Jünglinge, die geschworen haben, die Sprachen zu zerstören" (Zeile 1 - 4) sind natürlich die Dichter, die selbsternannten "Vorsitzenden des Erdballs".

Das frech über die Schulter geworfene Schaffell (Zeile 5) ist ein Attribut Razins. ${ }^{1}$ So wird es 2. . $_{\text {. in }}$ der Dichtung Ustrue Razina dreimal erwähnt (zweimal direkt

1 Das heißt nicht, daß hier nicht auch auf Johannes den Tëufer angespielt wird (der meistens im Fellkleid dargestellt ist - ein bekanntes ikonographisches lotiv): im Gegenteil, die meisten der von Chlebnikov verwendeten Bilder gewinnen ihre Tiefe und mehrschichtige Bedeutung gerade durch die Synthese gänzlich heterogener Ellemente. 
und einmal metaphorisch):

На голове его овца

$\ddot{3} \ddot{a}$ шляпо белого овечьего руна

Скрнвался взгляд головореза

- ․

Волги синяя овчина

На плечах богатнря

$$
(I, B d .1, S .247)
$$

Die Zeilen 10 - 16 enthalten, wie oft bei Chlebnikov, ironisierte Anspielungen auf seine durchaus ernste Beschäftigung mit Zahlen. Die Zeilen $10-11$, wie am Beispiel der Erzühlung Razin (siene S.91ff) gezeigt, sind die Widerspiegelung des Dichters in seinem "negativen" ( нет ceбя ), also nicht mehr vorhandenen Vorgänger Stepan Razin. $\mathrm{OH}_{\mathrm{H}}$ ist der Dicinter, der sich mit Zailen beschaftigt und sie als lunderstab für seine Nanderung, durch die Zeit benutzt, während нeт ceof , wie gesapt, mit dem aus Razin.Dve Troicy bekannten нет-единица icientisch ist.

Die "Iurzel zus minus Ich", die in der genannten Jro:jlun jeine "inaginäre" Gröle und in der Erzählung $\mathrm{Ka}^{2}$ eir "fremdes, der Versammlunr, nicint anrehörendes iesen" (siehe S.97) bedeutet, taucht erwartunjs semád zuch in Iadomir auf. Ver fleichen wir die Zeilen $11-12$ nit der entsorechencien Stelle zus Rain.je iroicy: inier:" И, корень взяв из нет себя,/Заметил зорко в нем русалку"; dort: "...корни из мнимон 'нет' из единицы русалок протягивакотся к 'да' единицам." (S. S5). Indem die Wassernymphe die 'ivrzel von -1 ' ist, ist sie zugleich die ifurzel, die aus kazin, dem "I:inus-Dichter", gezogen yird. Auf diese Veise :ann man in der Gestalt der Wassernymphe die verwandelte Prinzessin wiedererkennen, die lazin in aer violga ertränit hat. Die Perserin ist die 
"Premde", die Razin sich sozusagen aus dem Herzen riB (wie man eine Wurzel 'zieht'), weil sie nicht "zur Versammlung" der Razin-Gefährten gehörte. Auf ihre Fremdartigkeit weisen die Kampfgenossen Razins in Ustrug Razina hin, indem sie ihn auffordern, die Prinzessin zu ertränken, die sie abschätzig eine "geräucherte Göre"

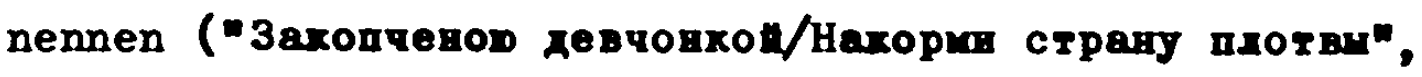
I,Bd.1,S.249), womit hier auf die sonnengebräunte Haut der Perserin angespielt wird.

Die Zeilen 11 - 12 des angefuhrten Abschnittes aus Ladomir sind eine eigenartige Aufforderung des Dichters an den Ieser, scharfblickend (sopxo ) hinzuschauen, um hinter die Bedeutung des enigmatischen Bildes zu komen. (Bs ist eigentlich die zweite Einladung zum Rätselspiel im zitierten Abschnitt; die erste ist in der 3. Zeile enthalten). Die Nixe oder Wassernymphe wird vom Dichter und vom aufmerksamen Beobachter - in der'Wurzel aus -1 ', also in der "ivurzel aus Razin" entdeckt.

Es ist interessant, der Frage nachzugehen, auf welche Weise der Dichter darauf kommt, in $\sqrt{-1}$ eine Nymphe zu entdecken. Das Wort 3opko legt es nahe, die Antwort im visuellen Bereich zu suchen. $\sqrt{-1}$ ist wie gezeigt (siehe S.96) "in. Auf die Gefahr des Vorwurfs einer uberinterpretation hin (obwohl in Bezug auf die Dichtung Chlebnikovs meistens die entgegengesetzte Gefahr, nämlich die einer ungenügend differenzierten Interpretation besteht) würden wir hier die Annahne wagen, daB die eigentliche Anspielung in den Zeilen $11-12$ sich direkt auf das visuelle Bild, àlso auf das graphische Zeichen der "imaginären GröBe" "i" etwa in handschriftlicher Reprasentation bezieht ( $i$ ). Gemeint ist damit wohl die Wiedergabe der Wölbung des Nymphenkörpers und ihres Kopfes durch das ihr im System der dichterischen Symbole Chlebnikovs zugeteilte Zeichen. Das "i" als mathematisches Zeichen fuir $\sqrt{-1}$, stellvertretend für 'imaginar', ist 
mit anderen Worten eine Art schematischer Zeichnung einer Wassermymphe, einer 'imaginären' Frau. ${ }^{1}$ Derartige Wortzeichen (Ideogramme), die ein bestimmtes Wort wiedergeben "ohne Ruicksicht auf seinen Lautbestand", kennen wir aus den altägyptischen Hieroglyphen, wo z.B. ein Rechteck mit einer öffnung 'Haus' bedeutet, zwei Beine 'gehen' u. ̈̈.ó Dab Chlebnikov mit seiner Neigung zur "Zerlegung des Wortes" in den einzelnen Buchstaben ideogrammatische Zeichen sah, ergibt sich aus mehreren seiner theoretischen Schriften. 3

Aufgrund der vorangegangenen Hypothesen stellen wir ferner fest, daB die Zeilen 13 - 16 unseres Abschnittes aus Ladomir eine Variation auf den Inhalt der Zeilen 10 - 12 darstellen. Zeile 13 mit der ironisierenden Verwendung des Ukrainismus немa für нет (möglicherweise eine Anspielung auf die Sprache des Don-Kosaken Razin) druickt die abwesende Person $(-1$, also Razin) aus. двуличнын корень in der Zeile 14 ist eine deutlicine Anspielung auf die Quadratwurzel aus -1; im 'Land der Zukunft' ( страна yмa ) wird sich die von Razin in die :iolga geworfene persische Prinzessin in der Gestalt der am versunkenen Baum ( кокорина ) sitzenden Wassernymphe wiederfinden, was an das bereits behandelte lotiv der

1 Es ist wohl interessant darauf hinzuweisen, da $B$ das gleiche Motiv, die Quadratwurzel aus -1, eine wichtige Rolle in der Gegenutopie von Evgenij Zamjatin liy spielt (das Werk wurde 1920 begonnen). Siehe z.B. das Kapitel Irracional 'nyj koren' :" Не хочу $\sqrt{-1}$ ! Выньте из из меня $\sqrt{-1}$ ! Этот иррациональнын корень врос в меня, как что-то чухое, инородное, страшное, он похирал меня его недьзя било осмислить, обезвредить, потому что он был внe ratio." In: E.Zamjatin, liv (New York, 1967) S.37. lian beachte die ïhnlichkeit, die hier das lotiv der 'Wurzel aus -1 ' als Symbol fuir etwas Fremciartiges (yyzoe, инородное ) mit dem hat, was Chlebnikov in der Erzahlung lia ${ }^{2}$ ủber die gleiche 'imaginäre Größd(III,S.127) schreibt. In liy heiBt die Frau, in die sich der Held verliebt, ebenfalls "I" und ist auf das engste mit dem Kotiv der' Wurzel aus -1 ' verbunden. $O b$ man in diesem Punkt von einer Beeinflussung Zamjatins durch Chleonikov sprechen liann, muß dahingestellt bleiben.

2 Lurker, a,a.0., S.81,f.

3 Siehe z.B. die Artikel Razloženie slova, O prostych imenach jazyka, Azbuka Uma (III, S. 138-205) 
Reinkarnation und der Auferstehung der Toten anknüpft. Sicherlich erinnern die hier angeführten kombinatorischen Techniken an kabbalistische Textentschlüsselung (und oft wird bei Chlebnikov das Anagram zum Kalauer), aber dennoch darf behauptet werden, daB auf diese Weise ein Zugang $z u$ manchen (glücklicherweise nicht den wichtigsten) Bereichen des Werkes von Chlebnikov eröffnet wird, die sonst im Dunklen bleiben würden. Soweit bekannt, ist bisher eine Arbeit, die in diese Richtung ginge, noch nicht unternommen worden.

Das gleiche gilt auch für eine umfassende Untersuchung der Frage, inwiefern die von Chlebnikov geforderte direkte Entsprechung zwischen Klang und Inhalt eines Wortes, wobei der Anfangskonsonant als Hauptelement fungiert ${ }^{1}$, in seinem dichterischen Werk tatsächlich verwirklicht ist.

Im Rahmen dieses Kapitels uber Stepan Razin läßt sich zumindest feststellen, daß die Bedeutung, die Chlebnikov in seinen theoretischen Ausführungen mit dem Anfangskonsonanten ' $R$ ' verbindet, mit seiner Auffassung der Gestalt Razins durchaus korrespondieren. So in dem Artikel O prostych imenach jazyka (erschienen 1916): "P присуme разрушение преград" (III,S.205) und in Caranina po nebu: "Pa свинца" (II,Bd.3,S.85). In der "Superdichtung" Zangezi werden für die signifikative Funktion des Klanges ' $R$ ' zum Teil die gleichen Prädikate gebraucht wie in Razin. Dve Troicy: "Эp - точка, прорезавшөя, просекшвя поперечную плодадь. Эр - реет, рвет, рассекает преградн..." (II,Bd.3,S.325 " Op, Pa, Po! Tpa-pa-pa!/Грохот охоты, хохот вонин" ( еbenda, $S$ 326). "Эр - точка, просекшая насквозь поперечную площадь" (еbenda, S.332). Vgl. mit Razin : "[...јдо истоков хизни молодого донца в Соловках, перерезавшего поперек всо Россир"(II, Bd.4,S.146).

1 Siehe z.B. die Abhandlung Razloženie slova (III S.198202) Das gleiche Thema wird In einem Briel an Aleksej Zrucénjch (16.X.1913) behandelt (III, S.3011). 
Abschließend zum Thema Stepan Razin, der, wie gezeigt wurde, die östliche Komponente in der idealen Gestalt des neuen Menschen verkörpert, sollen noch einmal sämtliche Aspekte der Behandlung dieses Motivs in der Dichtung Chlebnikovs zusammenfassend dargelegt werden:

I. Historischer Bezug. Vordergründig: Stepan Razin als Anfiuhrer des großen Bauernaufstandes von 1670-71.

II. Etymologischer Aspekt. Razin als der Mann, der am Fluß Ra (Bezeichnung der Wolga bei Ptolemäus) wirkte. Razin als eine Art Possessivum von Ra.

III. Mythologischer Aspekt. An den etymologischen Aspekt anknüpfend und ihm direkt entspringend: Ra-zin, der "Mann von der Wolga", deren alte Bezeichnung $\mathrm{Ra}$ als

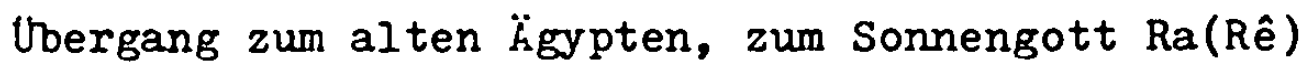
dient, ist dadurch ein Mann vom "afrikanischen Fluß" (Anspielung auf den Nil), ein Orientale.

IV. Morphologischer Aspekt. Der Dichter als der "umgekehrte" PazuH ergibt Huзapbl (am unteren Lauf der Wolga geboren). Auf diese Weise entsteht die innere Motivierung zur Abfassung der Dichtung Razin als Palindrom, in der Form des "rückwärts laufenden" Verses.

V. Nathematischer Aspekt. An den morphologischen Aspekt anknüpfend: Razin als der "negative", d.h. nicht mehr vorhandene Vor- und Doppelgänger des IchDichters, also "Minus-Ich" oder "-1". Paz wird hier als Synonym für 엽 betrachtet.

VI. Ideogrammatischer oder graphischer Aspekt. An den mathematischen Aspekt anknupfend: die "Quadratwurzel aus -1"(Razin), die "imaginäre GröBe" $\underline{i}$ als schematische Zeichnung der Wassernymphe, in die sich die von Razin in die Wolga geworfene persische Prinzessin verwandelt. 
VII. Signifikative Funktion des Klanges ' $R$ '.

Entsprechung zwischen den E1genschaften der Gestalt Razins als ungestümer Zerstörer aller Hindernisse einerseits, und den Inhalten, die der Dichter in seiner 'Sprachtheorle' mit dem Anfangskonsonanten des Namens Razin verbindet.

Die oblge Zusammenstellung zeigt in rerklirzter Form die komplexe Verwendung und Abwandlung elnes elnzigen Mot1ves, des Razin-Motivs, in der Dichtung Chlebnikovs. Dabel wurde versucht, die Vielfalt und Mehrschichtigke1t der Bezíge und Bedeutungsebenen moglichst erschbpfend zu erfassen, um anhand eines Belspieles e $x$ m $\mathrm{pla} r \mathrm{~s}_{\mathrm{c}} \mathrm{h}$ das Denken und die poetologlschen Verfahrensweisen Chlebnikovo (also z.B. das Denken mit Hilfe 'kodierter Axlome', die 'Zerlegung des Wortes' und die Vielschichtigkeit der Metaphern und Ansplelungen) darzulegen.

Es 1st anzunehmen, daB die hier erarbeiteten methodischen Ansätze eine über das behandelte Motiv hinausgehende Gultigkeit besitzen und einen zugang zu weiteren Bereichen des Werkes Chlebnikovs (z.B. In Hinblick auf die 'Ideogramme', den 'signifikativen Klang', die 'Poetisierung des Zeichens' und die 'Mythologisierung des Wortes') erbffnen. 


\section{SchluBwort}

Die vorliegende Arbeit befaßte sich mit verschiedenen Aspekten der orientalischen Thematik im Werke Chlebnikovs. Wie schon zu Anfang dargelegt, spielt das Thema des Orients in der russischen Literatur eine recht bedeutende Rolle. Vom Ansatz dieser Arbeit her ist es nun nur in sehr beschränktem laße möglich zu bestimmen, welchen Ort das Werk Chlebnikovs hinsichtlich dieses Themenbereiches innerhalb der Geschichte der russischen Literatur einnimmt und welche Impulse hier von seinem Werk ausgehen. Wie in der Einleitung schon angedeutet wurde, läbt sich aber feststellen, dab dieses Thema im Schaffen Chlebnikovs eine sehr viel tiefgehendere und bedeutsamere Ausprägung erfährt als bei den anderen Dichtern seiner Epoche. Man kann sogar soweit gehen zu sagen, daB Chlebnikov in dieser Hinsicht iberhaupt nur einen Vorgänger hat, bei dem die Behandlung des Themas iber die traditionelle 'Exotik' und die ornamentale Verwendung orientalischer Embleme hinausreicht, nänlich A.Puskkin. So schreibt Prof. I.Braginskij:

Puškin hat bekanntlich keinen eigenen 'West-östlichen Divan' geschaffen, doch bei einer eingehenden Analyse seiner Lyrik läßt sich feststellen, daß in dieser Lyrik ganze Gedichtzyklen zu finden sind, die das Zeichen einer west-östlichen literarischen Synthese tragen.1

Dasselbe läßt sich weitgehend auch für das Schaffen Chlebnikors feststellen, ohne daB er mit Puškin (oder Goethe) dadurch auf eine Stufe gestellt werden soll.

Wahrend die Beschäftigung Goethes bew.Puškins mit dem Thema des Orients in der Hauptsache wohl eher als Ausdruck inrer Aufgeschlossenheit und Offenheit für Einflüsse auch aus den entlegensten Kulturen zu sehen ist, geht es Chlebnikov um sehr viel mehr als um eine "west-östliche literarische Synthese."

1 I.Braginskij,"Zametki o zapadno-vostočnom sinteze $\mathrm{V}$ lirike Puskinan, In: Narody Azii i Afriki, IV(1965), S.117-126;S.123. 
Bei Chlebnikor wird die Aufgabe der Neudefinition einer ganzen im Umbruch begriffenen Kultur in Angriff genommen, wie sie sich für ihn in einer Zeit stellte, da die Zwischenposition RuBlands zwischen Europa und Asien nach neuen Antworten auf die frage des Selbstverständnisses dieses Landes suchte.

Wie in dem Kapitel uber das Notiv der Vergeltung im Schaffen Chlebnikovs dargelegt wurde, steht sein Verhältnis zum Orient innerhalb des Spannungsfeldes der russischasiatischen Beziehungen. Dabei wird eine doppelte Tendenz sichtbar, nämlich einerseits die Anerkennung einer Wesensverwandtschaft, andererseits die traditionelle Feindschaft zwischen den Russen und ihren asiatischen Nachbarn.

Aus diesem Grunde ist das Orient-Thema im Werke Chlebnikovs auch in seinen politisch-visionären Bezügen von groler Bedeutung. Die orientalisch-asiatische Vision ist Rückbesinnung, Erinnerung an die großen Kriege und Ahnung kïnftiger Erschütterungen zugleich.

Um Chlebnikov selbst zu zitieren:

В багровых струях лицо монгодьского Востока, Сдавянскою волнуяся чертои, Стоит могуче и жестоко, Как образ новын, время, твон!

$$
(I, B d .1, S .177)
$$


Literaturverzeichnis

Werkausgagaben

Chlebnikov, V.: Sobranfe soćinent, 4 Bde., Hrsg. D. Tschižewskij (Munchen, 1968-1972).

Chlebnikov, V.: Stichotvorenlfa 1 poeimy, Hrsg. N.Stepancr (Leningrad, 1960).

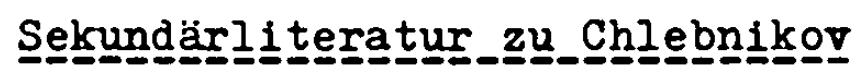

Baran, H.: "Chlebnikov's Poem 'Bech'", in: Russian Literature, VI(1974), S.5-19.

Berezark, I.: "Vstrec̆i s Chlebnikovym", in: Zvezda, XII(1965), S.173-176.

Erymovskij, K.: "Pevec Lebedi1", in: Legenda o lotose

(Ėista, 1969), S.151-188.

Gofman, V.: "Jazykovoe novatorstro Chlebnikova", in:

Zvezda, VI(1935), S.209-236.

Gumilev, N.: "Stat'i 1 zametki o russkof poèzil", Kap.XXXI,

in: Sobranle socinenif vètyrech tomach, Hrsg.

G.Struve und B.Filippov (Washington, 1962-1968),

Bd.4, S.319-333.

Ivanov, Vjač.Vs.: "Struktura stichotvorenija Chlebnikova

'Menja pronosjat na slonovych...'n', in: Teksty

sovetskogo literaturovedčeskogo struktural1zma, hirsg.

K.Eimermacher (München, 1971), S.378-393.

Jakobson, R.: Novejsaja Russkaja Poejifa, Nabrosok I:

V.Chlebnikov (Prag, 1921).

Kosterin, A.:"Russkie dervisin, in: Moskva, IX(1966),

S.216-221

Loščic, Ju. und Turbin, V.: "Tema Vostoka $v$ trorčestve

V.Chlebnikova", in: Narody Azil i Afrik1, IV(1966),

S.147-160. 
Machalski, F.: Ohne Titel (Besprechung des Artikels von V.P.Nikitin, "Ein russischer Derwisch in Persien", in der persischen Zeitschrift Jaghma (Teheran, 1955),

in: Przegląd Orientalistyczny, IV(1956), S.15. Mandel 'štam, 0.: "Burja 1 natisk", in: Sobranie sočinenij,

3 Bde., Hrsg. G.Struve und B.Filippor (Washington, 1964-1969), Bd.2, S.390.

Markov, V.: "O Chlebnikove" (Popytka apologil 1 soprotivlenija), in: Grani, XXII(1954), S.125-145.

Markov, V.: The Longer Poems of Velimir Khlebnikov

(Berkeley/Los Angeles, 1962).

Mirskij(Svjatopolk), D.: "Godovšciny. Chlebnikor", in:

Vërsty, III(1928), S.144-146.

Parnis, A.:"V.Chlebnikov $v$ revoljucionnom Giljanen, in:

Narody Azii 1 Afriki, $V(1967)$, S.156-164.

Pavlorskij, A.: "Iz perepiski N.A.Zabolockogo s K. $\dot{E}$. Ciol-

kovskim", in: Den' Poezil (Leningrad, 1964), 227-232. Samorodova, O.: "Poèt na Kavkaze", in: Zvezda, VI(1972),

S.186-194.

Scholz, F.: "Die Anfänge des russischen Futurismus in sprachwissenschaftlicher Sicht", in: Poetica, Bd.2, H.4 (Okt.1968), S.477-500.

Tynjanov, Ju.: "O Chlebnikove", in: Archaisty i novatory,

Nachdruck der Leningrader Ausgabe von 1929 (München, 1967).

Zelinskij, K.: "Na velikom rubeže (1917-1920). Derviš russkof poèziin, in: Znamja, XII(1957), S.148-152.

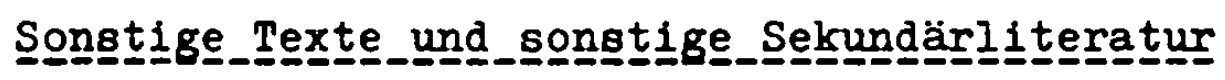

Blok, A.: Sobranie sočineni j v vos'mi tomach, V.Orlov, Hrsg. (Moskau/Ieningrad, 1960-1963).

Braginskij, I.: "Zametki o zapadno-vostočnom sinteze $v$ lirike Puskinan, in: Narody Azi1 i Afriki, IV(1965), S.117-126. 
Brooks, C.: The Well Wrought Urn (New York, 1966).

Bunting, R.-D. : Einfuhrung in die Linguistik (Frankfurt, 1972).

Chruslov, V.: "Japonskie slova $\nabla$ russkom jazyke", in:

Russkaja rec'', III(1971), S.124-130.

El lade, M.: Das Heilige und das Profane (Hamburg, 1957).

Fëdorov, N.: "o Turkestane", in: Vërsty, III(1928), S.278288.

Gardner, M. (Hrsg.): The Annotated Alice (Harmondsworth, 1972). Gericke, H.: Geschichte des Zahlbegriffs (Mannheim/Wien/ Zürich, 1970).

Haas, W.: Östliches und Westliches Denken (Reinbek bei Hamburg, 1967).

Heftrich, E.: Novalis. Vom Logos der Poesie (Frankfurt, 1969). Hofstätter, H.: Jugendst1l (Baden-Baden, 1973).

Homer.: Odyssee, thers. J.H. Voss (Stuttgart, 1970). Jung, C.G.: Symbole der Wandlung, Gesammelte Werke, 5. Band, (Olten und Freiburg im Breisgau, 1973).

Kerény 1, K.: Prometheus (Reinbek bei Hamburg, 1962). Kerény 1, K.: Töchter der Sonne (Zürich, 1944).

Lévi-Strauss, C.: "Die Struktur der Mythen" in: Strukturalismus in der Literaturwissenschaft, Hrsg. H. Blumensath (Köln, 1972), S.25-46.

Lo Gatto, E.: "Panmongolizmo di V. Solov'ëv, I Venienti Unni di v. Brjusor e Gli Sciti di A. Blokn, in: Hrsg. M. Halle, For Roman Jakobson. Essays on the occasion of his sixtieth birthday (Den Haag, 1956), S.295-300.

Iotman, Ju.: "O modelirujušcem znac̉enii ponjatij 'konca' 1 'naçala' $\nabla$ chudožestrennych tekstach", in: Teksty sovetskogo l1teraturovedceskogo strukturalizma, Hrsg. K. Eimermacher (Minchen, 1971), S.307-312.

Lotman, Ju.: "Tezisy $k$ probleme 'Iskusstro $\nabla$ rjadu model1rujuščich sistem'", ebenda, S.352-367.

Lotman, Ju. und Pjatigorskij, A.: "Tekst 1 funkcija", ebenda, S.483-497. 
Novalis,: Werke, Hrsg.G. Schulz (Munchen, 1969). Platon,: Sämtliche Werke, Hrsg.E. Grassi, 6 Bde.(Leck, 1959). Puškin, A.: Sočinenija $\nabla$ trēch tomach (Moskau, 1962).

Reiss, H.: Politisches Denken in der Deutschen Romantik (Bern, 1966).

Schlegel, Fr.: "Fragmente", In: Athenaeum, Hrsg. A.W. und Fr. Schlegel, Ba.I, 2. (Berlin, 1798. Nachdruck:

Darmstadt, 1970). S.178-322.

Septaer, I.: "Pesni razinskogo cikla 1 pesni o Ermake", in: očerki po istoril russkoj literatury. Leningradskij Gosudarstrennyj pedagogičeskij institut imeni A.I. Gercena, Uc̈ënye zapiski, Bd.309 (Leningrad, 1966), S.3-24.

Solov'ëv, V.: Tri razgovora (New York, 1954).

Tschižewskif, D.: Russische Gelstesgeschichte II. Zwischen

Ost und West, 2 Bde.(Reinbek bel Hamburg, 1961). Wellek, R.: "Romanticism Re-examined", in: Romanticism Reconsindered, Hrsg. N. Frye (New York/London, 1963), S.107-133.

Zamjatin, E.: My (New York, 1967).

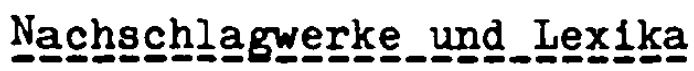

Andreevskij, I. und Arsen'ev, K.(Hrsg.): Enciklopediceskij slovar' Brokgauz 1 Efron, 82 Bde. (Petersburg, 18901904).

Brockhaus, E. (Hrsg.): Der Große Brockhaus, 12 Bde. (Wiesbaden, 1953-195716).

Cernov, M. (Hrsg.): Slovar' morskich 1 recinych terminov, 2 Bde, (Moskau, 1955-1956).

Dal', V.: Tolkovyl slovar' żivogo Velikorusskogo jazyka,

4 Bde.(Moskau/Petersburg, 19033).

Frazer, J.: The Golden Bough (London/Toronto, 1967). 
Gitterman, V.: Geschichte RuBlands, 3 Bde.(Hamburg, 1949). Hunger, H.: Lexikon der griechischen und römischen

Mrthologie (Reinbek bei Hamburg, 1974).

Lunačarskif, A. und Friče, V.(Hrsg.): Literaturnaja énciklopedija, 11 Bde. (Moskau, 1929-1938).

Lurker, M.: Götter und Symbole der alten Ägypter (München, 1974).

Riasanovsky, N.: A History of Russia (New York, 1963).

Rose, H.: A Handbook of Greek thology, including its extension to Rome (London/New York, 1965).

Shipley, J.: Dictionary of World Literature (Totowa, 1966). Vasmer, M.: Russisches Etymologisches Wörterbuch, 3 Bde. (Heidelberg, 1953).

Vinogradov, V.(Hrsg.): Slovar' jazyka Puškina, 4 Bde. (Moskau, 1956-1961).

Vvedenskif, V.(Hrsg.): Enciklopediceskij slovar'v drach tomach (Moskau, 1963). 


\section{SLAVISTISCHE BEITR A GE}

Verzeichnis der bisher erschienenen Bände

1. Maurer,J.: Das Plusquamperfektum im Polnischen. 1960, 64 S. - 2. Kadach,D.: Die Anfänge der Literaturtheorie bei den Serben. 1960, V, 182 S. - 3. Moskalik,M.: Janka Kupala, der Sänger des weibruthenischen Volkstums. 1961, $241 \mathrm{~S}$. - 4. Pleyer,V.: Das russische Altgläubigentum. 1961, 194 S. - 5. Mihailovíc,M.: Tempus und Aspekt im serbokroatischen Präsens. 1962, VIII, 64 S. - 6. Rösel,H.: Aus Vatroslav Jagićs Briefwechsel. 1962, $75 \mathrm{~S}$. - 7. Schmidt,A.: Valerij Brjusovs Beitrag zur Literaturtheorie. 1963, 159 S. - 8. Minde,R.: Ivo Andríc. 1962, 198 S. - 9. Panzer,B.: Die Funktion des Verbalaspekts im Praesens historicum des Russischen. 1963, $106 \mathrm{~S}$. - 10. Mrosik,J.: Das polnische Bauerntum im Werk Eliza Orzeszkowas. 1963, 211 S. - 11. Felber,R.: Vojislav Ilić. 1965, 271 S. - 12. Augustaitis,D.: Das litauische Phonationssystem. 1964,155 S. - 12a. Auras,C.: Sergej Esenin. 1965, 211 S. - 13. Koschmieder-Schmid,K.: Vergleichende griechisch-slavische Aspektstudien. 1967, $196 \mathrm{~S}$. - 14. Klum, E.: Natur, Kunst und Liebe in der Philosophie Vladimir Solov'evs. 1965, $333 \mathrm{~S}$. - 15. Albrecht, E.: Das Turkenbild in der ragusanisch-dalmatinischen Literatur des XVI. Jahrhunderts. 1965, 256 S. - 16. Gesemann,W.: Die Romankunst Ivan Vazovs. 1966, $131 \mathrm{~S}$. 17. Perí̌ić,D.: Goethe bei den Serben. 1968, 304 S. - 18. Mares,F.V.: Die Entstehung des slavischen phonologischen Systems und seine Entwicklung bis zum Ende der Periode der slavischen Spracheinheit. 1965, $87 \mathrm{~S}$. - 19. Holzheid,S.: Die Nominalkomposita in der Iliasübersetzung von $N$. I. Gnedic. 1969, 92 S. - 20. Chmielewski,H.: Aleksandr Bestuzev-Marlinskij. 1966, 134 S. - 21. Schaller,H.W.: Die Wortstellung im Russischen. 1966,389 S. - 22. Hielscher,K.: A. S. Puskins Versepik. 1966, 169 S. - 23. Küppers,B.: Die Theorie vom Typischen in der Literatur. 1966,354 S. - 24. Hahl-Koch,J.: Marianne Werefkin und der russische Symbolismus. 1967, 126 S. - 25. Gardner,J.: Das Problem des altrussischen demestischen Kirchengesanges und seiner linienlosen Notation. 1967, IX, $270 \mathrm{~s}$. - 26. Baldauf,L.: Der Gebrauch der Pronominalform des Adjektivs im Litauischen. 1967, $104 \mathrm{~S}$. - 27. Kluge,R.-D.: Westeuropa und RuBland im Weltbild Aleksandr Bloks. $1967,393 \mathrm{~S}$. - 28. Kunert, I.: J. U. Niemcewicz: Spiewy historyczne. 1968, II, $132 \mathrm{~s}$. - 29. Steinke, K.: Studien über den Verfall der bulgarischen Deklination. $1968, \mathrm{X}, 133 \mathrm{~S} .-30$. Tschøpl,C.: Vjąeslav Ivanov. 1968, $235 \mathrm{~S}$. - 31. Rehder,P.: Beiträge zur Erforschung der serbokroatischen Prosodie. 1968, $247 \mathrm{~S}$. - 32. Kulman,D.: Das Bild des bulgarischen Mittelalters in der neubulgarischen Erzăhiliteratur. 1968, $276 \mathrm{~S}$. - 33. Burkhart,D.: Untersuchungen zur Stratigraphie und Chronologie der südslavischen volksepik. 1968, III, 549 S. - 34. Günther, H.: Das Groteske bei N. V. Gogol'. 1968, 289 S. - 35. Kazoknieks,M.: Studien zur Rezeption der Antike bei russischen Dichtern zu Beginn des 19. Jahrhunderts. 1968, $269 \mathrm{~S}$. - 36. Schmidt, H.: Hus und Hussitismus in der tschechischen Literatur des 19 . und 20. Jahrhunderts. 1969, 296. S. - 37. Schneider, S.: Studien zur Romantechnik Miroslav Krlezas. 1969, 285 S. - 38. Stephan, B.: Studien zur russischen Castuska und ihrer Entwicklung. 1969, 358 S. - 39. Girke,W.: Studien zur Sprache N. S. Leskovs. 1969, VIII, 220 S. - 40. Mares, F. V.: Diachronische Phonologie des Ur- und Frühslavischen. 1969, $126 \mathrm{~S}$. - 41. Wosien,M.-G.: The Russian Folk-Tale. 1969, 237 S. - 42. Schulz, R.K.: The Portrayal of the German in Russian Novels. 1969, V, $213 \mathrm{~S}$. - 43. Baudisch,G.: Das patriarchalische Dorf im Erzählwerk vón Janko 
M. Veselinović. 1969, 225 S. - 44. Stölting,w.: Beiträge zur Geschichte des Artikels im Bulgarischen. 1970, VII, 296 S. - 45. Hucke,G.:Jurij Fedorovic Samarin. 1970, 183 S. - 46. Höcherl,A.: Zur Ubersetzungstechnik des altrussischen "Jüdischen Krieges" des Josephus Flavius. 1970, 183 S. - 47. Sappok,C.: Die Bedeutung des Raumes für die Struktur des Erzählwerks. 1970, 154 S. - 48. Guski, A.: M. Ju. Lermontovs Konzeption des literarischen Helden. 1970, $225 \mathrm{~S}$. - 49. Lettmann, R.: Die abstracta 'um' und 'razum' bei Belinskij. 1971, 167 S. - 50.Lettmann-Sadony, B.: Karolina Karlovna Pavlova. 1971, 181 S - 51. Brümmer, C.: Beiträge zur Entwicklungsgeschichte der frühen Romane L. M. Leonovs, 1971, $231 \mathrm{~S}$. - 52. Schmidt,C.: Bedeutung und Funktion der Gestalten der europäisch östlichen Welt im Werk Thomas Manns. 1971, $366 \mathrm{~S}$. - 53. Eschker,W.: Untersuchungen zur Improvisation und Tradierung der Sevdalinka an Hand der sprachlichen Figuren. 1971, 275 S. - 54. Schmidt О.: Нензвестний Поэт П.Д.Бутурлин. Анализ творчвства. 1971, $229 \mathrm{~S}$. 55. Mönke,H.: Das Futurum der polnischen Verba. 1971, 184 S. - 56.Raekke,J.: Untersuchungen zur Entwicklung der Nominalkomposition im Russischen seit 1917. - 57. Muller-Landau,C.: Studien zum Stil der Sava-Vita Teodosijes. 1972, 183 S. - 58. Dippe,G.: August Senoas historische Romane. 1972, $177 \mathrm{~S}$. - 59. Hetzer,A.: Vjaceslav Ivanovs Tragödie "Tantal" 1972, 202 S. - 60. Andreesen,W.: Untersuchungen zur Translation von Sub stantiven zu Adjektiven im Altrussischen. 1972, 151 S. - 61. Neureiter, F.: Kaschubische Anthologie. 1973, VIII, 281 S. - 62. Gavrin,M.: Kroatische Ubersetzungen und Nachdichtungen deutscher Gedichte zur zeit des Illyrismus. 1973, 226 S. - 63. Grahor,0.: France in the Work and Ideas of Antun Gustav Matos. 1973, 247 S. - 64. Döring,J.R.: Die Lyrik Paster naks in den Jahren 1928-1934. 1973, XXVI, $390 \mathrm{~S}$. - 65. Högemann-Ledwohn E.: Studien zur Geschichte der russischen Verserzählung in der zweiten Hälfte des 19. Jahrhunderts. 1973, $428 \mathrm{~S}$. - 66. Gonschior,H.: Die geneigten Vokale als Reflexe altpolnischer Längen im Wörterbuch von Jan Mączýski. 1973, 391 S. - 67. Talev,I.: Some problems of the Second South Slavic Influence in Russia. 1973, XIV, 430 S. - 68. Auerbach, I.: Nomina abstracta im Russischen des 16. Jahrhunderts. 1973, VI, 368 S. - 69. Holthusen,J.: RuBland in Vers und Prosa. 1973, 212 S. - 70. Guski,H.: Die satirischen Komödien V.I.Lukins (1737-1794). 1973, 250 S. 71. Sternkopf,J.: Sergej und Vladimir Solov'ev. 1973, XXXI, 667 S. 72. Wenzel,F.: SPLIT. Ein Verfahren zur maschinellen morphologischen Segmentierung russischer wörter. 1973, IX, $203 \mathrm{~S}$. - 73. Bachmann, E.: Ivo Kozarcanin - Leben und Werk. 1974, 250 S. - 74. Schmidt,B.: Stilelemente der mündichen Literatur in der vorrealistischen Novellistik der Serben und Kroaten. 1974, 309 S. - 75. Jakoby,W.: Untersuchungen zur Phonologie und Prosodie einer kajkavischen Mundart (Gornja Stubica) 1974, X. 256 S. - 76 Schultze,B.: Der Dialog in F.M.Dostoevskijs Idiot. 1974, 314 S. - 77. Hilf, E.A.: Homonyme und ihre formale Auflösbarkeit System Sprache, dargestellt an altrussischen Berufsbezeichnungen. 1974, $129 \mathrm{~S}$. - 78. Wiehl, I.: Untersuchungen zum Wortschatz der Freisinger Der mäler. Christliche Terminologie. 1974, 169 S. - 79. Pribic, R.: Bonavent ra's Nachtwachen and Dostoevsky's Notes from the Underground. A Compari son in Nihilism. 1974, $155 \mathrm{~S}$. - 80. Ziegler,G.: Moskau und Petersburg i der russischen Literatur (ca 1700-1850). Zur Gestaltung eines literarischen Stoffes. 1974, VI, 189 S. - 81. Wörn,D.: Aleksandr Bloks Drama Pesnja sud'by (Das Lied des Schicksals), übersetzt, kommentiert und interpretiert. 1974, X, 545 S. - 82. Timberlake,A.: The Nominative Object in Slavic, Baltic and West Finnic. 1974, VI, $265 \mathrm{~S} .-83$. Baumann,W.:Di Sage von Heinrich dem Löwen bei den Slaven. 1975, 185 S. - 84. EvertsGrigat, S.: V. V. Majakovskij: Pro èto. Ubersetzung und Interpretation. 1975, 262 S. - 85. Mirsky,S.: Der Orient im Werk Velimir Chlebnikovs. 1975, VIII, $112 \mathrm{~S}$. 